Prepared in cooperation with Sound Transit

\title{
Precipitation Thresholds for Landslide Occurrence Near Seattle, Mukilteo, and Everett, Washington
}

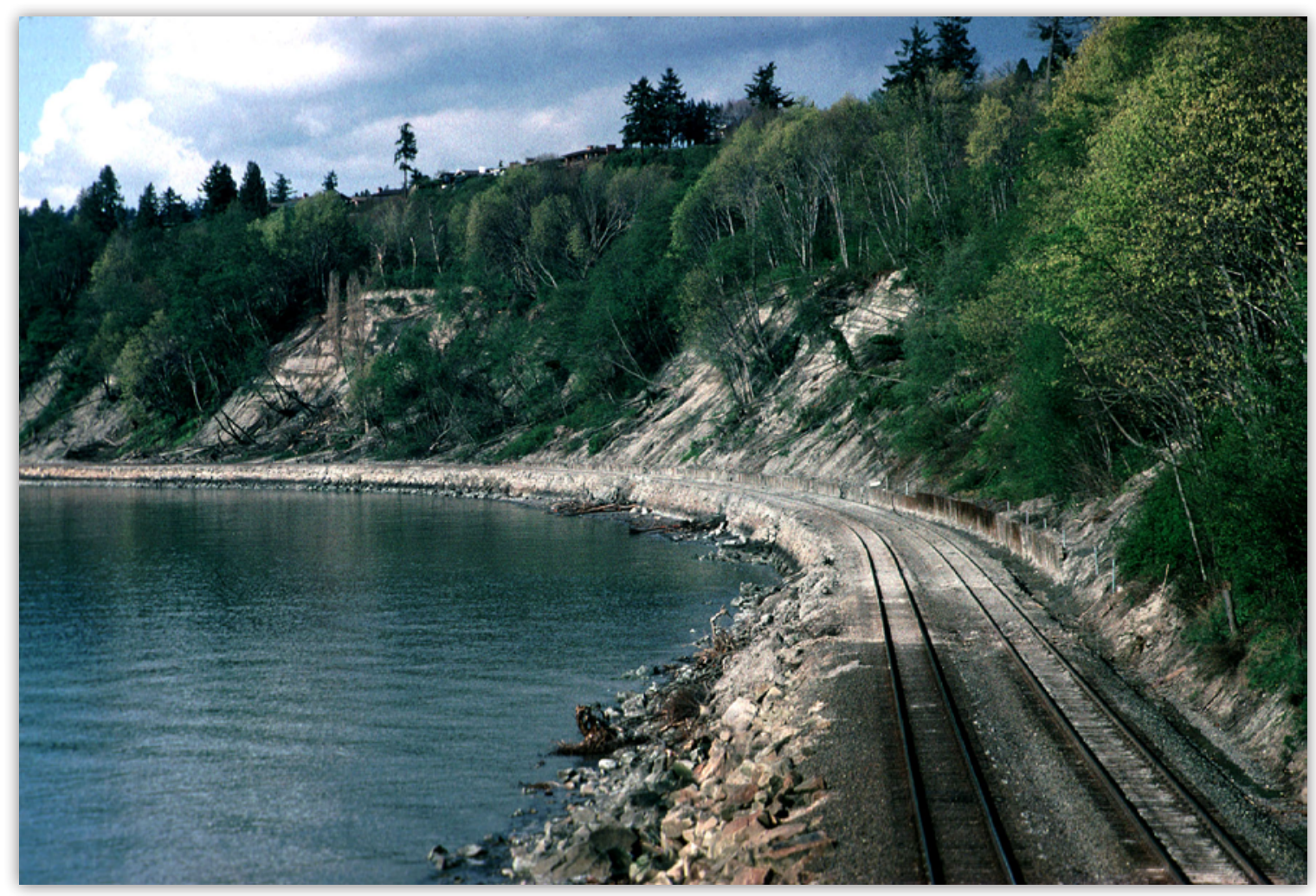

Open-File Report 2017-1039 
Cover. A January 1997 photo depicts recent landslides affecting the rail corridor north of Seattle. Photo credit: Ed Harp (USGS retired) 


\section{Precipitation Thresholds for Landslide Occurrence Near Seattle, Mukilteo, and Everett, Washington}

By Caroline R. Scheevel, Rex L. Baum, Benjamin B. Mirus, and Joel B. Smith

Prepared in cooperation with Sound Transit

Open-File Report 2017-1039 


\title{
U.S. Department of the Interior \\ RYAN K. ZINKE, Secretary
}

\section{U.S. Geological Survey William H. Werkheiser, Acting Director}

\author{
U.S. Geological Survey, Reston, Virginia: 2017
}

For more information on the USGS - the Federal source for science about the Earth, its natural and living resources, natural hazards, and the environment-visit http://www.usgs.gov/ or call 1-888-ASK-USGS (1-888-275-8747).

For an overview of USGS information products, including maps, imagery, and publications, visit http://store.usgs.gov.

\footnotetext{
Any use of trade, firm, or product names is for descriptive purposes only and does not imply endorsement by the U.S. Government.

Although this information product, for the most part, is in the public domain, it also may contain copyrighted materials as noted in the text. Permission to reproduce copyrighted items must be secured from the copyright owner.

Suggested citation:

Scheevel, C.R., Baum, R.L., Mirus, B.B., and Smith, J.B., 2017, Precipitation thresholds for landslide occurrence near Seattle, Mukilteo, and Everett, Washington: U.S. Geological Survey Open-File Report 2017-1039, 51 p., https://doi.org/10.3133/ofr20171039.
}

ISSN 2331-1258 (online) 


\section{Contents}

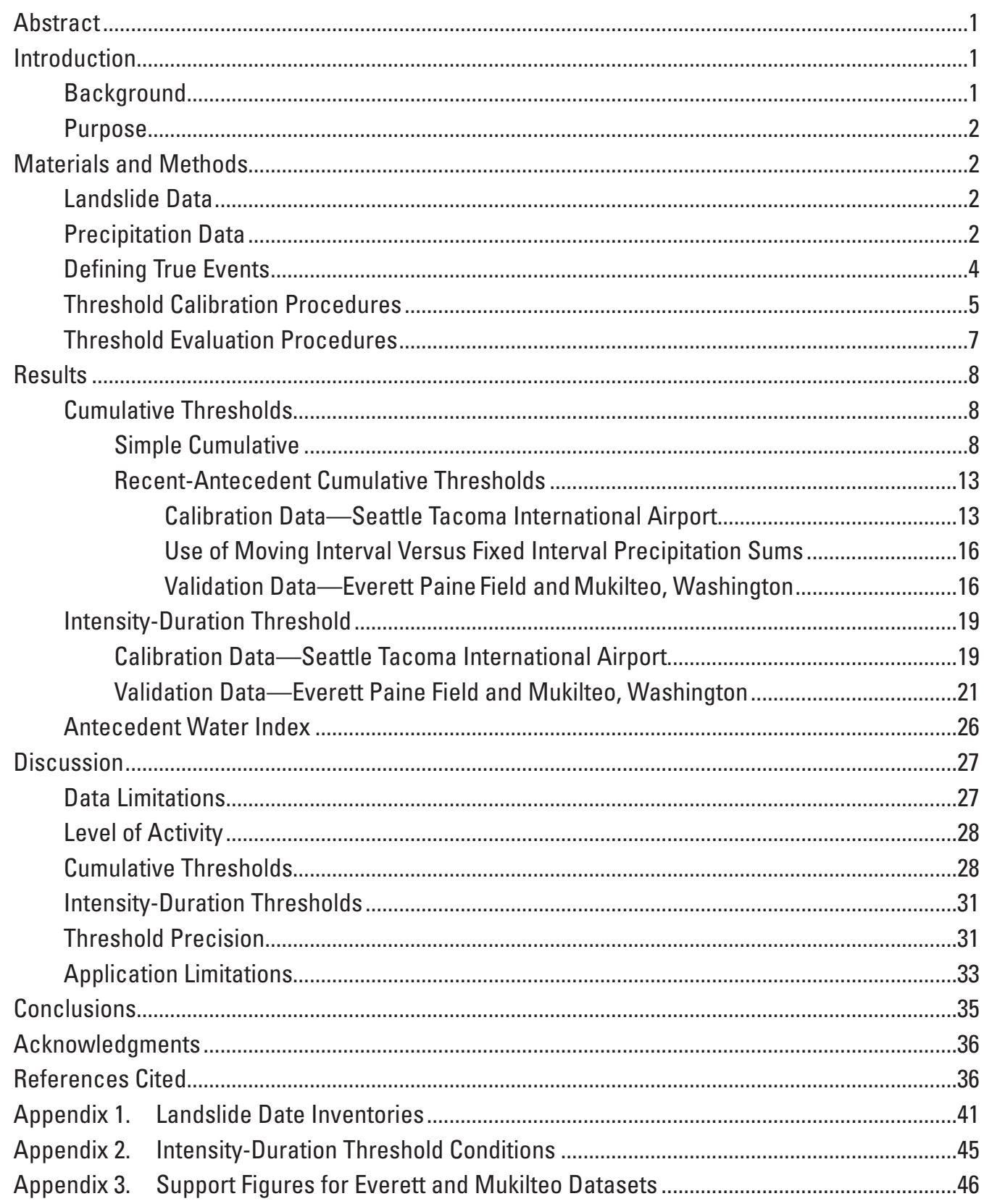




\section{Figures}

1. Regional map of study area in the Puget Sound area of Washington showing Sound Transit monitoring sites and National Weather Service Stations .

2. Graph depicting fixed intervals, which yield only 1 precipitation sum per date, and moving intervals, which yield 24 sums per date.

3. Receiver operating characteristics graph .......................................................................

4. Explanation of recent-antecedent space and recent-antecedent thresholds ................7

5. Comparison of receiver operating characteristics curves calculated from both fixed and moving intervals at Seattle Tacoma International Airport, 1978-2003 ............10

6. Receiver operating characteristics curves of simple cumulative thresholds based on short (less than 72 hours) durations for Seattle Tacoma International Airport.

7. Histograms showing the amount of precipitation accumulated during specified time durations prior to each landslide date in the Seattle landslide database...

8. Graphs of the 3-15-, 3-32-, and 10-40-day thresholds use recent-antecedent space to plot moving interval precipitation accumulation calculated for dates in the Seattle landslide database.

9. Graphs showing relative frequency of rainfall conditions near Seattle Tacoma International Airport plotted by rainfall intensity and storm duration ...

10. Graphs showing relative frequency of landslides near Seattle Tacoma International Airport plotted by rainfall intensity and storm duration

11. Graphs showing the relative probability of landsliding near Seattle Tacoma International Airport plotted by rainfall intensity and storm duration

12. Graph showing landslides near Seattle Tacoma International Airport plotted by rainfall intensity and storm duration.

13. Graphs showing storm event intensity on dates of landslides that occurred near Mukilteo, Washington.

14. Graph of the antecedent water index receiver operating characteristics curve ...........26

15. Graphs showing Mukilteo daily precipitation totals at specified monitoring stations minus the daily precipitation totals at Everett Paine Field, Washington

16. Graphs showing relative slide frequency, relative rainfall condition frequency, and sliding probability at Seattle Tacoma International Airport, defined by the precipitation in the previous 3 days against the antecedent 15-day precipitation (18 days total)

17. Graphs showing relative slide frequency, relative rainfall condition frequency, and sliding probability at Seattle Tacoma International Airport, defined by the precipitation in the previous 3 days against the antecedent 32-day precipitation (35 days total)

18. Graphs showing relative slide frequency, relative rainfall condition frequency, and sliding probability at Seattle Tacoma International Airport, defined by the precipitation in the previous 10 days against the antecedent 40 -day precipitation (40 days total)

3-1. Graphs of the 3-15-, 3-32-, and 10-40-day thresholds use recent-antecedent space to plot moving interval precipitation accumulation calculated for dates in the Everett landslide database.

3-2. Graphs showing recent-antecedent precipitation accumulation (3-15 days) calculated using moving intervals on dates of known landsliding near Mukilteo, Washington 
3-3. Graphs showing recent-antecedent precipitation accumulation (3-32 days) calculated using moving intervals on dates of known landsliding near Mukilteo, Washington.

3-4. Graphs showing recent-antecedent precipitation accumulation (10-40 days) calculated using moving intervals on dates of known landsliding near Mukilteo, Washington.

3-5. Graph showing landslides near Everett Paine Field, Washington, plotted by rainfall intensity and storm duration.....

\section{Tables}

1. Calibration Dataset (Seattle) —Simple cumulative threshold statistics derived from fixed intervals

2. Calibration Dataset (Seattle)—Simple cumulative threshold statistics derived from moving intervals and associated assumptions

3. Calibration Dataset (Seattle)—Statistical performance of simple cumulative thresholds identified for precipitation accumulation durations of less than 72 hours ...10

4. Calibration Dataset (Seattle) —Example of raw counts for two simple cumulative thresholds that examine the same accumulation duration but require different minimum numbers of landslides on a given day to define a true event

5. Calibration Dataset (Seattle) - Statistical performance of recent-antecedent thresholds derived from both fixed interval and moving interval simple cumulative thresholds

6. Calibration Dataset (Seattle)—Recent-antecedent thresholds considered but not pursued for further analysis.

7. Calibration Data (Seattle) - The relative difference in statistics gathered from moving interval precipitation sums relative to the fixed interval precipitation sums .....17

8. Validation Dataset 1 (Everett)—Recent and antecedent cumulative threshold statistical performance calculated using moving precipitation sums.

9. Validation Dataset 2 (Mukilteo)—Recent and antecedent cumulative threshold statistical performance calculated using moving precipitation sums

10. Calibration Dataset (Seattle)—Intensity-duration threshold statistical performance

11. Calibration Dataset (Seattle) - Counts of true hours identified by only one threshold type - recent-antecedent cumulative or intensity-duration — but not the other.

12. Calibration Dataset (Seattle)—Ratios of true hours when both the recent-antecedent threshold and the intensity-duration thresholds are exceeded.......24

13. Validation Dataset 1 (Everett) - Intensity-duration threshold statistical performance

14. Validation Dataset 2 (Mukilteo) —Intensity-duration threshold statistics for durations of 12 hours or more.

15. Mukilteo 2015-2016 —Cumulative rainfall difference during 2015-2016 landslide season between Mukilteo and Everett

16. Model precision across all considered thresholds and locations applied to moving interval precipitation sums

1-1. Landslide Database 1-Landslides that occurred during 1978-2003 near Seattle Tacoma International Airport..

1-2. Landslide Database 2-Landslides that occurred during 2006-2014 near Everett, Washington. 
1-3. Landslide Database 3-Landslides that occurred during 2015-2016 along the railway corridor between Seattle and Everett, Washington

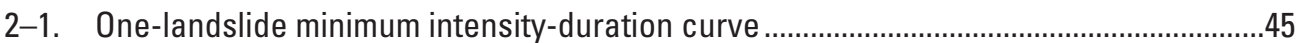

2-2. Two-landslide minimum intensity-duration curve .............................................................45

\title{
Conversion Factors
}

U.S. customary units to International System of Units

\begin{tabular}{lcll}
\hline & Multiply & By & To obtain \\
\hline inch (in.) & Length & \\
inch (in.) & 2.54 & centimeter (cm) \\
foot (ft) & 25.4 & millimeter (mm) \\
mile (mi) & 0.3048 & meter (m) \\
\hline
\end{tabular}

International System of Units to U.S. customary units

\begin{tabular}{lccc}
\hline & Multiply & By & To obtain \\
\hline meter $(\mathrm{m})$ & Length & \\
\hline
\end{tabular}

\section{Abbreviations}

\author{
AWI antecedent water index \\ FI fixed interval \\ ID intensity-duration \\ KPAE Everett Paine Field, Washington \\ KSEA Seattle Tacoma International Airport \\ LS Waterton Circle \\ NCEI National Centers for Environmental Information \\ M1 Mukilteo Lighthouse Park \\ M2 Mukilteo Water and Wastewater District Treatment Plant \\ MI moving interval \\ OT optimum threshold \\ RA recent-antecedent \\ ROC receiver operating characteristics \\ USGS U.S. Geological Survey \\ VH Marine View Drive \& 116th St. SW
}




\title{
Precipitation Thresholds for Landslide Occurrence Near Seattle, Mukilteo, and Everett, Washington
}

\author{
By Caroline R. Scheevel, Rex L. Baum, Benjamin B. Mirus, and Joel B. Smith
}

\begin{abstract}
Shallow landslides along coastal bluffs frequently occur in the railway corridor between Seattle and Everett, Washington. These slides disrupt passenger rail service, both because of required track maintenance and because the railroad owner, Burlington Northern Santa Fe Railway, does not allow passenger travel for 48 hours after a disruptive landslide. Sound Transit, which operates commuter trains in the corridor, is interested in a decision-making tool to help preemptively cancel passenger railway service in dangerous conditions and reallocate resources to alternative transportation.

Statistical analysis showed that a majority of landslides along the Seattle-Everett Corridor are strongly correlated with antecedent rainfall, but that 21-37 percent of recorded landslide dates experienced less than 1 inch of precipitation in the 3 days preceding the landslide and less than 4 inches of rain in the 15 days prior to the preceding 3 days. We developed two empirical thresholds to identify precipitation conditions correlated with landslide occurrence. The two thresholds are defined as $P_{3}=2.16-0.44 P_{15}$ and $P_{3}=2.16-0.22 P_{32}$, where $P_{3}$ is the cumulative precipitation in the 3 days prior to the considered date and $P_{15}$ or $P_{32}$ is the cumulative precipitation in the 15 days or 32 days prior to $P_{3}$ (all measurements given in inches). The two thresholds, when compared to a previously developed threshold, quantitatively improve the prediction rate.

We also investigated rainfall intensity-duration (ID) thresholds to determine whether revision would improve identification of moderate-intensity, landslide-producing storms. New, optimized ID thresholds evaluate rainstorms lasting at least 12 hours and identify landslide-inducing storms that were typically missed by previously published ID thresholds. The main advantage of the ID thresholds appears when they are combined with recent-antecedent thresholds because rainfall conditions that exceed both threshold types are more likely to induce two or more landslides than conditions that exceed only one threshold type.
\end{abstract}

\section{Introduction}

Precipitation-induced landslides pose a serious threat to public safety in many areas throughout the world, and landslide early warning systems exist in several countries including parts of the United States (Baum and Godt, 2010). Precipitation thresholds began to be developed in the 1970s (Campbell, 1975) as one of the earliest means for forecasting landslides. Decades later, precipitation thresholds have become widely used in early warning systems to recognize hydrologic conditions that facilitate landslide activity (Guzzetti and others, 2008; Baum and Godt, 2010). This report describes new empirical precipitation thresholds that have been developed for use in forecasting landslide activity along the coastal bluffs of Puget Sound between Seattle and Everett, Washington, and particularly in the vicinity of the cities of Mukilteo and Everett. Simple statistical techniques based on receiver operating characteristics (ROC) analysis have been used to find optimum values of the thresholds and test their performance against historical data (Begueria, 2006; Fawcett, 2006). Our analysis revealed the strengths and limitations of the new thresholds, which are also described in this report.

\section{Background}

Following major landslide damage in the communities of Puget Sound in January 1997, the U.S. Geological Survey (USGS) cooperated with the city of Seattle and its geotechnical consultant, Shannon \& Wilson, Inc., to develop precipitation thresholds for landslide occurrence and procedures for applying the thresholds to early warning systems (Chleborad, 2000, 2003; Chleborad and others, 2006, 2008; Godt and others, 2006; Baum and Godt, 2010). In subsequent years, several entities in the Seattle area have used the thresholds as a planning tool to aid in landslide preparedness. 
Sound Transit began running commuter trains between Seattle and Everett in 2003. Landslides impact operations of the commuter trains because the owner of the railroad tracks, Burlington Northern Santa Fe Railway, imposes a 48-hour moratorium on passenger traffic following a landslide. Most service-interrupting landslides have obstructed sections of track but not made direct contact with passenger trains. However, derailments have occurred, including recently in April 2013 (Associated Press, 2013b).

\section{Purpose}

Despite recent work to mitigate landslides on coastal bluffs along the rail corridor (Washington State Department of Transportation, 2015), landslide potential still exists and landslides continue to impact rail service (Associated Press, 2016). Thus, a need exists to plan and prepare for landslides that could potentially interrupt service in the corridor. The analysis presented in this report was undertaken in an effort to develop thresholds that can predict dates of landslide occurrence more accurately than previously published thresholds (Chleborad and others, 2006, 2008). We identified new precipitation thresholds and evaluated the true positive rate, the true negative rate, and the precision of each. We used these metrics to determine which threshold identified the most dates when landsliding occurred and which model's predictions were the most reliable. The work is part of a larger effort to develop tools that can be used by Sound Transit to assess the time-varying probability of landslides (in response to precipitation) so that the company can plan and prepare for potential service interruptions.

\section{Materials and Methods}

\section{Landslide Data}

This analysis made use of three landslide databases (appendix 1) and precipitation data for stations in Seattle, Mukilteo, and Everett. Two of the datasets have long periods of record, but the third characterizes a single winter using data from newly installed instruments. The first database contains data on landslide occurrences in Seattle between 1978 and 2003 that were compiled for previous studies (Chleborad and others 2006, see table 1-1 in appendix 1). Although this database is the most complete database available for validating landslide thresholds in the Seattle area (172 dates), it is known to be incomplete because it excludes landslides without verified dates. The second database (see table 1-2 in appendix 1) is a newly developed list of dates when landslides caused cancellation of Amtrak and Sound Transit passenger service on the rail corridor north of Seattle, near Everett. These data come from a variety of published sources, most of which are published news stories. This list also is incomplete and covers only selected timespans between 2006 and 2014. The third database (see table 1-3 in appendix 1) contains dates of landslides found in published news stories or detected at a field-monitoring site using a USGS time-lapse camera during the 2015-2016 landslide season. Our analysis required only dates and relative numbers of landslides. These data are summarized in appendix 1.

Landslides near Mukilteo are assumed to be triggered by similar precipitation conditions that trigger landslides near Everett and Seattle. However, the same proportion of landslides classified as "minimal preceding precipitation" slides, defined as those occurring with less than 1 inch of rainfall during the preceding 3 days and less than 4 inches of rainfall in the 15 days prior to the 3 days, is not observed in the three databases. More than 27 percent of the landslides' dates in both the Everett and Seattle databases are associated with minimal preceding precipitation. However, the seven slide dates in the Mukilteo dataset include only one date with minimal preceding precipitation (14.3 percent). Thus, the Mukilteo dataset may be incomplete and overrepresent slides that occurred during wet conditions. However, the Mukilteo rain gages are closer to the landslides than the Seattle and Everett gages, and correlation between observed precipitation and landslide activity is known to increase with rain gage proximity (Chleborad and others 2006, 2008).

\section{Precipitation Data}

Hourly precipitation data were obtained from three sources: the National Centers for Environmental Information (NCEI) (http://www.ncdc.noaa.gov/), the National Weather Service (http://www.weather.gov/), and monitoring at sites installed by the USGS for Sound Transit (fig. 1). We used hourly precipitation records from NCEI for Seattle Tacoma International Airport (KSEA) (fig. 1) to calibrate thresholds against the 1978-2003 Seattle landslides. We used hourly data from Everett Paine Field, Wash. (KPAE) (fig. 1), obtained over the years by direct download from the National Weather Service, to evaluate the thresholds against the 2006-2014 database of landslides affecting the rail corridor north of Seattle. The KPAE data begin December 27, 2005, and end June 4, 2016. However, there are gaps in the data for the periods May 5, 2010, to July 23, 2010, and July 11, 
2013, to June 13, 2014, because of operation issues with the USGS systems used to collect these data. Despite obvious limitations, we chose to use these data because hourly data for KPAE were not available from the NCEI for the period of interest. The nearest alternative NCEI station, in downtown Everett (farther inland), had hourly data reported to only the nearest $0.1 \mathrm{inch}$.

Finally, we also performed threshold evaluation with data from four monitoring sites installed by the USGS for Sound Transit in the city of Mukilteo at Marine View Drive \& 116th St. SW, Waterton Circle, Mukilteo Lighthouse Park, and the Mukilteo Water and Wastewater District Treatment Plant (fig. 1).

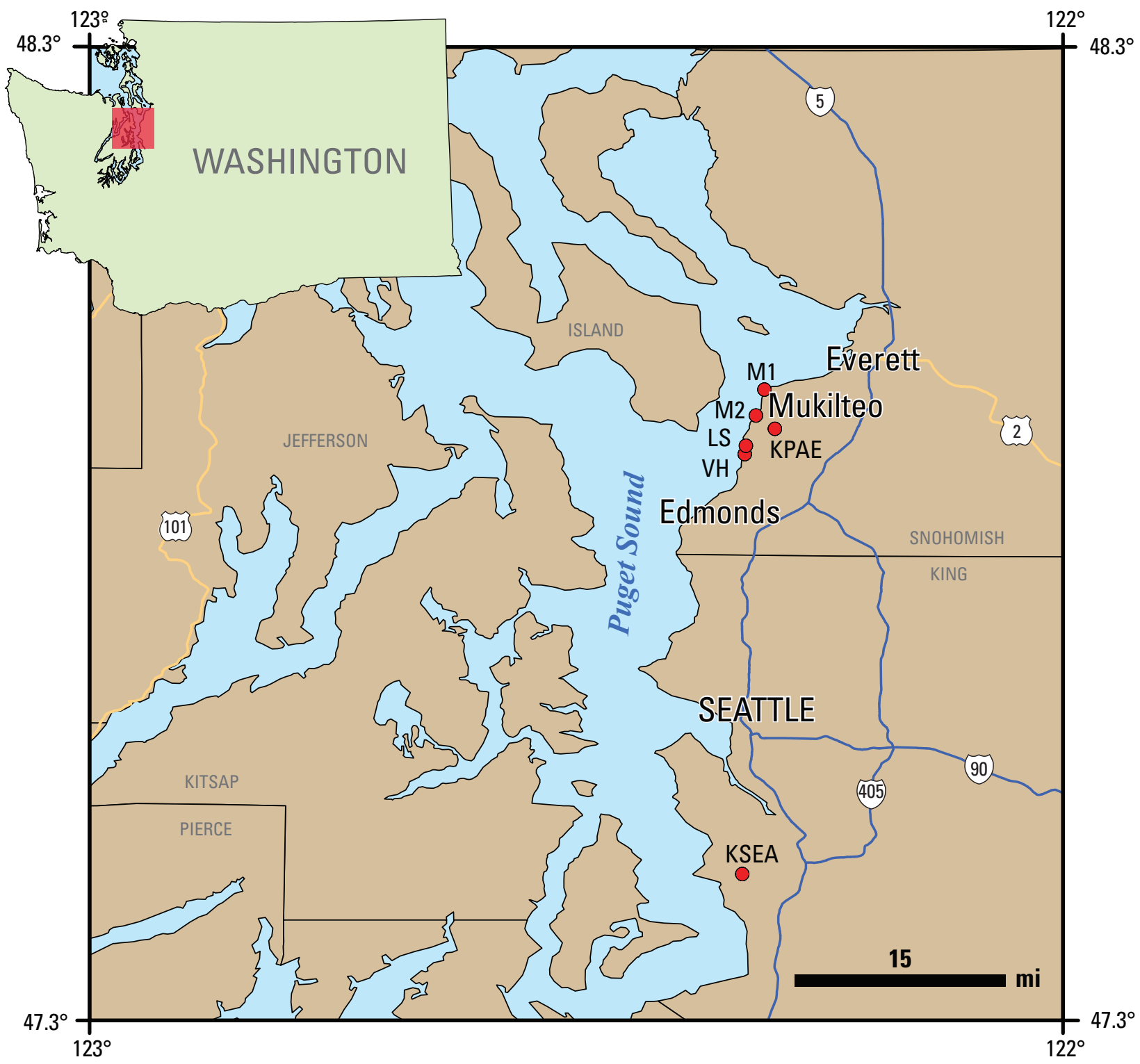

Figure 1. Regional map of study area in the Puget Sound area of Washington showing Sound Transit monitoring sites (Waterton Circle [LS], Marine View Drive \& 116th St. SW [VH], Mukilteo Lighthouse Park [M1], and Mukilteo Water and Wastewater District Treatment Plant [M2]) and National Weather Service Stations (Seattle Tacoma International Airport [KSEA] and Everett Paine Field [KPAE]) (Modified from Mirus and others, 2016). 


\section{Defining True Events}

For this analysis, we defined true events as (1) dates on which one or more landslides occurred and a precipitation threshold was exceeded (true positives) or (2) dates on which no landslides occurred and a threshold was not exceeded (true negatives). Chleborad $(2000,2003)$ developed thresholds based on daily precipitation totals, making the definition of true events straightforward because there was only one rainfall sum per day. This report refers to the consistent temporal boundaries of Chleborad's $(2000,2003)$ precipitation sums as "fixed intervals" (FIs).

Our precipitation data have hour-scale resolution, which allows precipitation totals to be calculated at any hour during a single date. Therefore, 24 different precipitation sums, all evaluating the same length of time, can be calculated for the same date (fig. 2). This report refers to these variable temporal boundaries as "moving intervals" (MIs).

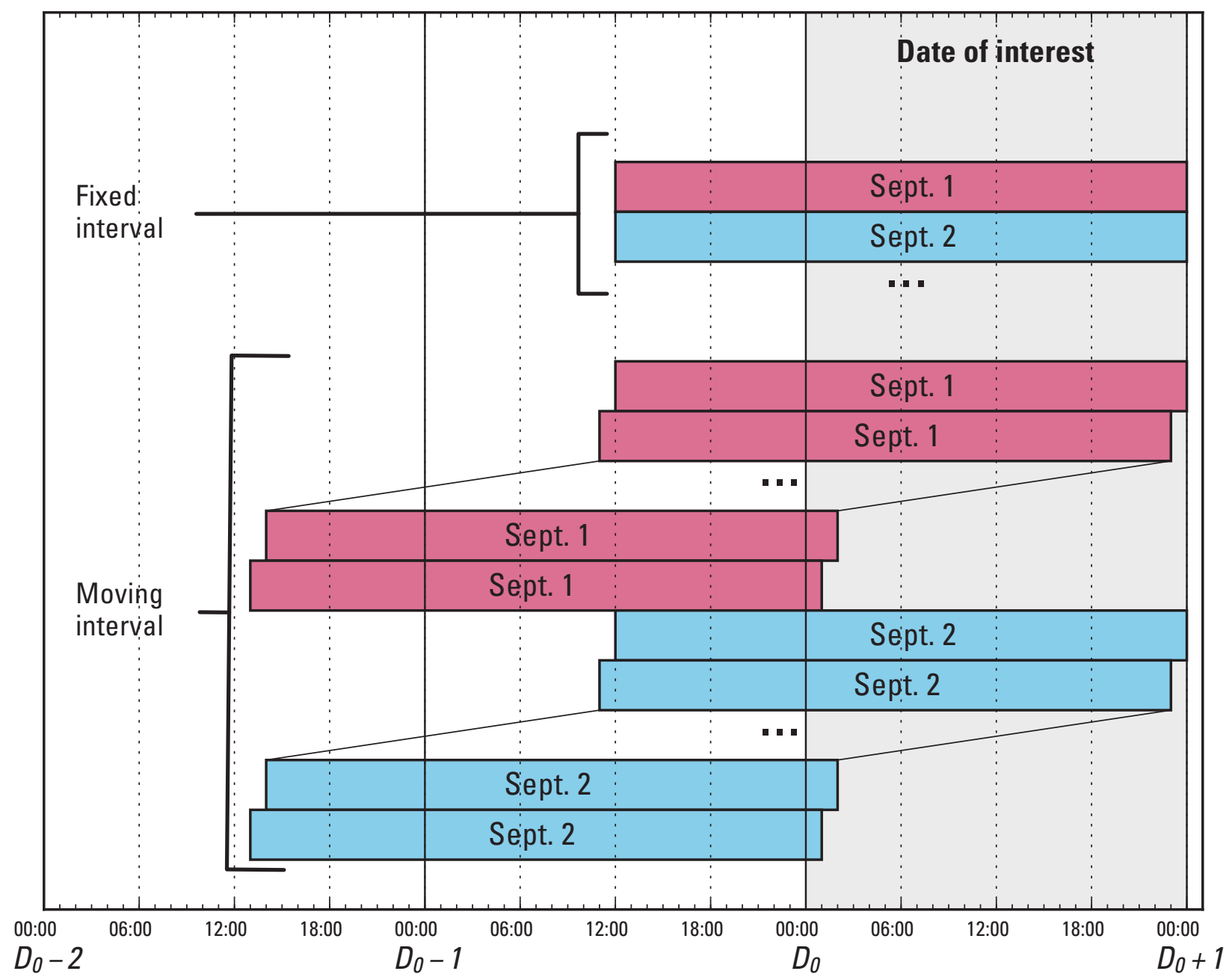

Figure 2. Fixed intervals yield only 1 precipitation sum per date, but moving intervals yield 24 sums per date. The interval must always end on the date of interest, $\mathrm{D}_{0}$, in order to be associated with that date. The figure shows 36 -hour intervals, but interval duration is arbitrary (as long as it is consistent). 
Identifying true events when analyzing MI precipitation sums is more complicated than when analyzing FI precipitation sums. Dates of known landslides are classified as true because the landslide databases have 24-hour-scale resolution, not hourly. Therefore, all 24 of the MI precipitation sums must be classified as true. Though landsliding is unlikely to have occurred during all 24 hours of a day, this assumption allows us to develop tools that use near-real-time data and subsequently evaluate them against tools that rely on FIs. Note that results generated from FI precipitation sums are considered more trustworthy than MI results because the data resolution of inputs and outputs are the same. Comparisons of the MI and FI calibration dataset results were used to verify the validity of using hour-scale precipitation data to identify landslide dates.

Godt and others (2006) also used hourly data to develop a rainfall intensity-duration (ID) threshold, relying on total storm duration and average rainfall intensity. Each storm produced a single duration and intensity. Multiple storm events occurring on a single day were treated similarly to MIs; each storm was designated as true if it ended on a landslide date. ID thresholds produced from this analysis required storms to last longer than 12 hours and be separated from one another by more than 3 hours of quiescence; therefore, this report's ID results are more similar to FI results because only one storm could be linked to one date.

\section{Threshold Calibration Procedures}

For this analysis, we adapted some of the ROC methods used by Staley and others (2013) to objectively redefine precipitation thresholds for Seattle. These methods are widely used in many fields for decision making and machine learning (Fawcett, 2006), and in recent years, have been widely applied in hazard assessment (Begueria, 2006). Plotting ROC curves allows classifiers to be evaluated independently of any specific threshold (fig. 3). Classifiers that fall towards the lower left of the plot are referred to as "pessimistic" because they minimize false positives at the expense of true positives; classifiers that fall towards the upper right of the plot are referred to as "optimistic" because they maximize true positives but allow an increased proportion of false positives (fig. 3). Optimistic classifiers are more conservative for safety, but the high proportions of false alarms can make them unusable.

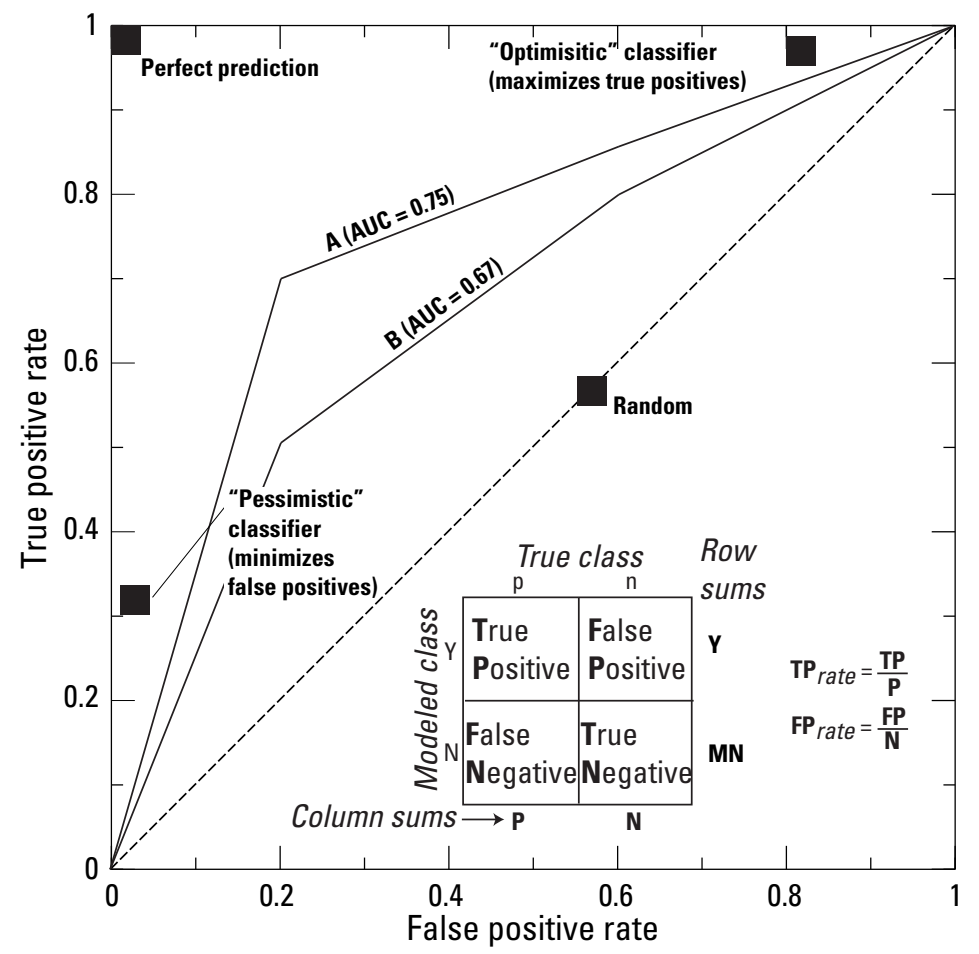

Figure 3. Receiver operating characteristics (ROC) graph (From Fawcett, 2006). A confusion matrix (inset, lower center) gives the definition of model outcomes and statistics relevant to ROC analysis. The ROC space shows the true positive rate versus the false positive rate for a specified classifier. Labeled points represent a perfect prediction model $(0,1)$, a random model that performs no better than random guess, an "optimistic" model (conservative for safety), and a "pessimistic" model. Curves $A$ and $B$ represent hypothetical ROC curves created by evaluating all possible classifier values. Curve $A$, with a higher area under the curve (AUC), performs better than Curve B. (p, positive class; $n$, negative class; $Y$, modeled yes; $\mathrm{N}$, modeled no; $\mathbf{P}$, positive class column sum; $\mathbf{N}$, negative class column sum; $\mathbf{Y}$, modeled yes row sum; $\mathbf{M N}$, modeled no row sum; TP, true positive; FP, false positive)

The KSEA database, our most complete database with longest period of record, was selected as the calibration database. As a first step, we analyzed simple cumulative precipitation thresholds based on precipitation accumulation measured over lengths of time (durations). Evaluated durations varied between 12 hours and 60 days prior to the landslide date. To do this, we generated two files. One file recorded the MI precipitation sums associated with each date of known landsliding; the other file recorded every MI precipitation sum associated with a date contained in the dataset (1978-2003). We sorted both files so that rainfall sums were sorted from smallest to largest. We then compared the precipitation sums in these two files to a steadily 
increasing threshold value that ranged from zero to the maximum value of a given duration's precipitation sum. The threshold value discriminated between positive (greater than or equal to the threshold) and negative (less than the threshold) model results.

For each threshold increment, we computed the true positive rate (equations 1 and 3), true negative rate (equation 2), threat score (equation 4), model precision (equation 5), and related statistics. The threat score equally penalizes a threshold for false positives and false negatives. False negatives (failed alarms) can result in loss of life or resources, but too many false positives (false alarms) can result in a tool that users do not trust. We weighted these problems evenly because of the high quantity of nonevents (Staley and others, 2013). We also computed the area under the ROC curve for the entire range of thresholds and created ROC graphs for each duration. Note that the false positive rate used in the ROC graphs is related to the true negative rate. The optimum precipitation threshold is defined as the rainfall accumulation that had the highest calculated threat score.

$$
\begin{gathered}
T P_{\text {rate }}=\frac{T P}{T P+F N}, \\
T N_{\text {rate }}=\frac{T N}{T N+F P}, \\
T P_{\text {rate }}=1-T N_{\text {rate }}, \\
T S=\frac{T P}{T P+F N+F P}, \\
\text { precision }=\frac{T P}{T P+F P},
\end{gathered}
$$

where $T P \quad$ is the count of true (correctly classified) positive events;

$F P \quad$ is the count of false (incorrectly classified) positive events, sometimes known as false alarms;

$T N \quad$ is the count of true negative events;

$F N \quad$ is the count of false negative events, also sometimes known as failed alarms; and

$T S \quad$ is the threat score, which is equally weighted between false negatives and false positives.

The recent-antecedent (RA) cumulative precipitation thresholds of the type identified by Chleborad (2000) are defined by two optimum cumulative thresholds. The intercept on the recent precipitation (vertical) axis is defined as the optimum threshold (OT) for a short duration (typically a few days). The intercept on the horizontal axis is defined by the OT for a longer duration of many days. However, the "antecedent precipitation" plotted on the horizontal axis is only the precipitation accumulation that occurred in the days between the durations defining the horizontal and vertical intercepts (fig. 4). The RA thresholds are defined in this way to take advantage of two temporally related measures of rainfall while reducing the correlation between them because there is no overlap. For example, the horizontal axis of a 3-day recent and 15-day antecedent threshold accounts for an 18-day period $(3+15=18)$, so the OT for an 18-day cumulative threshold would define the intercept of the antecedent axis (fig. 4).

Using ROC methods, we analyzed the distribution of true positives, true negatives, false positives, and false negatives to define performance of these RA cumulative thresholds. This whole process was repeated using FI-precipitation sums. The resultant statistics were compared to those from the MI-derived thresholds. The FI results are assumed to be more accurate because data were kept at the same resolution throughout the entire analysis. We also contoured relative frequencies and probabilities on the threshold plots to further characterize their performance.

We also examined ID thresholds similar to the style of Godt and others (2006). Godt and others (2006) originally defined their ID threshold for days with two or more landslides, finding that $I=3.257 D^{-1.13}$, where $I$ is intensity in inches/hour and $D$ is duration in hours. We computed ROC statistics for a reduced list of dates when two or more landslides occurred in order to emulate Godt and others (2006), but we also computed the same statistics for all dates with any known landslide. The twolandslide minimum was applied in part because a significant number of historical landslides are known to be poorly correlated with short-term (less than a few days) precipitation. We defined an ID threshold for each dataset; one dataset was defined by the database including all landslide dates and one was defined by the dataset containing dates with two or more known landslides. We computed the threat score for short-term cumulative thresholds of durations ranging from 12 hours to 60 hours, then used the optimum intensities from those cumulative thresholds to fit a power curve (see tables 2-1 and 2-2 in appendix 2). The lowrainfall intensities obtained using this method precluded considering durations shorter than 12 hours. 


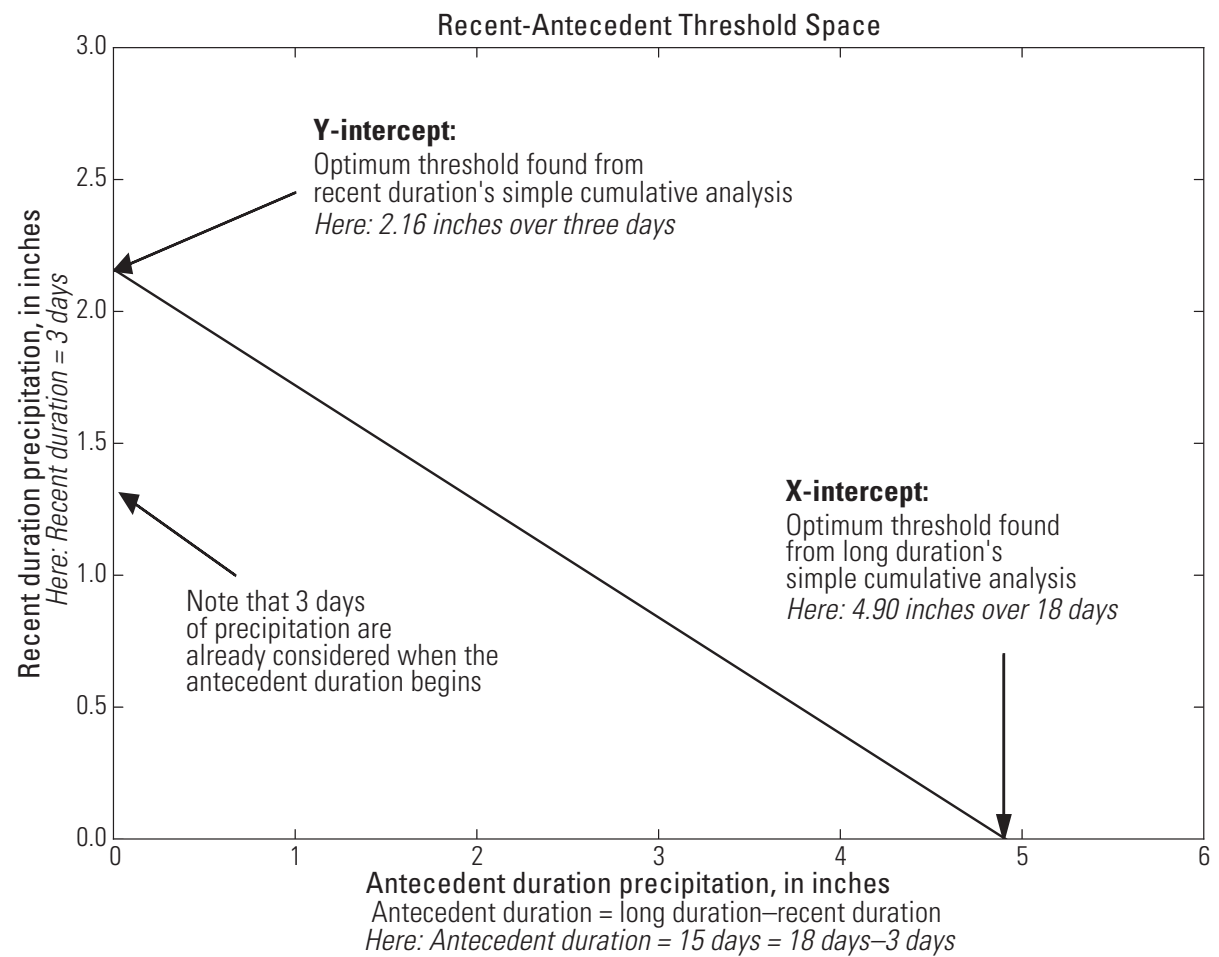

Figure 4. Recent-antecedent thresholds plot in recent-antecedent space. The total time represented is recent duration plus antecedent duration, but the times represented on the $x$ - and $y$-axes do not overlap. When considering a 3-15-day threshold, where the recent duration is 3 days long and the antecedent duration is 15 days long, 18 days of precipitation accumulation are represented on the plot.

We also examined the antecedent water index (AWI) that Godt and others (2006), Chleborad and others (2008), and Baum and Godt (2010) used in conjunction with ID thresholds to trigger landslide outlooks, watches, and warnings similar to the warning levels employed by the National Weather Service. The AWI helps to identify when soils have sufficiently elevated moisture content that even low intensity rainfall may trigger slope failure (Baum and Godt, 2010). The AWI utilizes rainfall input and average evapotranspiration to identify the depth of water above or below the depth needed to bring a 6.56-foot column of soil to field capacity (equations 6 and 7). Godt and others (2006) estimate that typical hillside colluvium's field capacity—the amount of water that soil retains after gravity drainage - is typically 7.1 inches. We examined AWI thresholds at KSEA using the same ROC curve analysis discussed for cumulative thresholds.

$$
\begin{gathered}
A W I_{t}=A W I_{t-1}+I_{i}, A W I<0, \\
A W I_{t}=A W I_{t-1} \exp \left(-k_{d} \Delta t\right)+\frac{I_{i}}{k_{d}}\left(1-\exp \left(-k_{d} \Delta t\right)\right), A W I \geq 0,
\end{gathered}
$$

where $A W I$ is the antecedent water index;

$<\quad$ is less than;

$\geq$ is greater than or equal to;

$k d \quad$ is an empirical drainage constant, measured with in units of length;

$\Delta t \quad$ is the time increment;

Ii is the current rainfall intensity minus the area's published evapotranspiration rate, measured in units of length/

time;

$t \quad$ is the present time step; and

$t-1 \quad$ is the previous time step.

\section{Threshold Evaluation Procedures}

After calibrating any kind of classifier, it is necessary to evaluate it to confirm that it is suitable for the intended application (Begueria, 2006). The calibration procedure just described was applied to a dataset from Seattle, but most of the area where Sound Transit wants to apply the thresholds is in the Mukilteo-Everett area, approximately 25 miles north of Seattle. Historical average precipitation amounts in Seattle are similar to amounts in Everett and Mukilteo for the period covered by our most complete landslide records, 1978-2003, but yearly and daily totals vary considerably between them. Ideally, we would have performed both calibration and validation using data from Mukilteo and Everett, but adequate precipitation and landslide records were not available for the Mukilteo-Everett area. Instead, we used our smaller datasets for Mukilteo and Everett to test the calibration-optimized thresholds using previously described ROC statistics. 


\section{Results}

\section{Cumulative Thresholds}

\section{Simple Cumulative}

Because our landslide databases do not note the hour of landsliding, developing an hour-resolution tool necessitates that we designate as true all 24 hours of the day a landslide occurred. Tables 1 and 2 examine cumulative thresholds, determined from precipitation accumulation over set time durations, to examine the validity of this simplification.

The results in table 1 rely on precipitation accumulations calculated from FIs ending at 23:59 on the date of interest. We refer to results calculated from FIs as "official" because the model inputs and outputs are of the same resolution. The results in table 2 rely on precipitation accumulations calculated using MIs, so there are 24 separate sums representing a single date. Models using MIs actually indicate whether a given precipitation accumulation during an associated hour exceeds the threshold (positive or negative), but we then classify these results as true or false depending on whether the hour falls within a known landslide date.

The difference in the area under the ROC curve between paired durations in tables 1 and 2 is negligible at 0.005 or less. None of the ROC curves derived from FIs and MIs show notable shape changes (fig. 5). Both intervals' curves give steep rising limbs, indicating that classifiers derived from each interval type are appropriate for consideration against landslides correlated with rainfall accumulated during the examined durations. The areas under the ROC curves are more than 0.5 , which indicates that each classifier model identifies landslide dates better than random guessing.

Table 1. Calibration Dataset (Seattle)—Simple cumulative threshold statistics derived from fixed intervals.

[ROC, Receiver operating characteristics]

\begin{tabular}{|c|c|c|c|c|c|c|}
\hline $\begin{array}{l}\text { Duration } \\
\text { (days) }\end{array}$ & $\begin{array}{l}\text { Area under } \\
\text { ROC curve }\end{array}$ & $\begin{array}{l}\text { Maximum threat } \\
\text { score }\end{array}$ & $\begin{array}{l}\text { True positive } \\
\text { rate }\end{array}$ & $\begin{array}{l}\text { True negative } \\
\text { rate }\end{array}$ & Precision & $\begin{array}{c}\text { Optimum } \\
\text { threshold } \\
\text { (inches) }\end{array}$ \\
\hline \multicolumn{7}{|c|}{ Seattle Tacoma International Airport (KSEA) } \\
\hline 3 & 0.754 & 0.121 & 0.157 & 0.996 & 0.342 & 2.74 \\
\hline 4 & 0.759 & 0.134 & 0.180 & 0.996 & 0.341 & 3.17 \\
\hline 7 & 0.762 & 0.121 & 0.215 & 0.990 & 0.218 & 3.84 \\
\hline 8 & 0.769 & 0.115 & 0.238 & 0.987 & 0.182 & 3.85 \\
\hline 9 & 0.777 & 0.106 & 0.267 & 0.981 & 0.149 & 3.88 \\
\hline 10 & 0.782 & 0.099 & 0.308 & 0.974 & 0.128 & 3.84 \\
\hline 30 & 0.818 & 0.082 & 0.180 & 0.985 & 0.130 & 9.14 \\
\hline 35 & 0.820 & 0.077 & 0.233 & 0.975 & 0.104 & 9.67 \\
\hline 40 & 0.816 & 0.071 & 0.308 & 0.959 & 0.085 & 10.04 \\
\hline 45 & 0.816 & 0.062 & 0.169 & 0.979 & 0.090 & 12.36 \\
\hline 50 & 0.813 & 0.055 & 0.250 & 0.957 & 0.066 & 12.20 \\
\hline 55 & 0.806 & 0.052 & 0.320 & 0.936 & 0.058 & 12.35 \\
\hline 60 & 0.808 & 0.053 & 0.384 & 0.922 & 0.058 & 12.76 \\
\hline
\end{tabular}


Table 2. Calibration Dataset (Seattle)—Simple cumulative threshold statistics derived from moving intervals and associated assumptions.

[ROC, Receiver operating characteristics]

\begin{tabular}{ccccccc}
\hline $\begin{array}{c}\text { Duration } \\
\text { (days) }\end{array}$ & $\begin{array}{c}\text { Area under } \\
\text { ROC curve }\end{array}$ & $\begin{array}{c}\text { Maximum threat } \\
\text { score }\end{array}$ & $\begin{array}{c}\text { True positive } \\
\text { rate }\end{array}$ & $\begin{array}{c}\text { True negative } \\
\text { rate }\end{array}$ & Precision & $\begin{array}{c}\text { Optimum } \\
\text { threshold } \\
\text { (inches) }\end{array}$ \\
\hline & & Seattle Tacoma & International Airport (KSEA) & & \\
\hline 3 & 0.754 & 0.105 & 0.189 & 0.990 & 0.192 & 2.16 \\
4 & 0.764 & 0.102 & 0.142 & 0.995 & 0.265 & 3.12 \\
5 & 0.762 & 0.109 & 0.165 & 0.994 & 0.243 & 3.38 \\
6 & 0.759 & 0.110 & 0.187 & 0.991 & 0.210 & 3.55 \\
7 & 0.761 & 0.107 & 0.229 & 0.986 & 0.169 & 3.52 \\
8 & 0.767 & 0.098 & 0.173 & 0.991 & 0.183 & 4.26 \\
9 & 0.776 & 0.092 & 0.196 & 0.986 & 0.149 & 4.22 \\
10 & 0.779 & 0.086 & 0.213 & 0.982 & 0.127 & 4.25 \\
15 & 0.790 & 0.074 & 0.295 & 0.963 & 0.089 & 4.70 \\
18 & 0.794 & 0.067 & 0.356 & 0.947 & 0.076 & 4.91 \\
20 & 0.797 & 0.068 & 0.263 & 0.965 & 0.084 & 5.99 \\
30 & 0.815 & 0.072 & 0.161 & 0.985 & 0.114 & 9.12 \\
35 & 0.815 & 0.075 & 0.225 & 0.975 & 0.101 & 9.67 \\
40 & 0.812 & 0.067 & 0.286 & 0.959 & 0.080 & 10.08 \\
45 & 0.812 & 0.057 & 0.183 & 0.973 & 0.076 & 11.93 \\
50 & 0.808 & 0.053 & 0.432 & 0.912 & 0.057 & 10.48 \\
55 & 0.801 & 0.050 & 0.329 & 0.932 & 0.056 & 12.17 \\
60 & 0.803 & 0.050 & 0.174 & 0.970 & 0.066 & 14.87 \\
\hline
\end{tabular}

The maximum threat score is consistently larger when calculated using FI data instead of MI data (tables 1 and 2). True positive rates are not consistently larger for one interval method or another, but the differences can be as large as 0.210 . The FI 60-day duration gives a true positive rate that is 0.210 more than the MI 60-day duration. Precision is consistently higher when calculated from FI data. The largest variation in precision is 0.150 for the 3-day duration. An inverse relationship between the true positive rate and model precision is also observed in both tables. Tables 1 and 2 do not definitively show whether the use of MIs is valid or not, so we continued to examine FIs and MIs for other threshold designations.

We also examined simple cumulative thresholds for well-performing, short-duration thresholds that might identify slides that occurred with small amounts of preceding precipitation (table 3 ). The OTs in table 3 were calibrated against hourly precipitation data collected at KSEA from 1978 to 2003. The MI precipitation sums were used to ensure that smaller durations, such as 12 hours and 18 hours, considered the entire date. Two subsets of dates were pulled from the Seattle dataset:

- all dates when one or more landslides occurred, and

- all dates when at least two landslides occurred.

Statistics in table 3 indicate that the thresholds optimized from the sample set with two or more landslides per date outperform the thresholds optimized from the sample set with one or more slides per date. The two-landslide thresholds always have a larger area under the ROC curve compared to the one-landslide thresholds. The two-landslide thresholds' true positive rates, true negative rates, and model precision are also frequently higher than those of the one-landslide thresholds. This is to be expected given the higher values of the two-landslide thresholds, which exclude more of the false positives that exceed the one-landslide thresholds. This generally improved performance for dates with multiple landslides is consistent with previous findings. Chleborad and others $(2006,2008)$ and Godt and others (2006) found that their thresholds were better suited for identifying conditions when multiple landslides are likely. That is, to show a direct causal relationship between rainfall and landslides, two landslides in a 24-hour period is a more reasonable level of activity than one landslide in the same period (Godt and others, 2006; Chleborad and others, 2008). 


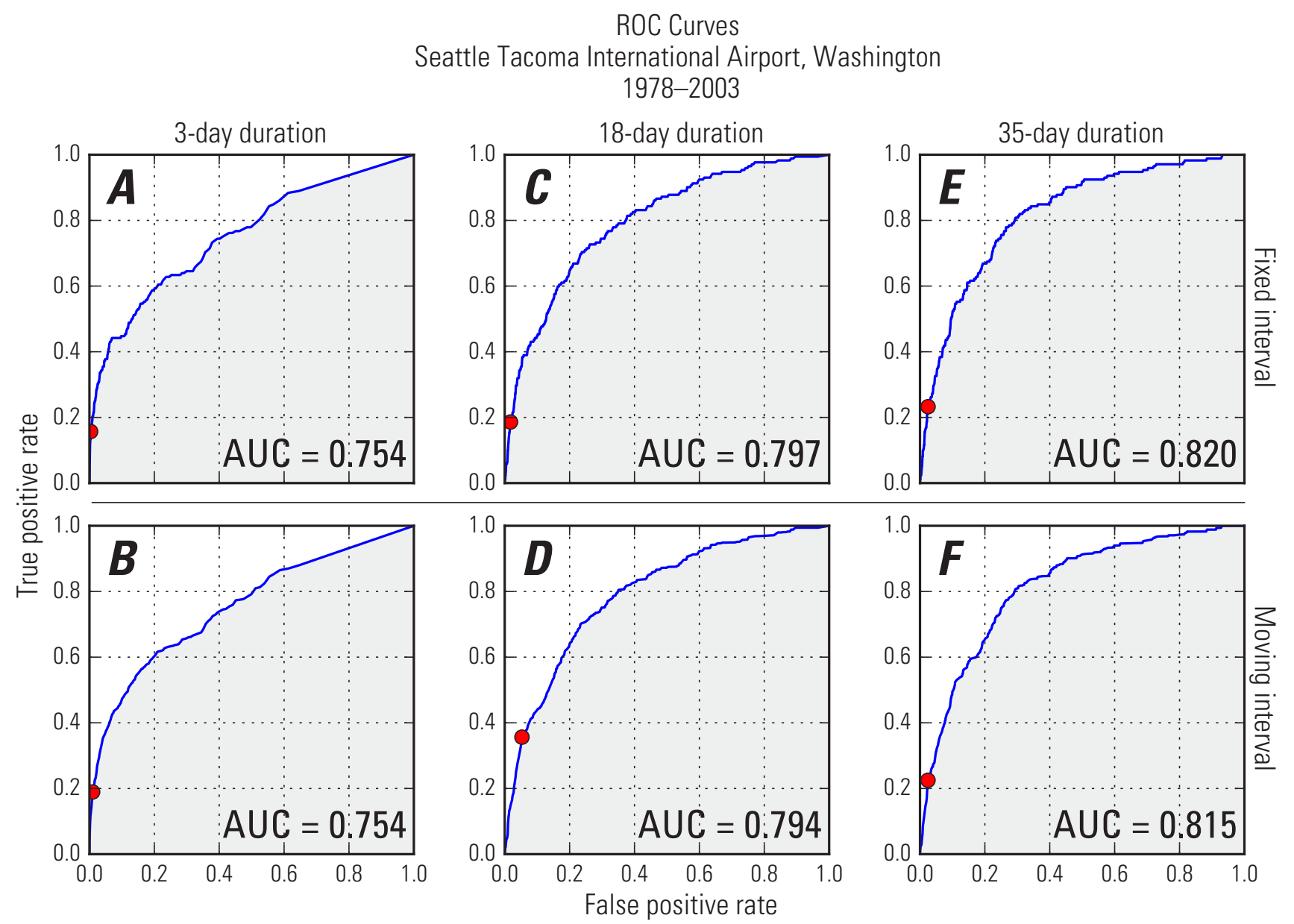

Figure 5. Receiver operating characteristics (ROC) curves for Seattle Tacoma International Airport, 1978-2003, derived over the same duration from both moving intervals and fixed intervals. The top row shows fixed interval ROC curves and the bottom row shows moving interval ROC curves. $A$ and $B, 3$-day duration; $C$ and $D, 18$-day duration; $E$ and $F, 35$-day duration. Note that the optimum classifier value from each ROC analysis is designated with a red dot. (AUC, area under the curve)

Table 3. Calibration Dataset (Seattle)—Statistical performance of simple cumulative thresholds identified for precipitation accumulation durations of less than 72 hours. Results are calculated from moving interval precipitation sums.

[ROC, Receiver operating characteristics; hr, hour]

\begin{tabular}{ccccccc}
\hline $\begin{array}{c}\text { Duration } \\
\text { (hours) }\end{array}$ & $\begin{array}{c}\text { Area under } \\
\text { ROC curve }\end{array}$ & $\begin{array}{c}\text { Maximum } \\
\text { threat score }\end{array}$ & $\begin{array}{c}\text { True positive } \\
\text { rate }\end{array}$ & $\begin{array}{c}\text { True negative } \\
\text { rate }\end{array}$ & Precision & $\begin{array}{c}\text { Optimum } \\
\text { threshold } \\
\text { (inches) }\end{array}$ \\
\hline 12 & 0.671 & 0.068 & 0.113 & 0.992 & 0.147 & 0.69 \\
18 & 0.693 & 0.083 & 0.142 & 0.991 & 0.165 & 0.88 \\
24 & 0.707 & 0.094 & 0.172 & 0.990 & 0.172 & 1.01 \\
36 & 0.731 & 0.105 & 0.180 & 0.991 & 0.202 & 1.41 \\
48 & 0.745 & 0.103 & 0.239 & 0.984 & 0.154 & 1.41 \\
60 & 0.750 & 0.104 & 0.157 & 0.994 & 0.238 & 2.16 \\
\hline 12 & & & Two-landslide minimum & & \\
\hline 18 & 0.780 & 0.095 & 0.169 & 0.997 & 0.178 & 0.195 \\
\\
\hline 14
\end{tabular}


Table 3. Calibration Dataset (Seattle)—Statistical performance of simple cumulative thresholds identified for precipitation accumulation durations of less than 72 hours. Results are calculated from moving interval precipitation sums.-Continued

[ROC, Receiver operating characteristics; hr, hour]

\begin{tabular}{ccccccc}
\hline $\begin{array}{c}\text { Duration } \\
\text { (hours) }\end{array}$ & $\begin{array}{c}\text { Area under } \\
\text { ROC curve }\end{array}$ & $\begin{array}{c}\text { Maximum } \\
\text { threat score }\end{array}$ & $\begin{array}{c}\text { True positive } \\
\text { rate }\end{array}$ & $\begin{array}{c}\text { True negative } \\
\text { rate }\end{array}$ & Precision & $\begin{array}{c}\text { Optimum } \\
\text { threshold } \\
\text { (inches) }\end{array}$ \\
\hline 36 & 0.841 & 0.125 & 0.199 & 0.998 & 0.250 & 2.11 \\
48 & 0.856 & 0.128 & 0.173 & 0.999 & 0.330 & 2.83 \\
60 & 0.866 & 0.131 & 0.265 & 0.996 & 0.206 & 2.58 \\
\hline
\end{tabular}

Table 4. Calibration Dataset (Seattle) —Example of raw counts for two simple cumulative thresholds that examine the same accumulation duration but require a different minimum number of landslides on a given day to define a true event. Results are calculated from moving interval precipitation sums.

\begin{tabular}{ccccccc}
\hline $\begin{array}{c}\text { Minimum number } \\
\text { of landslides }\end{array}$ & $\begin{array}{c}\text { Precipitation } \\
\text { threshold } \\
\text { (inches) }\end{array}$ & True positive & False positive & False negative & True negative & $\begin{array}{c}\text { True event } \\
\text { count }\end{array}$ \\
\hline & & & 36-Hour duration \\
\hline 1 & 1.41 & 744 & 2,931 & 3,384 & 332,818 & 4,128 \\
2 & 2.11 & 244 & 732 & 980 & 337,921 & 1,224 \\
\hline
\end{tabular}

A closer examination of each threshold's raw counts, as with the example in table 4, reveals that there are fewer true events in the two-landslide sample than in the one-landslide sample. This discrepancy improves the precision of the model. The same thresholds, plotted against the inventory of all slides, perform worse than the one-landslide thresholds in table 3.

Each duration in table 3 gives an area under the ROC curve of more than 0.5. This indicates that classifiers derived from precipitation accumulation during the specified duration perform better than random guessing. The high area under the curve and steep ascent of the ROC curves in figure 6 indicate that these durations are strong classifiers for events that are well correlated with short-term (less than 72 hours) precipitation accumulation.

\section{ROC Curves \\ Seattle Tacoma International Airport, Washington \\ 1978-2003}
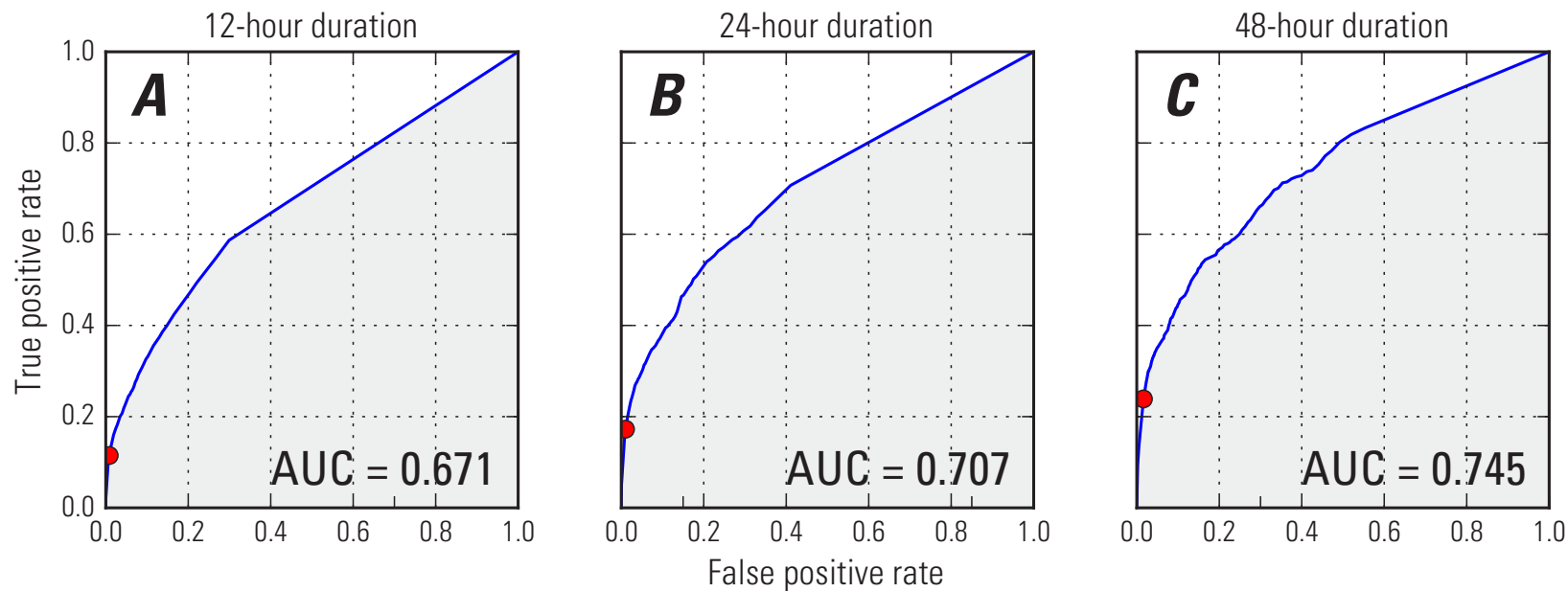

Figure 6. Receiver operating characteristics (ROC) curves of simple cumulative thresholds based on short (less than 72 hours) durations for Seattle Tacoma International Airport, 1978-2003. A, 12-hour duration; B, 24-hour duration; C, 48-hour duration. The red dot represents the optimum threshold value. (AUC, area under the curve) 
Used independently, the cumulative thresholds with areas under the curve of more than 0.75 correctly identify between 14 and 38 percent of landslide dates when calculated with FI precipitation sums. However, these simple cumulative thresholds are likely to miss the slope failures that occur with small amounts of preceding rainfall. Figure 7 shows that the majority of slides occur in conditions that do not exceed the simple cumulative thresholds.

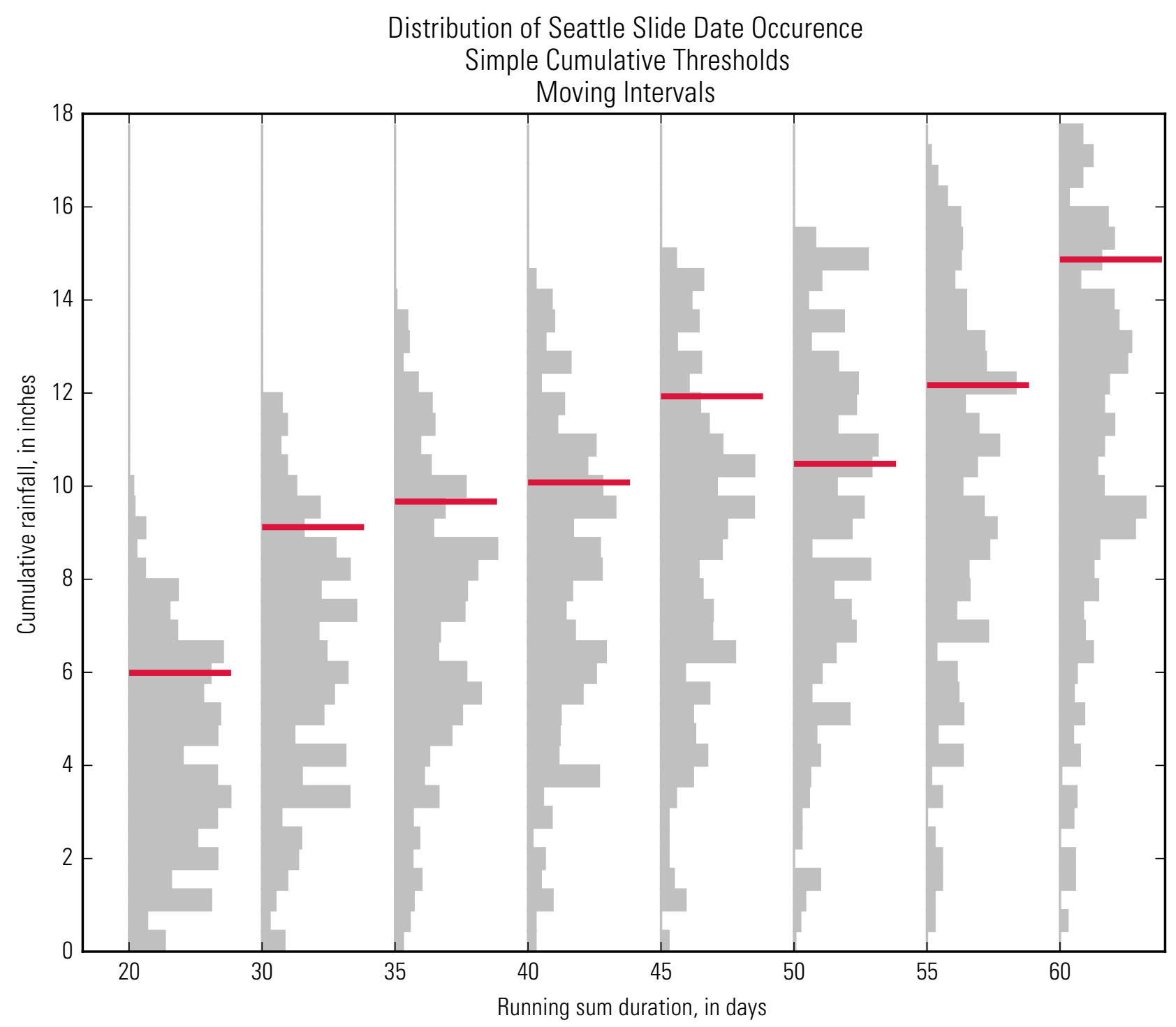

Figure 7. Histograms of landslide dates' total accumulated precipitation over specified durations. The simple cumulative threshold for each moving interval duration with areas under the curve of more than 0.75 is represented by the red line. Bins above the red lines show landslide dates that would have been identified by the moving interval optimum threshold (table 2). 


\section{Recent-Antecedent Cumulative Thresholds}

\section{Calibration Data-Seattle Tacoma International Airport}

Previously published thresholds for landslide events from 1933 to 1997 identified an RA threshold of $P_{3}=3.5-0.67 P_{15}$ where $P_{3}=$ precipitation accumulation (inches) during the 3 days prior to the considered date and $P_{15}=$ precipitation accumulation (inches) during the 15 days preceding $P_{3}$ (Chleborad, 2000, 2003; Chleborad and others, 2006, 2008). The threshold developed by Chleborad and others (2008) is the most recently developed RA threshold for the area; we used its statistical performance as a benchmark against which to evaluate RA thresholds developed in this report. Applied to the FI calibration data from KSEA, this threshold yields a true positive rate of 0.424 and precision of 0.084 (table 5). Applied to MI calibration data, the threshold yields a true positive rate of 0.404 and precision of 0.080 (table 5).

Table 5. Calibration Dataset (Seattle)—Statistical performance of recent-antecedent (RA) thresholds derived from both fixed interval and moving interval simple cumulative thresholds. The RA thresholds are evaluated against both fixed interval precipitation sums and moving interval precipitation sums. The moving interval precipitation sums are analyzed only with RA thresholds that were also derived from moving intervals.

$\left[P_{3,10}\right.$, precipitation accumulation (inches) during the 3 or 10 days, respectively, prior to the considered date; $P_{15,32,40}$, precipitation accumulation (inches) during the 15,32 , or 40 days, respectively, preceding $P_{3}$; RA, recent-antecedent]

\begin{tabular}{ccccccc}
\hline Name & $\begin{array}{c}\text { Duration } \\
\text { (days) }\end{array}$ & $\begin{array}{c}\text { Interval used to } \\
\text { define RA }\end{array}$ & $\begin{array}{c}\text { Threshold } \\
\text { equation } \\
\text { (inches) }\end{array}$ & $\begin{array}{c}\text { True positive } \\
\text { rate }\end{array}$ & $\begin{array}{c}\text { True negative } \\
\text { rate }\end{array}$ & Precision \\
\hline \multicolumn{7}{c}{ Fixed interval precipitation sums } \\
\hline Chleborad and others (2008) & $3-15$ & Fixed & $P_{3}=3.50-0.67 P_{15}$ & 0.424 & 0.943 & 0.084 \\
Modified 3-15 & $3-15$ & Fixed & $P_{3}=2.74-0.49 P_{15}$ & 0.448 & 0.938 & 0.081 \\
Modified 3-15 & $3-15$ & Moving & $P_{3}=2.16-0.44 P_{15}$ & 0.541 & 0.897 & 0.061 \\
$3-32$ & $3-32$ & Fixed & $P_{3}=2.74-0.28 P_{32}$ & 0.517 & 0.923 & 0.076 \\
$3-32$ & $3-32$ & Moving & $P_{3}=2.16-0.22 P_{32}$ & 0.558 & 0.902 & 0.066 \\
$10-40$ & $10-40$ & Fixed & $P_{10}=3.84-0.32 P_{40}$ & 0.674 & 0.830 & 0.046 \\
$10-40$ & $10-40$ & Moving & $P_{10}=4.25-0.41 P_{40}$ & 0.692 & 0.804 & 0.042 \\
\hline & \multicolumn{7}{c}{ Moving interval precipitation sums } & & & 0.080 \\
\hline Chleborad and others (2008) & $3-15$ & Fixed & $P_{3}=3.50-0.67 P_{15}$ & 0.404 & 0.943 & 0.059 \\
Modified 3-15 & $3-15$ & Moving & $P_{3}=2.16-0.44 P_{15}$ & 0.527 & 0.897 & 0.067 \\
$3-32$ & $3-32$ & Moving & $P_{3}=2.16-0.22 P_{32}$ & 0.561 & 0.903 & 0.041 \\
\hline
\end{tabular}

Both sets of results may differ from those of Chleborad and others $(2006,2008)$ because KSEA is farther from most of the slides in the database than are any of the rain gages in the Seattle network. The Chleborad and others $(2006,2008)$ RA threshold was previously tested for its ability to identify landslide conditions near the monitored Seattle network rain gages; the relatively increased distance between the single KSEA rain gage used for this report and the landslides recorded by Chleborad and others $(2006,2008)$ is likely to introduce noise into the model.

The MIs may also vary more than the FIs because Chleborad and others $(2006,2008)$ counted daily exceedances (that is, FIs) but we counted hourly exceedances (to simulate conditions under which the thresholds are likely to be used) and the threshold was not exceeded during all 24 hours of many dates on which slides occurred. Dates with nonuniform classification were left in our analysis to reflect anticipated usage conditions, when there are no guarantees that all 24 hours will fall on a single side of the RA threshold.

The MI precipitation sums of known slide dates frequently show less than 1 inch of precipitation over the recent 3 days and 0-4 inches of precipitation over the antecedent 15 days (fig. $8 A$ ). Of the recorded slide dates, 37 percent plotted all 24 of the MI precipitation sums in this zone. These events cluster near the origin, where precipitation thresholds are ineffective. The poor correlation observed between many landslide dates and significant accumulations of either short-term or antecedent precipitation 
indicates that the KSEA rain gage may not reflect the precipitation conditions at all Seattle landslide locations. Multiple rain gages in close proximity to slide-prone areas will likely perform better than the single KSEA gage (Chleborad and others, 2006, 2008). Other indicators of potential landslide activity not based on rainfall accumulation also warrant additional investigation.

We examined the simple cumulative thresholds in tables 1 and 2 to identify possible alternative relationships to use in RA thresholds. The RA thresholds are defined by the simple cumulative thresholds presented earlier. The OT of a single duration identified from FIs differs from that identified by MIs (tables 1 and 2). For example, the FI 3-day duration finds OT $=2.74$ inches but the MI 3-day duration finds OT $=2.16$ inches. Now, there are two options for defining RA thresholds (table 1 and table 2 OT) and two datasets to apply them to (FI and MI precipitation sums).

We chose to analyze a modified 3-15-day threshold in order to compare our results directly to those of Chleborad and others (2008) even though the 18-day durations in tables 1 and 2 do not outperform the other durations on any metric. Two modified 3-15-day thresholds are presented in table 5: one defined from the FI OT and one from the MI OT. Table 5 indicates that the MI-defined 3-15-day threshold, when applied to the FI precipitation sums, identifies 0.093 more landslide dates than the FI-defined threshold and 0.117 more landslide dates than the threshold of Chleborad and others (2008).

We also looked for alternative duration combinations of recent and antecedent hours, prioritizing different sets of ROC statistics to select different threshold permutations. We prioritized the MI ROC statistics because preliminary examination (table 5) indicates that thresholds defined with MI OTs better identify landslide dates. We first selected threshold permutations that relied on durations with high areas under the curve and threat scores. The MI 6-day duration outperforms all of the other short MI durations with regard to maximum threat score $(0.110)$ and has relatively high precision $(0.210)$ (table 2$)$. These statistics led us to examine RA thresholds that used precipitation accumulated over 6 days in the threshold's recent component.

We then selected the longer duration for the antecedent component of the RA threshold from MI simple durations with areas under the curve of 0.75 or more. Of these, the 35 -day duration has the highest threat score, 0.075 , indicating that it best minimizes false positive and false negative errors (table 2). It also gives the highest area under the curve of the remaining options. Consequently, we selected 29 days for the antecedent duration so that the recent and antecedent duration totaled 35 days.

We alternatively considered RA thresholds based on MI simple cumulative durations with high true positive rates, high precision, and high areas under the curve. The 4-day duration has the highest precision (0.265) of any considered duration (table 2). The 7-day duration has the highest true positive rate $(0.229)$ of durations of 10 days or less. The 10-day duration has the highest area under the curve of the short durations and the second highest true positive rate $(0.213)$. These three short durations were used as the recent component of the RA thresholds and combined with each of the longer durations that gave the highest area under the curve ( 30 days at 0.815 ), highest precision (30 days at 0.114 ), highest threat score ( 35 days at 0.075 ), and highest true positive rate (50 days at 0.432 ) (table 2 ).

Finally, we examined thresholds that used precipitation accumulated in the 3 days prior to failure in the RA thresholds' recent component. We suspected that the recent durations selected from the ROC statistics may last too long to maintain a strong correlation with rainfall that induces slope failure. Therefore, we decided to examine the same 3-day recent duration used by Chleborad and others $(2006,2008)$ with all of the selected longer durations. The resulting alternative RA thresholds are shown in tables 5 and 6 . The MI precipitation sums are plotted against the 3-32-day threshold in figure $8 B$.

These thresholds do find high true positive rates, ranging from 0.500 to 0.692 , but when applied to FI precipitation sums, the precision is reduced to a range between 0.042 and 0.086 . Sound Transit's stated aims include maximizing the number of slides identified, so we continued to analyze the 10-40-day threshold, which yielded the highest true positive rate of 0.692 . The 10-40-day threshold applied to MI precipitation sums is compared to the 3-15- and 3-32-day thresholds in figure 8.

The modified 3-15-day threshold, the 3-32-day threshold, and the 10-40-day threshold all have much higher true positive rates when applied to FI precipitation sums - $0.541,0.558$, and 0.692 , respectively - than the 0.424 of Chleborad and others (2008) (table 5). However, the improved classification rate can come at the expense of precision. The modified 3-15-day threshold has a precision of 0.061 , the 3-32-day threshold has a precision of 0.066 , and the 10-40-day threshold gives the precision of 0.042 (table 5). The precision of each of these thresholds is lower than the precision of 0.084 in Chleborad and others (2006, 2008) (table 5).

The true negative rate of each newly identified threshold also decreased relative to the threshold in Chleborad and others (2008). This trend supports the decreased precision results as the models return more false negatives and false positives. The modified 3-15- and 3-32-day thresholds reduced the FI precipitation sums' true negative rates by 0.02 or less, and the 10-40-day threshold dropped the true negative rate by approximately 0.14 (table 5).

Figure 8 (following page). Precipitation accumulation calculated using moving intervals on dates of known landsliding near Seattle Tacoma International Airport (KSEA). A date's hour with the highest previous 3-day precipitation is represented with an opaque circle. Note that the circles, although not taken from a consistent hour on each date, approximate a plot of fixed interval precipitation sums because only a single sum is represented per date. $A$, The modified 3-15-day threshold, $P_{3}=2.16-0.44 P_{15^{\prime}}$ is compared to the Chleborad and others (2008) threshold. $B$, The 3-32-day threshold, defined by $P_{3}=2.16-0.22 P_{32^{\circ}} C$, The 10-40-day threshold, defined as $P_{10}=4.25-0.41 P_{40^{\circ}}$ 
Recent - Antecedent Thresholds

Seattle Tacoma International Airport, Washington

1978-2003

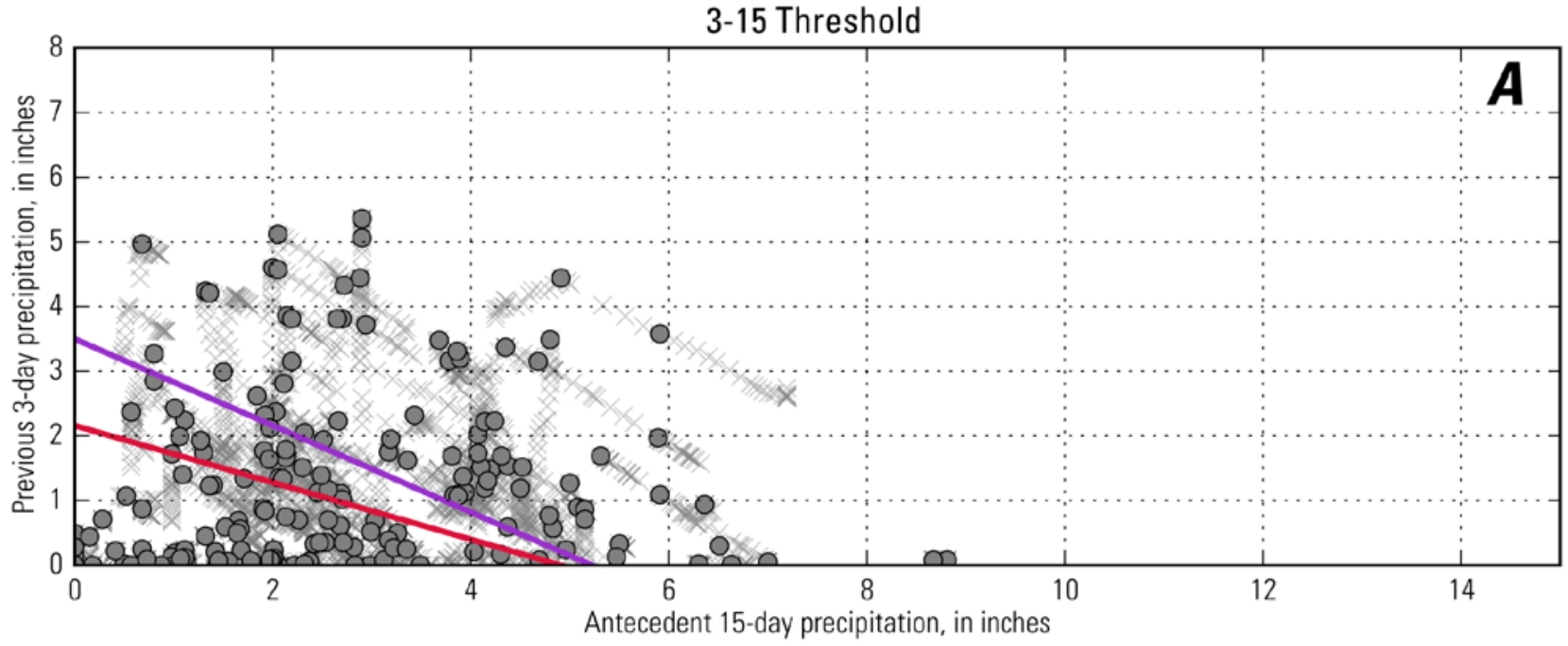

3-32 Threshold

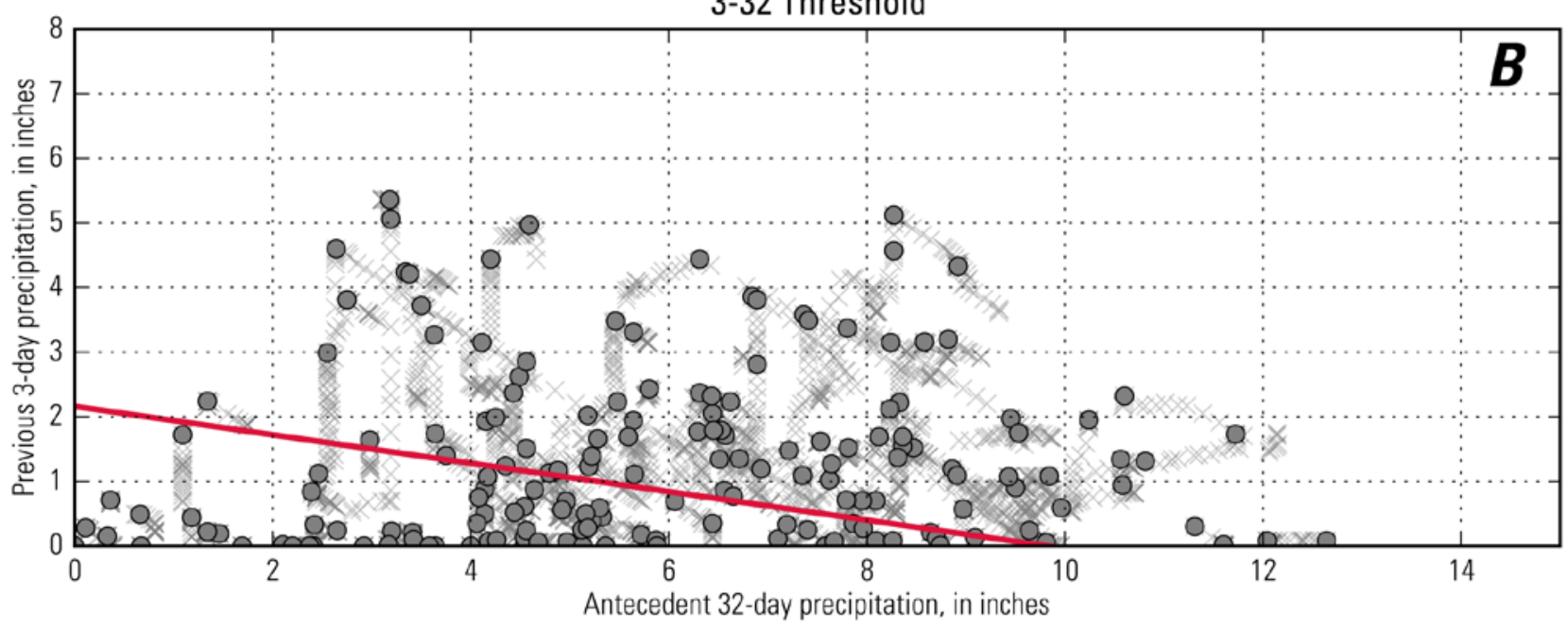

10-40 Threshold

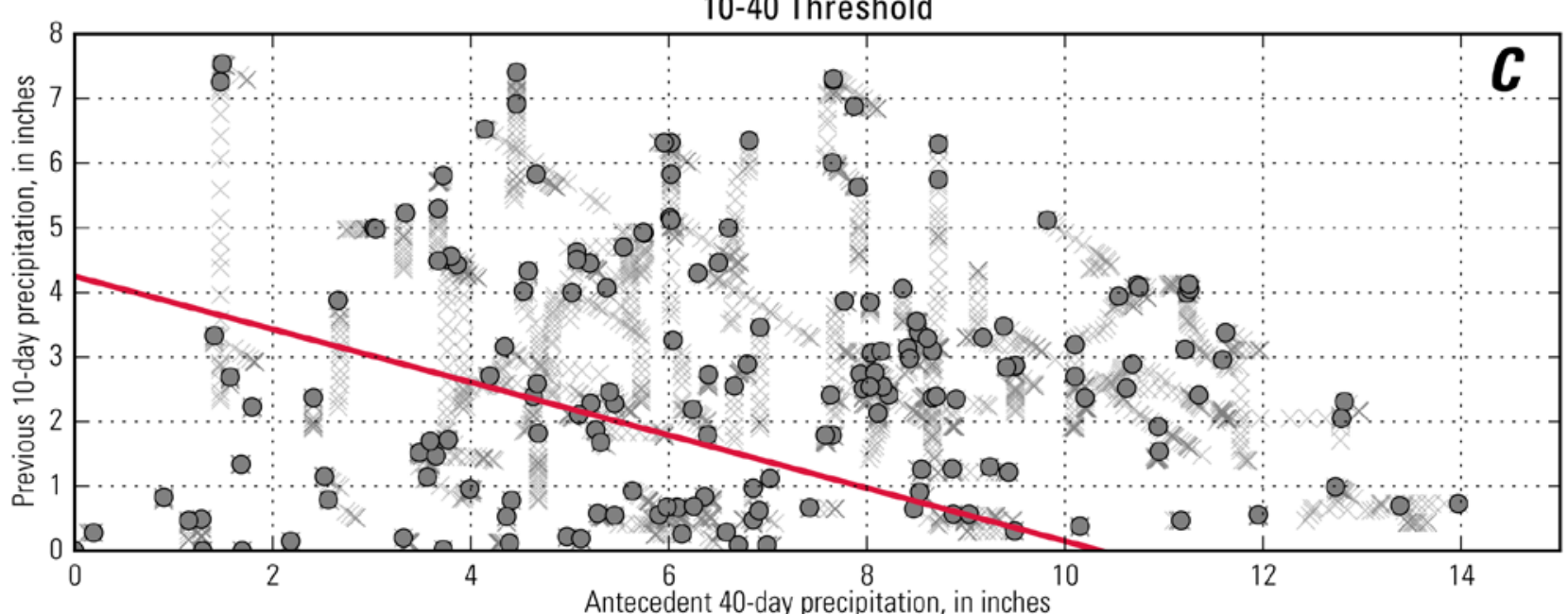

Antecedent 40-day precipitation, in inches

\begin{tabular}{|lllll|}
\hline$\times \begin{array}{l}\text { Moving interval sums } \\
\text { from slide dates }\end{array}$ & $0 \begin{array}{l}\text { Highest moving interval } \\
\text { sum on slide date }\end{array}$ & $-\begin{array}{l}\text { Analyzed threshold, } \\
\text { this report }\end{array}$ & $\begin{array}{l}\text { Chleborad and others (2008) } \\
P_{3}=3.50-0.67 P_{15}\end{array}$ \\
\hline
\end{tabular}


Table 6. Calibration Dataset (Seattle)—Recent-antecedent thresholds considered but not pursued for further analysis. Thresholds were defined from moving intervals and applied to both types of precipitation sums.

$\left[P_{3,4,6,7,}\right.$ or ${ }_{10}$, precipitation accumulation (inches) over the $3,4,6,7$, or 10 days, respectively, prior to the considered date; $P_{20,23,25,26,27,28,29,31,40,43,46,}$ or ${ }_{47}$, precipitation accumulation (inches) during the $20,23,25,26,27,28,29,31,40,43,46$, or 47 days, respectively, preceding $P_{3,4,6,7}$, or $\left.{ }_{10}\right]$

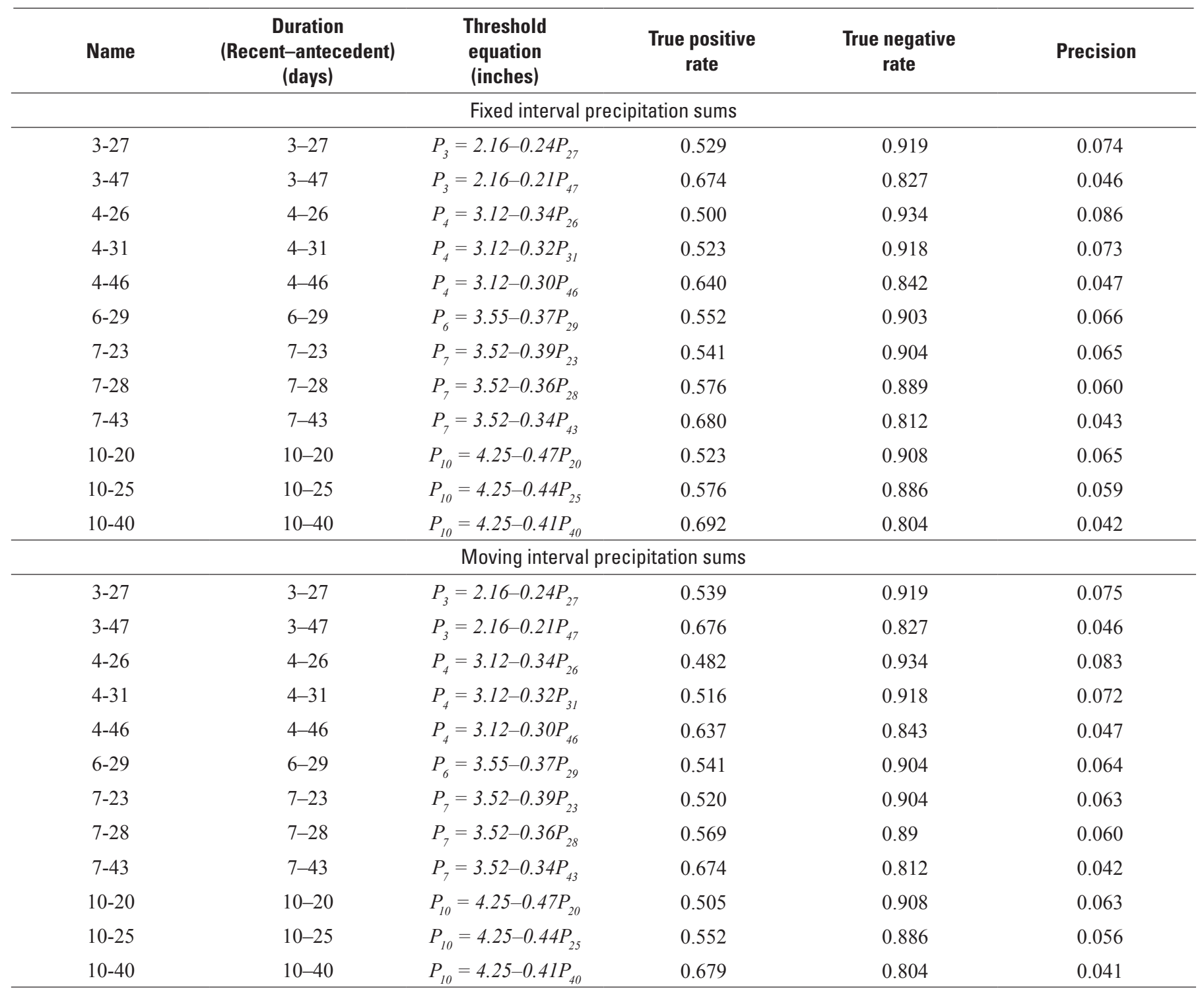

\section{Use of Moving Interval Versus Fixed Interval Precipitation Sums}

Applying all four thresholds to MI precipitation sums, rather than FI precipitation sums, reveals that all reported statistics are relatively unaffected. Table 7 shows that the MI precipitation sums tend to underestimate the FI true positive rate by less than 5 percent. A similar trend is observed with precision-relative difference; the RA thresholds show relative differences of less than 6 percent in either direction (table 7). The relative difference between true negative rates is less variable, generally overestimating the FI true negative rate by less than 1 percent. The relatively steady behavior of these performance measures, as well as the benefit of near-real-time decision making, support the continuing examination of MI performance.

\section{Validation Data-Everett Paine Field and Mukilteo, Washington}

Once calibrated using the KSEA data, the developed thresholds were validated against the two remaining databases: KPAE and the four Mukilteo stations. Evaluation of the thresholds against the 2006-2014 KPAE dataset indicates that both the 3-15-day threshold and the 3-32-day threshold do not identify events near KPAE as well as they do near KSEA (tables 5 and 8 and figures 8 and 3-1). The modified 3-15-day threshold true positive rate decreased from 0.527 to 0.466 . Table 8 shows that the 
Table 7. Calibration Dataset (Seattle) —-The relative difference in statistics gathered from moving interval precipitation sums relative to the fixed interval precipitation sums. The true positive rate, true negative rate, and precision of the all examined recent-antecedent thresholds are provided.

[\%, percentage; $P_{3,4,6,7}$, or ${ }_{10}$, precipitation accumulation (inches) over $3,4,6,7$, or 10 days, respectively, prior to the considered date; $P_{15,20,25,26,27,28,29,31,32}$, ${ }_{40,43,46}$, ${ }_{47}$, precipitation accumulation (inches) during the $15,20,25,26,27,28,29,31,32,40,43,46$, or 47 days, respectively, preceding $P_{3,4,6,7,}$, or ${ }_{10}$; Rel. diff., relative difference]

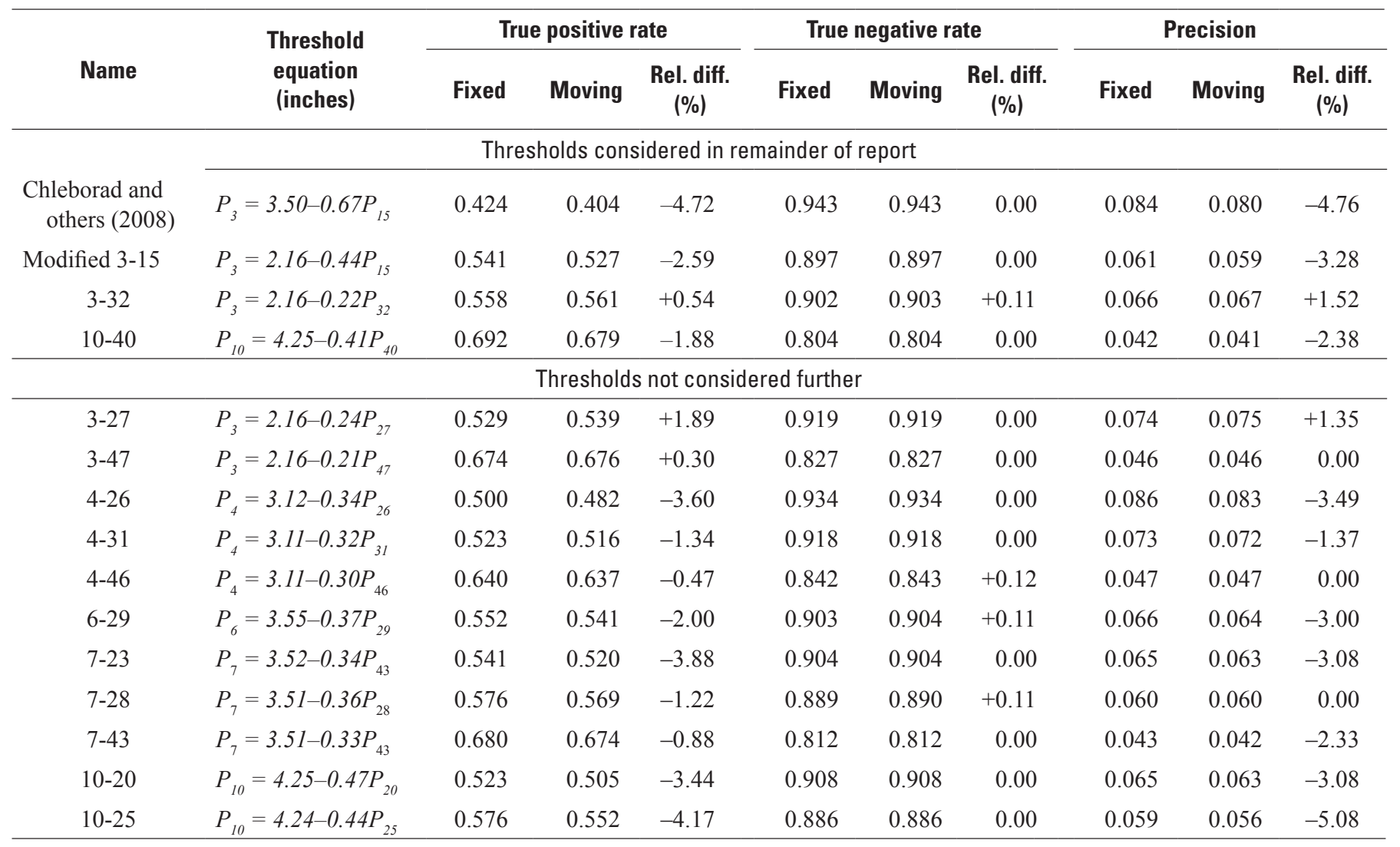

3-32-day threshold undergoes a slightly larger drop in true positive rate, from 0.561 to 0.486 . The modified 3-15-day threshold precision increased by 0.024 and the 3-32-day threshold precision increased by 0.040 . The increased precision of the two thresholds is expected with the decrease in true positive rate because the thresholds screen out more events, which consequently sends more true negative events to the correct classification.

The 10-40-day threshold does not follow the performance trends of the other thresholds at KPAE. Instead, the 10-40 true positive rate increases from 0.679 to 0.935 and its precision drops from 0.041 to 0.015 (tables 5 and 8). The true negative rate drops all the way from 0.804 to 0.167 . Although the true positive rate increases at KPAE, the other metrics are so negatively affected that the threshold performs very poorly. Only 1 in 100 hourly predictions identifies an hour from a date when sliding was recorded.

KPAE and KSEA had similar mean annual precipitation (36.73 inches and 36.70 inches, respectively) during 1978-2003 (National Climatic Data Center, 2016). The similar rainfall conditions lead us to expect that landsliding in both Seattle and Everett should initiate under similar conditions and that the thresholds should be similarly applicable at both locations. The statistical comparison of the thresholds at both locations reveals that the true positive rates for the 3-15- and 3-32-day thresholds are in a similar range, although the KPAE dataset yields rates that are approximately 13 percent smaller than the KSEA dataset. The difference is likely partially explained by the difference in sample size - the KPAE dataset contains 47 unique slide dates and 8 years of records, but the KSEA dataset contains 172 dates and 25 years of records. Meaningful comparison of the two areas would require records that cover an equal length of time and include similar landslide data developed using uniform reporting and methods.

The 2015-2016 data from Mukilteo support the universal applicability of the modified 3-15-day threshold. The modified 3-15-day threshold, relative to the Chleborad and others $(2006,2008)$ threshold, increases the true positive rate at each Mukilteo station by 0.119 to 0.395 (table 9 and figure 3-2). Relative to the KSEA dataset, the Mukilteo modified 3-15 true positive rates increase by 0.186 to 0.254 (tables 5 and 9). The true negative rates are more variable than either the KSEA or KPAE datasets, varying between 0.80 and 0.89 instead of remaining near 0.90 . The small size of the Mukilteo dataset causes larger shifts in the true positives and true negatives when an error occurs. 
Table 8. Validation Dataset 1 (Everett)—Recent and antecedent cumulative threshold statistical performance calculated using moving precipitation sums.

$\left[P_{3}\right.$ or ${ }_{10}$, precipitation accumulation (inches) over the 3 or 10 days, respectively, prior to the considered date; $P_{15,32, \text { or } 40}$, precipitation accumulation (inches) during the 15,32 , or 40 days, respectively, preceding $P_{3}$ or ${ }_{10}$ ]

\begin{tabular}{cccccc}
\hline Name & $\begin{array}{c}\text { Duration } \\
\text { (Recent-antecedent) } \\
\text { (days) }\end{array}$ & $\begin{array}{c}\text { Threshold } \\
\text { equation } \\
\text { (inches) }\end{array}$ & $\begin{array}{c}\text { True positive } \\
\text { rate }\end{array}$ & $\begin{array}{c}\text { True negative } \\
\text { rate }\end{array}$ \\
\hline \multicolumn{2}{c}{ Everett Paine Field, Washington (KPAE) } & & & \\
\hline Phleborad and others (2008) & $3-15$ & $P_{3}=3.50-0.67 P_{15}$ & 0.352 & 0.964 \\
Modified 3-15 & $3-15$ & $P_{3}=2.16-0.44 P_{15}$ & 0.466 & 0.117 \\
$3-32$ & $3-32$ & $P_{3}=2.16-0.22 P_{32}$ & 0.486 & 0.930 & 0.083 \\
$10-40$ & $10-40$ & $P_{10}=4.25-0.41 P_{40}$ & 0.935 & 0.107 & 0.167 \\
\hline
\end{tabular}

Table 9. Validation Dataset 2 (Mukilteo)—Recent and antecedent cumulative threshold statistical performance calculated using moving interval precipitation sums.

$\left[P_{3}\right.$ or ${ }_{10}$, precipitation accumulation (inches) over the 3 or 10 days, respectively, prior to the considered date; $P_{15,32, \text { or } 40}$, precipitation accumulation (inches) during the 15,32 , or 40 days, respectively, preceding $P_{3}$ or $\left.{ }_{10}\right]$

\begin{tabular}{|c|c|c|c|c|c|}
\hline Name & $\begin{array}{c}\text { Duration } \\
\text { (Recent-antecedent) } \\
\text { (days) }\end{array}$ & $\begin{array}{l}\text { Threshold } \\
\text { equation } \\
\text { (inches) }\end{array}$ & $\begin{array}{l}\text { True positive } \\
\text { rate }\end{array}$ & $\begin{array}{l}\text { True negative } \\
\text { rate }\end{array}$ & Precision \\
\hline \multicolumn{6}{|c|}{ Marine View Drive \& 116th St. SW (VH) } \\
\hline Chleborad and others (2008) & $3-15$ & $P_{3}=3.5-0.67 P_{15}$ & 0.381 & 0.886 & 0.070 \\
\hline Modified 3-15 & $3-15$ & $P_{3}=2.16-0.44 P_{15}$ & 0.749 & 0.852 & 0.102 \\
\hline \multicolumn{6}{|c|}{ Waterton Circle (LS) } \\
\hline Chleborad and others (2008) & $3-15$ & $P_{3}=3.5-0.67 P_{15}$ & 0.658 & 0.837 & 0.083 \\
\hline Modified 3-15 & $3-15$ & $P_{3}=2.16-0.44 P_{15}$ & 0.777 & 0.801 & 0.081 \\
\hline $3-32$ & $3-32$ & $P_{3}=2.16-0.22 P_{32}$ & 0.772 & 0.809 & 0.084 \\
\hline Modified 3-15 & $3-15$ & $P_{3}=2.16-0.44 P_{15}$ & 0.713 & 0.810 & 0.089 \\
\hline $3-32$ & $3-32$ & $P_{3}=2.16-0.22 P_{32}$ & 0.625 & 0.866 & 0.108 \\
\hline $10-40$ & $10-40$ & $P_{10}=4.25-0.41 P_{40}$ & 0.982 & 0.672 & 0.072 \\
\hline \multicolumn{6}{|c|}{ Mukilteo Lighthouse Park (M1) } \\
\hline Chleborad and others (2008) & $3-15$ & $P_{3}=3.5-0.67 P_{15}$ & 0.527 & 0.902 & 0.113 \\
\hline Modified 3-15 & $3-15$ & $P_{3}=2.16-0.44 P_{15}$ & 0.781 & 0.848 & 0.108 \\
\hline $3-32$ & $3-32$ & $P_{3}=2.16-0.22 P_{32}$ & 0.787 & 0.879 & 0.133 \\
\hline $10-40$ & $10-40$ & $P_{10}=4.25-0.41 P_{40}$ & 0.976 & 0.704 & 0.072 \\
\hline
\end{tabular}


The 10-40-day threshold identifies 85.7-98.2 percent of hours falling on dates in the Mukilteo landslide database (table 9 and figure $3-4)$. The precision also increases by a range between 0.013 and 0.031 compared to KSEA. The Mukilteo precision shows both increases and decreases relative to KPAE, with changes ranging between -0.002 and +0.016 . The generally improved performance of the 10-40-day threshold in Mukilteo is likely due to the small sample size. The small sample size and small period of record minimizes the proportion of nonevents, thus minimizing the number of false positives and increasing the precision. It is unlikely that the 10-40-day threshold discriminates markedly better at the Mukilteo sites than it does at KPAE and KSAE.

The 3-32-day threshold consistently yields the highest precision in Mukilteo. The modified 3-15-day threshold often has the highest true positive rate but exceeds the 3-32-day threshold by only $0.005-0.088$ at three of the four stations. The 3-32-day threshold true positive rate exceeds the modified 3-15-day threshold true positive rate by 0.006 at Mukilteo Lighthouse Park (table 9 and figure 3-3); the anomalous behavior may be attributable to the small sample size and variable location of storms.

\section{Intensity-Duration Threshold}

\section{Calibration Data-Seattle Tacoma International Airport}

Many slides that occur with minimal precipitation in the hours immediately preceding failure are not identified by cumulative precipitation thresholds (figs. 7 and 8). The ID thresholds, which consider the amount of precipitation delivered in a continuous storm event, may give insight into the probability of landslide events resulting from moderate-intensity rainfall and high-antecedent precipitation.

Godt and others (2006) identified an ID threshold of $I=3.257 D^{-1.13}$ for rainfall likely to induce multiple landslides, where $I$ is rainfall intensity in inches/hour and $D$ is duration in hours. We used this threshold as a benchmark against which to evaluate ID threshold performance because it is the most recent threshold developed for the Seattle area. Applied to our calibration data from KSEA, the threshold of Godt and others (2006) has a true positive rate of 0.125 and a precision of 0.374 (table 10). This indicates that the model correctly identified 12 percent of all storm hours associated with landslide dates and that 37 percent of storm hours that exceeded the threshold were associated with known landslide dates. Nearly 90 percent of all storm hours on dates when landslides occurred were not identified by the Godt and others (2006) model (table 10).

When considering ID thresholds, it is helpful to understand how often landsliding occurs relative to how often the rainfall condition occurs. Figure 9 illustrates that most rainfall events have durations of less than 1.5 hours. Landslides also frequently occur during storms lasting less than 1.5 hours (fig. 10). Figure 11 illustrates the relative probability of landsliding during any rainfall condition; regions of high ( 0.50 or more) and moderate ( 0.12 or more) probability exclude almost all ID combinations in which the duration is less than 10 hours. The moderate probability boundary of 0.12 was selected because of the broad probability gradient in figure 11 and to maintain a conservative approach for identifying potential landslide conditions. The inability of shorter durations to satisfy this probability condition indicates that ID thresholds are most useful for identifying low-frequency rainstorms of longer duration; these longer storms are likely to induce large numbers of landslides (Chleborad and others, 2008). Knowing this, we again examined the performance of the threshold of Godt and others (2006), this time for storms with durations of 12 hours or more (fig. 12). The true positive rate increases by 0.171 , but the precision is unchanged (table 10).

We used the OTs and associated durations identified in table 3 to fit two ID curves, one defined with OTs from dates with one or more recorded landslides (one-landslide threshold), and one defined with OTs from dates with two or more recorded landslides (two-landslide threshold). Although the two-landslide threshold curve was calibrated against dates with two or more landslides, we evaluated that threshold against all known landslides. We also required that the storm durations evaluated by both threshold types be 12 hours or more. The one-landslide threshold gives KSEA's true positive rate at 0.702 , but the two-landslide threshold gives the true positive rate at 0.450 (table 10). The increased classification accuracy decreases the model precision, lowering the precision to 0.165 for the one-landslide threshold and to 0.265 for the two-landslide threshold. The one-landslide threshold true negative rate drops roughly 0.2 below the true negative rates of the other considered thresholds (table 10).

The ID thresholds tend not to identify true hours that fail to exceed the RA thresholds (table 11). The RA thresholds, in contrast, identify thousands of true hours that are not identified by the ID thresholds. The RA counts do include true hours in which duration is less than 12 hours despite the ID threshold's duration condition. These counts are included in table 11 because they are important to understanding the performance difference between the two types of thresholds.

Although the ID thresholds rarely identify landslide dates that do not exceed RA thresholds, the two thresholds combined are useful for identifying rainfall conditions that are likely to produce multiple landslides. Approximately 11 percent of all known landslide hours exceed both the one-landslide ID threshold and the 3-32-day RA threshold (table 12). Of those hours, 63 percent belong to dates on which two or more landslides occurred. The 63 percent represent nearly one-fourth of all hours that fall on landslide dates with two or more slides (table 12). Conversely, the 3-32-day threshold alone, when applied only to MIs that fall on known landslide dates, finds 55 percent of the hours; of those, 42 percent fell on dates with two or more landslides. The two or more landslide hours identified by the modified 3-15-day threshold represent 79 percent of all hours known to have experienced two or more landslides. 
Table 10. Calibration Dataset (Seattle)_Intensity-duration threshold statistical performance.

[>, greater than; $\geq$, greater than or equal to; D, duration in hours; I, rainfall intensity in inches/hour; $\mathrm{R}^{2}$, coefficient of determination]

\begin{tabular}{llcccc}
\hline \multicolumn{1}{c}{ Criteria } & $\begin{array}{c}\text { Threshold } \\
\text { equation } \\
\text { (inches) }\end{array}$ & $\mathbf{R}^{2}$ & Condition & $\begin{array}{c}\text { True positive } \\
\text { rate }\end{array}$ & $\begin{array}{c}\text { True negative } \\
\text { rate }\end{array}$ \\
\hline & \multicolumn{1}{c}{ Seattle Tacoma International Airport (SKEA), Zero duration excluded } \\
\hline Godt and others (2006) & $I=3.257 D^{-1.13}$ & - & $\mathrm{D}>0$ hours & 0.125 & 0.994 \\
Godt and others (2006) & $I=3.257 D^{-1.13}$ & - & $\mathrm{D} \geq 12$ hours & 0.296 & 0.962 \\
One-landslide & $I=0.134 D^{-0.35}$ & 0.855 & $\mathrm{D} \geq 12$ hours & 0.702 & 0.729 \\
Two-landslides & $I=0.193^{-0.34}$ & 0.842 & $\mathrm{D} \geq 12$ hours & 0.450 & 0.905 \\
\hline
\end{tabular}

Relative Frequency of Rainfall Conditions

Seattle Tacoma International Airport, Washington

1978-2003

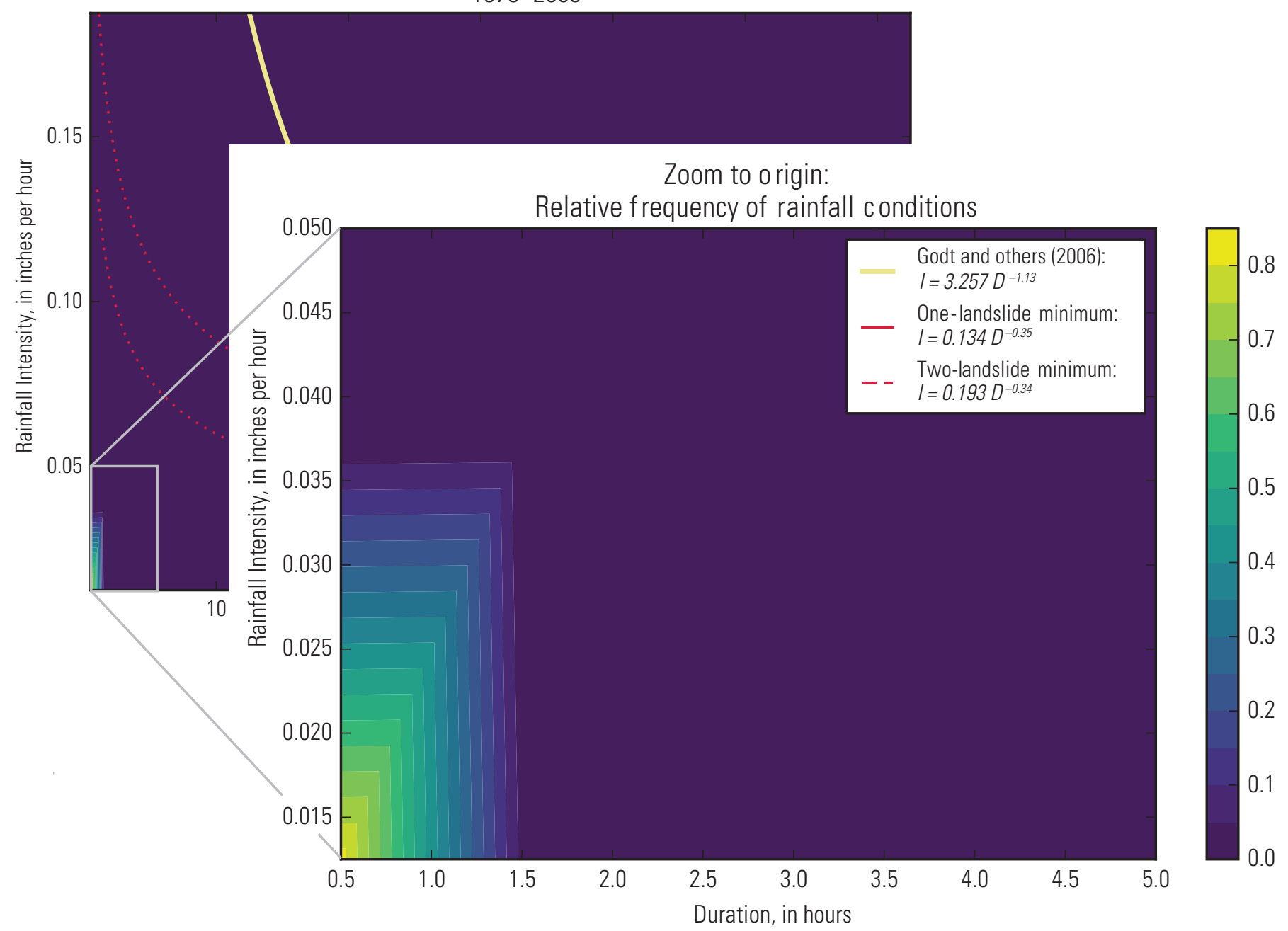

Figure 9. Relative frequency of rainfall conditions near Seattle Tacoma International Airport (KSEA) plotted by rainfall intensity and storm duration. The relative frequency is given by the count of rainfall condition occurrence during 1978-2003 divided by number of recorded hours in the dataset. (D, duration in hours; I, rainfall intensity in inches/hour) 


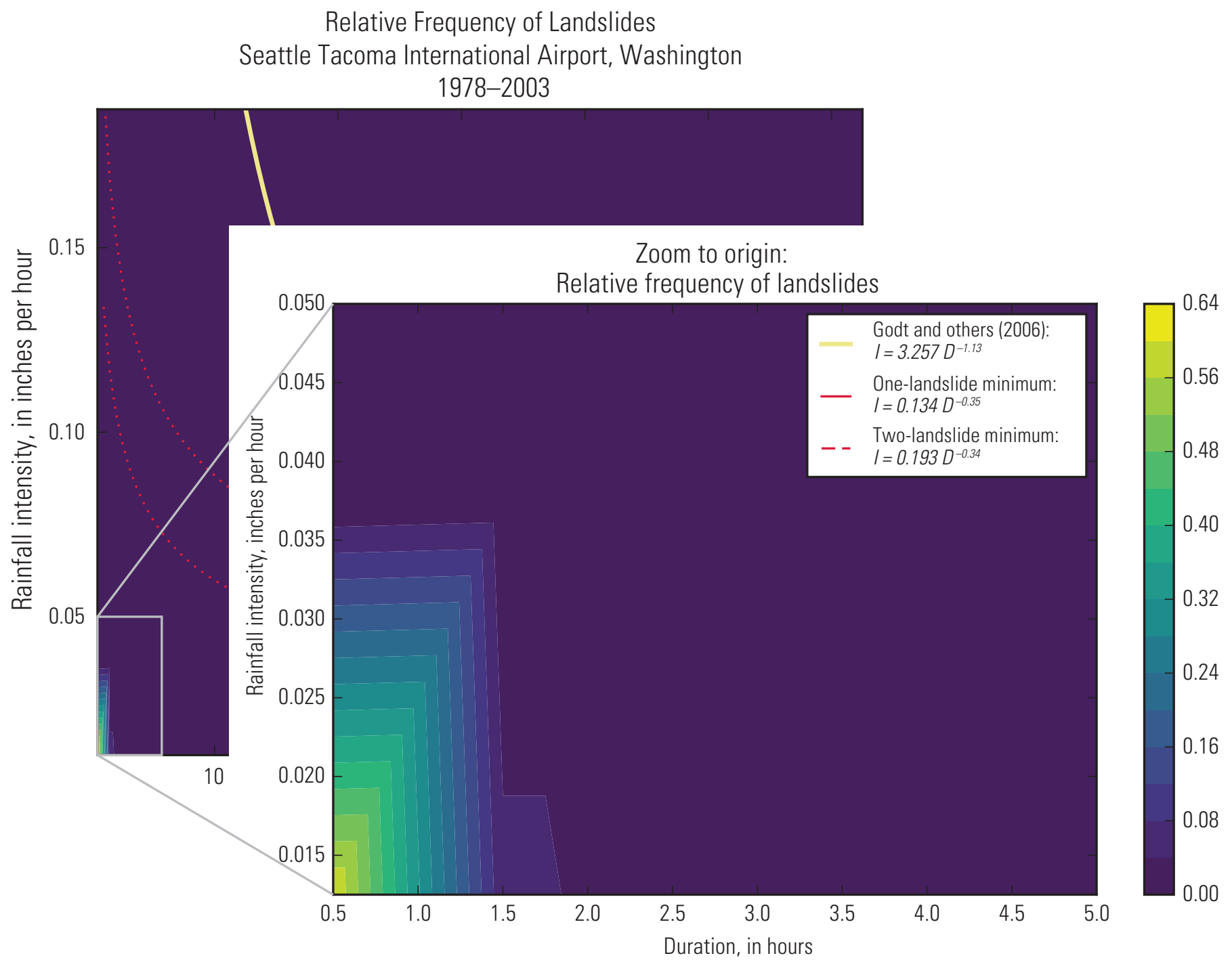

Figure 10. Relative frequency of landslides near Seattle Tacoma International Airport (KSEA) plotted by rainfall intensity and storm duration during 1978-2003. The relative frequency is given by the number of landslides at any given condition divided by the total number of known landslides. (D, duration in hours; I, rainfall intensity in inches/hour)

Table 12 demonstrates that the ID threshold, rather than the RA threshold, controls the number of hours that pass both threshold types. Ratios considered for a single ID threshold and all four RA thresholds usually vary by less than 0.04 , although they may vary by as much as 0.10 .

\section{Validation Data-Everett Paine Field and Mukilteo, Washington}

As occurred with the RA cumulative thresholds, the ID thresholds identify KPAE events at somewhat lower rates than KSEA events (tables 10 and 13). The true positive rate of the constrained threshold of Godt and others (2006) decreases by 0.109 relative to KSEA, but its true negative rate increases by 0.03 and the true positive rate jumps by 0.406 . The true positive rate of the one-landslide threshold decreases by 0.056 , the true negative rate increases by 0.14 , and the precision increases by 0.253 (tables 10 and 13). 


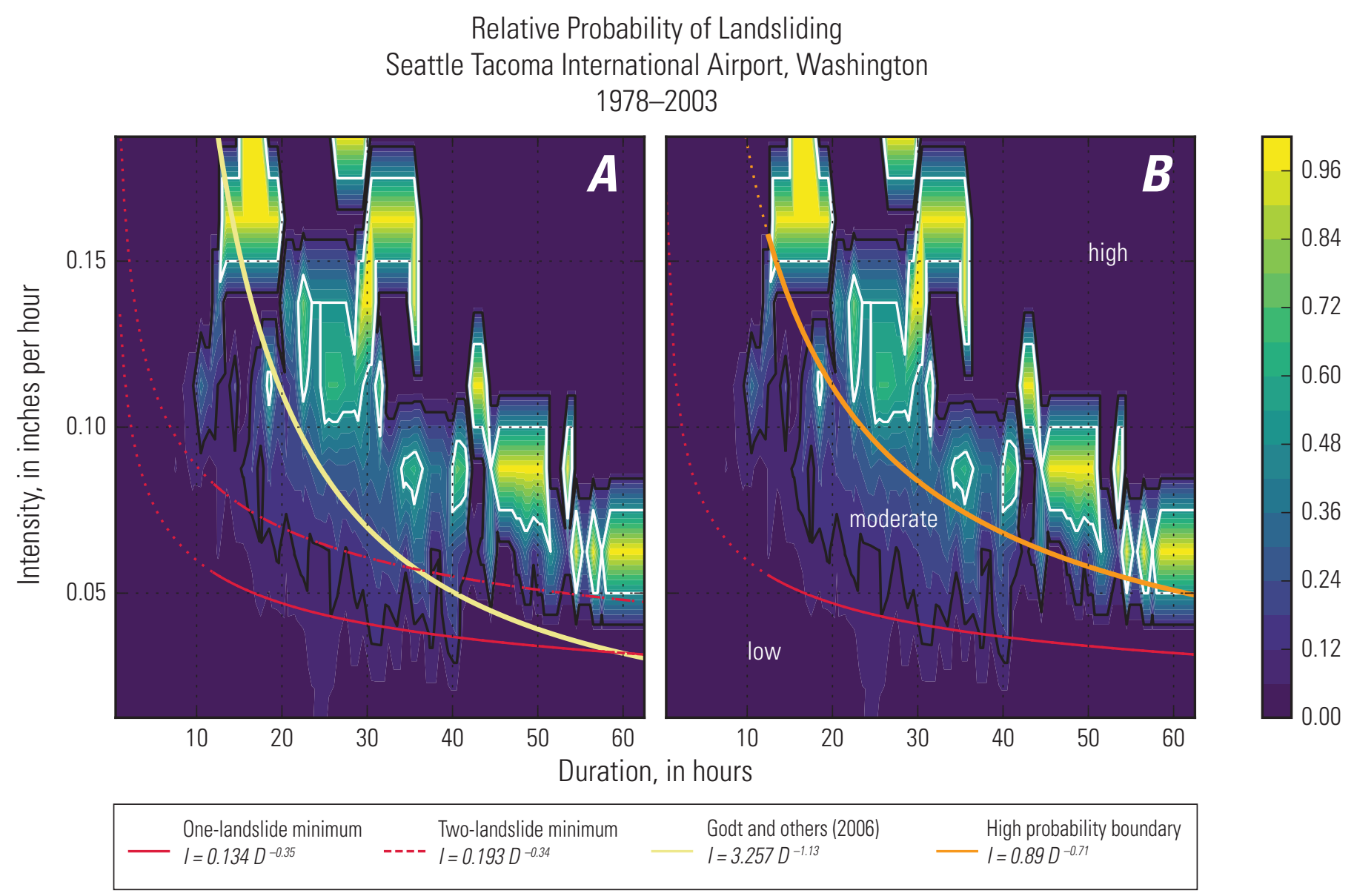

Figure 11. Relative probability of landsliding near Seattle Tacoma International Airport (KSEA) during 1978-2003 plotted by rainfall intensity and storm duration. The relative probability was determined by dividing the number of landslides at a given condition by the count of condition occurrence. Regions of moderate probability ( 0.12 or more) are contoured in black; regions of high probability $(0.50$ or more) are contoured in white. (D, duration in hours; I, rainfall intensity in inches/hour)

Table 11. Calibration Dataset (Seattle) — Counts of true hours identified by only one threshold type—recent-antecedent cumulative or intensity-duration—but not the other. Intensity-duration thresholds only consider hours with storm durations of 12 hours or more but recent-antecedent thresholds consider all hours.

[ID, intensity-duration; RA, recent-antecedent]

\begin{tabular}{|c|c|c|c|c|c|c|}
\hline \multirow[t]{2}{*}{$\begin{array}{l}\text { Recent-antecedent } \\
\text { cumulative threshold }\end{array}$} & \multicolumn{2}{|c|}{ ID: Godt and others (2006) } & \multicolumn{2}{|c|}{ ID: One-landslide minimum } & \multicolumn{2}{|c|}{ ID: Two-landslide minimum } \\
\hline & \multicolumn{4}{|c|}{ Seattle Tacoma International Airport (KSEA) } & & \\
\hline \multirow[b]{2}{*}{ Chleborad and others $(2006,2008)$} & RA only & ID only & RA only & ID only & RA only & ID only \\
\hline & 1468 & 9 & 1313 & 141 & 1394 & 44 \\
\hline Modified 3-15 & 1967 & 0 & 1712 & 32 & 1858 & 0 \\
\hline $3-32$ & 2080 & 0 & 1812 & 19 & 1971 & 0 \\
\hline $10-40$ & 2611 & 2 & 2353 & 31 & 2511 & 11 \\
\hline
\end{tabular}

Figure 12 (following page). Landslides near Seattle Tacoma International Airport (KSEA) during 1978-2003 plotted by rainfall intensity and storm duration. The grey region represents the 12 hours not considered by this report's intensity-duration thresholds. A date's hour of highest storm intensity is marked with a grey circle. (D, duration in hours; I, rainfall intensity in inches/hour) 
Storm Event Intensity on Slide Dates

Seattle Tacoma International Airport, 1978-2003

Sliding Intervals

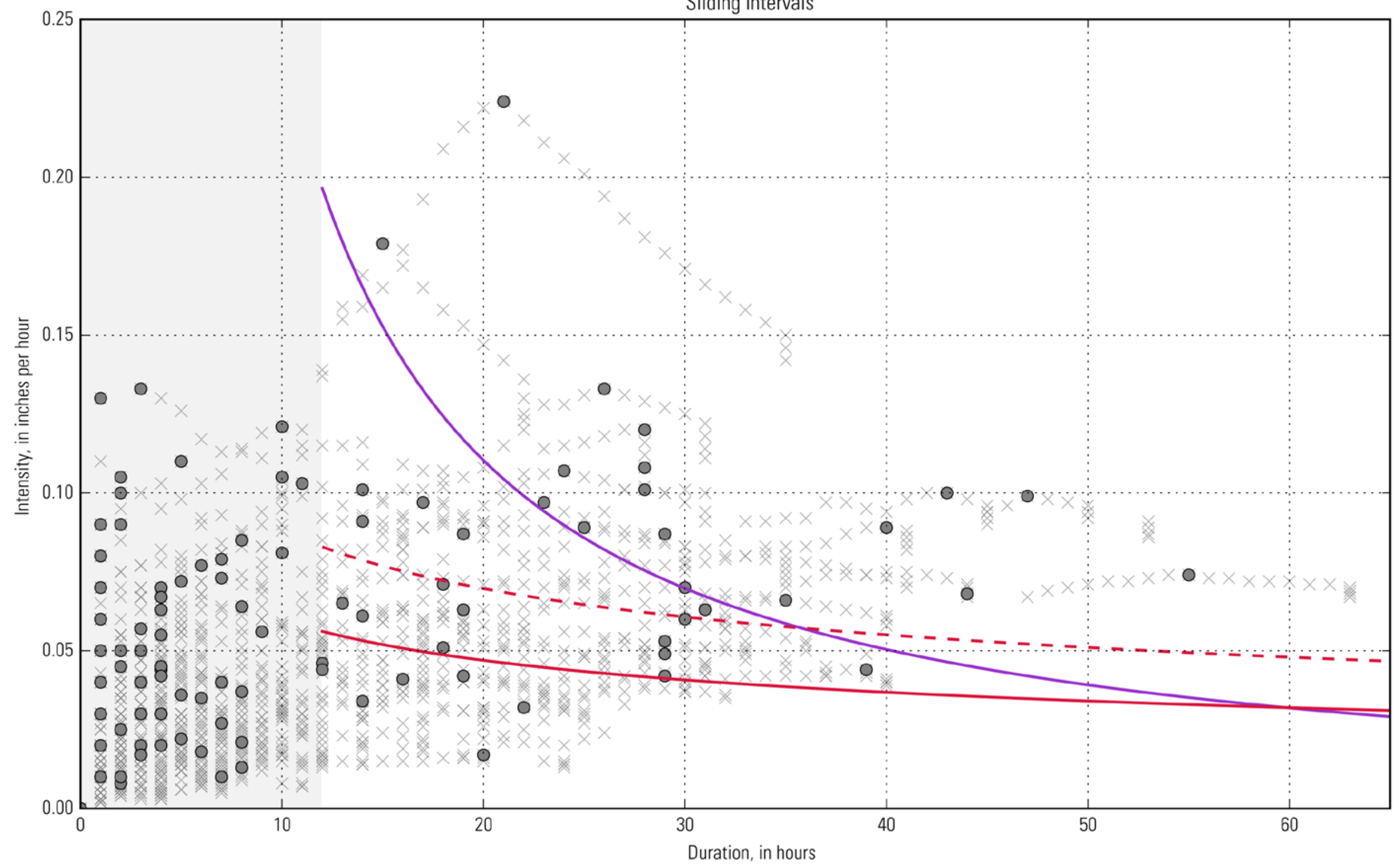

\begin{tabular}{|lll|}
\hline$\times \begin{array}{l}\text { Hourly data of } \\
\text { slide date }\end{array}$ & $\begin{array}{l}\text { Godt and others (2006) } \\
I=3.257 D-1.13\end{array}$ \\
$\begin{array}{l}\text { Hour datum representing } \\
\text { single slide date }\end{array}$ & $\begin{array}{l}\text { One-landslide minimum } \\
I=0.134 D^{-0.35}\end{array}$ & $\begin{array}{l}\text { Two-landslide minimum } \\
I=0.193 D-0.34 \\
\text { Duration not } \\
\text { considered }\end{array}$ \\
\hline
\end{tabular}


Table 12. Calibration Dataset (Seattle) —Ratios of true hours when both the recent-antecedent and the intensity-duration thresholds are exceeded. Ratios are provided for three conditions: Ratio A, count of true hours when both thresholds exceeded to count of all true hours; Ratio B, count of true hours that exceed both thresholds and fall on dates with two or more landslides to count of all true hours that fall on dates with two or more landslides; and Ratio $\mathrm{C}$, count of true hours that exceed both thresholds and fall on dates with two or more landslides to count of true hours that exceed both thresholds.

[ID, intensity-duration; RA, recent-antecedent]

\begin{tabular}{ccccc}
\hline \multicolumn{2}{c}{ Threshold combination } & Ratio A & Ratio B & Ratio C \\
\hline ID threshold & RA threshold & & 0.121 & 0.740 \\
Godt and others (2006) & Chleborad and others (2006, 2008) & 0.048 & 0.124 & 0.727 \\
Godt and others (2006) & Modified 3-15 & 0.051 & 0.124 & 0.727 \\
Godt and others (2006) & $3-32$ & 0.051 & 0.123 & 0.725 \\
Godt and others (2006) & $10-40$ & 0.050 & 0.203 & 0.699 \\
One-landslide minimum & Chleborad and others (2006, 2008) & 0.086 & 0.240 & 0.634 \\
One-landslide minimum & Modified 3-15 & 0.112 & 0.238 & 0.610 \\
One-landslide minimum & $3-32$ & 0.116 & 0.227 & 0.598 \\
One-landslide minimum & $10-40$ & 0.113 & 0.708 \\
Two-landslide minimum & Chleborad and others (2006, 2008) & 0.066 & 0.158 & 0.676 \\
Two-landslide minimum & Modified 3-15 & 0.077 & 0.176 & 0.676 \\
Two-landslide minimum & $3-32$ & 0.077 & 0.176 & 0.664 \\
Two-landslide minimum & $10-40$ & 0.074 & 0.167 & 0.441 \\
None & Chleborad and others (2006, 2008) & 0.404 & 0.601 & 0.447 \\
None & Modified 3-15 & 0.527 & 0.794 & 0.424 \\
None & $3-32$ & 0.555 & 0.792 & 0.379 \\
None & $10-40$ & 0.683 & 0.873 & \\
\hline
\end{tabular}

Table 13. Validation Dataset 1 (Everett)—Intensity-duration threshold statistical performance. Statistics exclude hours when storm duration was less than 12 hours.

[ $\geq$, greater than or equal to; D, duration in hours; I, rainfall intensity in inches/hour]

\begin{tabular}{cllccc}
\hline \multicolumn{1}{c}{ Criteria } & $\begin{array}{l}\text { Threshold } \\
\text { equation } \\
\text { (inches) }\end{array}$ & Conditions & $\begin{array}{c}\text { True positive } \\
\text { rate }\end{array}$ & $\begin{array}{c}\text { True negative } \\
\text { rate }\end{array}$ & Precision \\
\hline \multicolumn{7}{c}{} & \multicolumn{1}{c}{ Everett Paine Field, Washington (KPAE) } \\
\hline Godt and others (2006) & $I=3.257 D^{-1.13}$ & None & 0.079 & 0.999 & 0.780 \\
Godt and others (2006) & $I=3.257 D^{-1.13}$ & $\mathrm{D} \geq 12$ hours & 0.187 & 0.992 & 0.780 \\
One-landslide minimum & $I=0.134 D^{-0.35}$ & $\mathrm{D} \geq 12$ hours & 0.646 & 0.869 & 0.418 \\
Two-landslide minimum & $I=0.193 D^{-0.34}$ & $\mathrm{D} \geq 12$ hours & 0.260 & 0.967 & 0.533 \\
\hline
\end{tabular}

The small size of the 2016 Mukilteo dataset precludes drawing broad conclusions about the performance of any ID threshold. Results may look different with a longer dataset. Ratios greater than 0 and less than 0.143 correspond to one of the seven dates in the Mukilteo dataset; the smaller true positive rate results (for example, 0.120) are from threshold exceedances of less than a full day (fig. 13). The threshold of Godt and others (2006) identified between 0.0 and 0.120 of true hours at Mukilteo (table 14). The one-landslide minimum threshold, as expected, identified the most true hours with true positive rates ranging from 0.949 to 1.00. 


\section{Storm Event Intensity on Slide Dates Mukilteo, Washington 2015-2016}
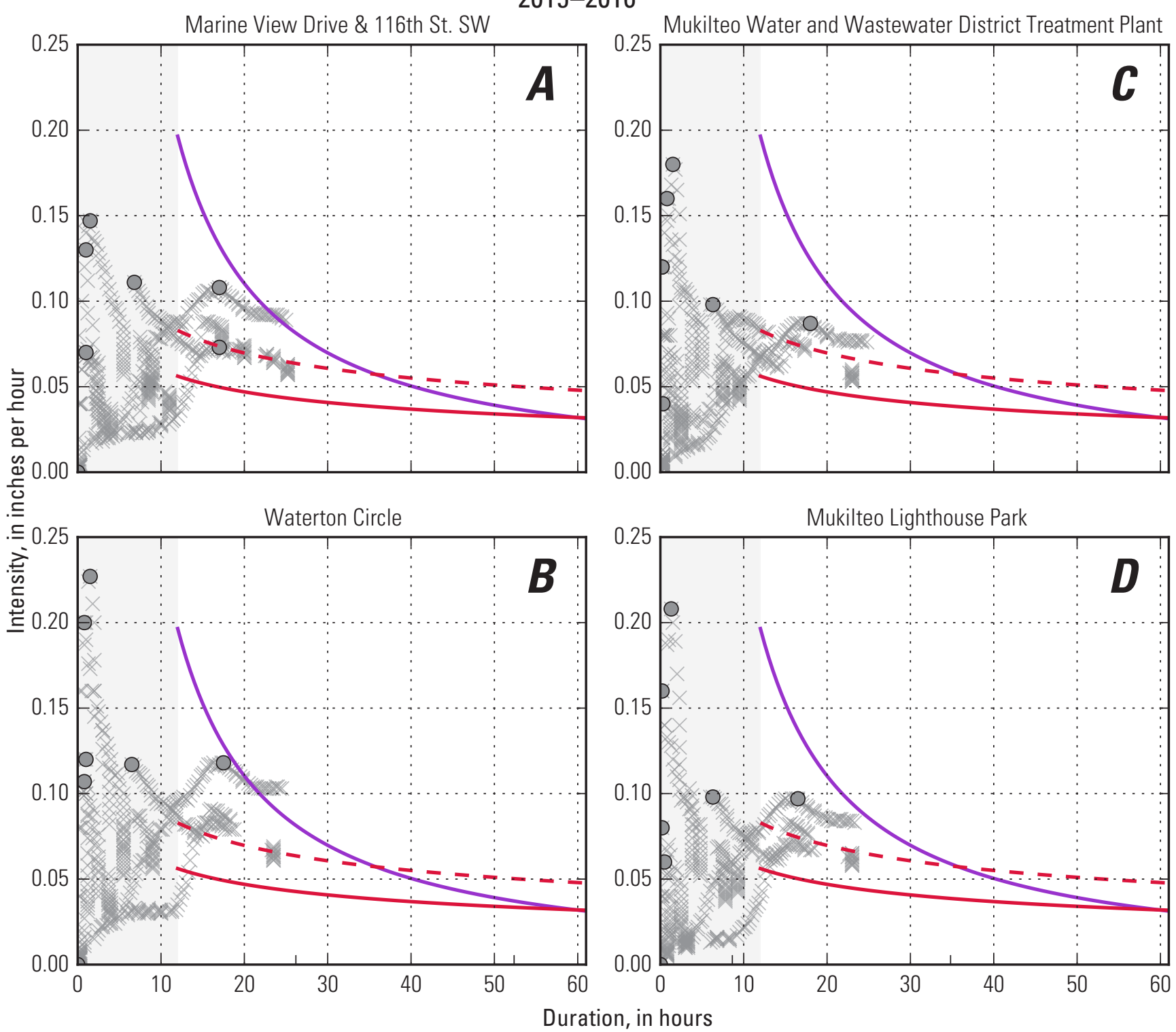

\begin{tabular}{|c|c|c|c|c|c|}
\hline$x$ & $\begin{array}{l}15 \text { minute data } \\
\text { of slide dates }\end{array}$ & 0 & $\begin{array}{l}\text { Representative } \\
15 \text { minute datum }\end{array}$ & $\square$ & Duration not considered \\
\hline & $\begin{array}{l}\text { One-landslide minimum } \\
I=0.134 D-0.35\end{array}$ & - & $\begin{array}{l}\text { Two-landslide minimum } \\
I=0.193 D^{-0.34}\end{array}$ & 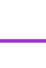 & $\begin{array}{l}\text { Godt and others (2006) } \\
I=3.257 D^{-1.13}\end{array}$ \\
\hline
\end{tabular}

Figure 13. Storm event intensity on dates of landslides that occurred near Mukilteo, Washington, during 2015-2016 plotted by rainfall intensity and duration. Note that the " $\mathrm{x}$ " markers denote measurements taken every 15 minutes. A date's 15 minutes of the highest storm intensity is marked with a grey circle. The same seven dates are evaluated at $A$, Marine View Drive \& 116th St. SW $B$, Waterton Circle; $C$, Mukilteo Water and Wastewater District Treatment Plant; and D, Mukilteo Lighthouse Park. (D, duration in hours; I, rainfall intensity in inches/hour) 
Table 14. Validation Dataset 2 (Mukilteo)_-Intensity-duration threshold statistics for durations of 12 hours or more.

[D, duration in hours; I, rainfall intensity in inches/hour]

\begin{tabular}{|c|c|c|c|c|}
\hline Criteria & $\begin{array}{l}\text { Threshold } \\
\text { equation } \\
\text { (inches) }\end{array}$ & $\begin{array}{l}\text { True positive } \\
\text { rate }\end{array}$ & $\begin{array}{l}\text { True negative } \\
\text { rate }\end{array}$ & Precision \\
\hline \multicolumn{5}{|c|}{ Marine View Drive \& 116th St. SW (VH) } \\
\hline Godt and others (2006) & $I=3.257 D^{-1.13}$ & 0.046 & 0.881 & 0.111 \\
\hline One-landslide minimum & $I=0.134 D^{-035}$ & 0.954 & 0.419 & 0.345 \\
\hline \multicolumn{5}{|c|}{ Waterton Circle (LS) } \\
\hline Godt and others (2006) & $I=3.257 D^{-1.13}$ & 0.120 & 0.893 & 0.175 \\
\hline One-landslide minimum & $I=0.134 D^{-035}$ & 0.949 & 0.460 & 0.251 \\
\hline Two-landslide minimum & $I=0.193 D^{-0.34}$ & 0.795 & 0.795 & 0.425 \\
\hline \multicolumn{5}{|c|}{ Mukilteo Water and Wastewateristrict Treatment Plant (M2) } \\
\hline \multicolumn{5}{|c|}{ Mukilteo Lighthouse Park (M1) } \\
\hline Godt and others (2006) & $I=3.257 D^{-1.13}$ & 0.0 & 1.0 & 0.0 \\
\hline One-landslide minimum & $I=0.134 D^{-035}$ & 0.964 & 0.679 & 0.412 \\
\hline Two-landslide minimum & $I=0.193 D^{-0.34}$ & 0.514 & 0.874 & 0.487 \\
\hline
\end{tabular}

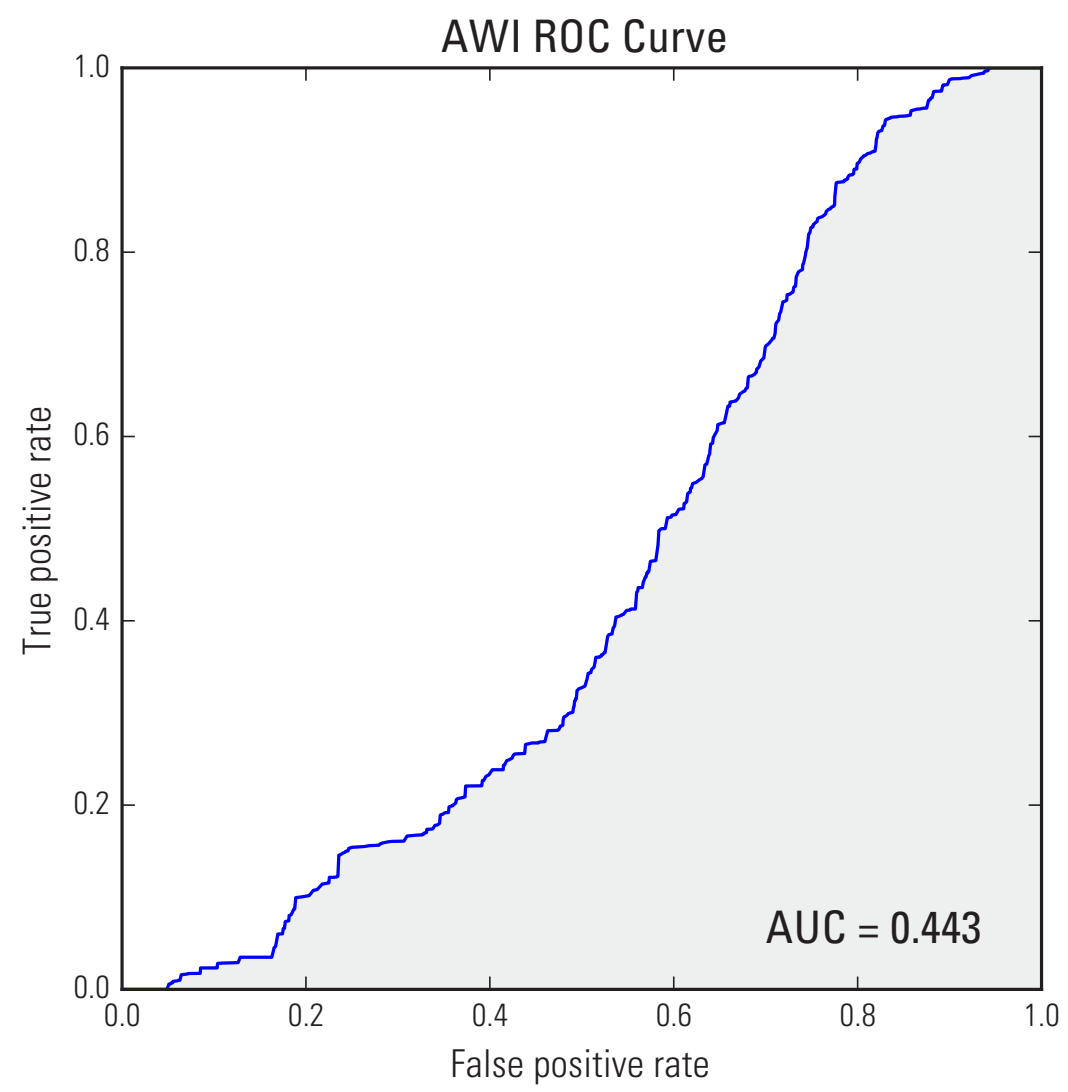

\section{Antecedent Water Index}

The AWI of landslide dates identified at KSEA range from 1.18 to 43.15 inches. The ROC curve of the AWI at KSEA indicates that the area under the curve is 0.446 (fig. 14). The ROC curve does not follow the typical log shape seen in figures 5 and 6. This irregularity, combined with the area under the curve of less than 0.5 , indicates that the AWI alone is not a useful indicator of slide activity. We did not evaluate AWI combined with ID thresholds.
Figure 14. The antecedent water index (AWI) receiver operating characteristics (ROC) curve does not follow the typical log shape. The area under the curve (AUC) is 0.446 . 


\section{Discussion}

\section{Data Limitations}

The landslide inventories from KSEA, KPEA, and Mukilteo (Marine View Drive \& 116th St. SW, Waterton Circle, Mukilteo Lighthouse Park, and Mukilteo Water and Wastewater District Treatment Plant) indicate the date of recorded landslides, but not all dates have a recorded time of occurrence. Thus the associated MIs, which touch all 24 hours of a landslide date, are each considered to be true positives. The statistics in the "Results" section of this report identify whether each discreet hour (or 15 minutes at the four Mukilteo stations) passes the threshold, meaning that the true positive rate identifies how many hours (or 15 minutes) of the true positive set exceed the threshold. The true positive rate, when derived from MI precipitation sums, is therefore not a perfect proxy for the percentage of landslides that the threshold may identify. Three factors affect interpretation of the true positive rate:

1. Dates on which multiple landslides occurred are not weighted.

2. Landsliding is unlikely to have occurred in every hour of every identified date. The true positive count, which functions in the denominator of the true positive rate, is thus too large.

3. Each hour or 15-minute period plots independently. Unless each hour or 15-minute period of a single date plots above or below the threshold, there is no way to verify that the recorded landslide occurred during threshold exceedance conditions.

Factors 1 and 2 indicate that the true positive rate identified in this analysis may be lower than if the true positive rate had incorporated landslide count and timing. Factor 3 indicates that this report's true positive rate may be too high if sliding occurred in the hours prior to a threshold exceedance. We cannot distinguish which factors are more influential without more precise landslide times.

This analysis relies on hourly or 15-minute data so as to reflect the anticipated usage conditions. Decision makers will monitor conditions in real time, so it is useful to know how precisely the thresholds perform against near-real-time data. The results from FI precipitation sums, presented in tables 1, 3, and 5, indicate that the KSEA true positive rate is largely unaffected by the usage of FI or MI precipitation sums. The MI true positive rates are roughly 5 percent smaller than the FI precipitation sums. It thus appears that the factors discussed above are roughly negating each other's effects, allowing the use of near-real-time data.

Data collection at KPAE began on December 27, 2005. The first recorded slide occurred on January 6, 2006. The 10-day difference means that this slide cannot be considered in any of the cumulative threshold analyses, which require 18,35 , or 50 days of recorded precipitation. The second slide, which occurred January 29, 2016, is included in the 3-15-day analysis but not the 3-32- or 10-40-day analyses. The temporal limitations of data collection resulted in the various thresholds not being considered over the exact same KPAE dataset.

All rate differences at Mukilteo stations are partially attributable to the small sample size of the dataset. The 2015-2016 inventory of slides includes only seven dates. The dataset is likely skewed towards threshold exceedance conditions because only one of the seven slides occurred during conditions of minimal preceding precipitation, that is, when less than 1 inch of rainfall was recorded in the preceding 3 days and less than 4 inches of rainfall was recorded in the 15 days before those 3 days. These slides were either reported in published news reports, which tend to refer to "mudslides" that occur during rainy weather, or were identified by the USGS time-lapse camera at the Waterton Circle site (fig. 1).

Mukilteo's location (approximately 25 miles north of Seattle and bordering Everett to the southeast) suggests that it should experience a distribution of sliding conditions similar to Seattle and Everett. This expectation is further supported by the precipitation similarities between the Mukilteo and Everett rain gages during landslide season (October through April). Daily precipitation totals between the two towns are variable, but the net precipitation during the 2015-2016 landslide season usually varied by 12 percent or less, usually hovering near 5 percent (table 15 and fig. 15). Several dates show slightly higher rainfall at Mukilteo gages than at KPAE, perhaps due to slow moving storms. The similar rainfall conditions indicate that landslides near Mukilteo should occur under similar circumstances to those in Everett. The low proportion of recorded low-precipitation landslides in Mukilteo, therefore, suggests that these types of slides have not been well recorded, rather than that they do not occur.

The small sample size also makes the statistics vulnerable to new data. Slide dates recorded in future years will help fill the dataset and give a more accurate description of the thresholds' classifying accuracy near Mukilteo. The Mukilteo true positive rates are likely to approach the KPAE true positive rates as the dataset is expanded. 
Table 15. Mukilteo 2015-2016 —Cumulative rainfall difference between Mukilteo and Everett Paine Field during 2015-2016 landslide season.

[\%, percentage; KPAE, Everett Paine Field, Washington]

\begin{tabular}{lcccc}
\hline & $\begin{array}{c}\text { Marine View Drive \& } \\
\text { 116th St. SW }\end{array}$ & $\begin{array}{c}\text { Waterton } \\
\text { Circle }\end{array}$ & $\begin{array}{c}\text { Mukilteo Water and } \\
\text { Wastewateristrict } \\
\text { Treatment Plant }\end{array}$ & $\begin{array}{c}\text { Mukilteo } \\
\text { Lighthouse } \\
\text { Park }\end{array}$ \\
\hline \multicolumn{1}{c}{ 0ctober 1, 2015-April 30, 2016 } & & & \\
\hline Mukilteo precipitation minus KPAE precipitation (inches) & -1.50 & 4.60 & 0.35 & -1.37 \\
Precipitation difference (\%) & -4.6 & 12.0 & 0.4 & -4.2 \\
\hline
\end{tabular}

\section{Level of Activity}

For most of the analyses presented in this report, we have implicitly assumed that one landslide in a 24-hour period is an adequate level of activity to indicate a causal relationship between the landslide and recent or antecedent precipitation. Previous studies were based on higher levels of activity, namely two or more landslides in 24 hours for the ID threshold (Godt and others, 2006) and three or more landslides in a 3-day period for the RA cumulative threshold (Chleborad and others, 2008). We recognize that the causal link between single landslides and recent precipitation is weak or perhaps nonexistent for dates of many historical landslides in our databases. Our reason for adopting the weak criterion of one or more landslides in 24 hours stems from the need to identify as many days as possible when the probability of landslide activity may be significant as only one landslide intersecting the tracks is sufficient to disrupt passenger service.

\section{Cumulative Thresholds}

Slides predominantly occur during conditions with minimal rainfall (that is, recent rainfall of less than 3 inches and antecedent rainfall of less than 4 inches) but are not strongly clustered at any unique rainfall conditions (figs. 16A, 17A, and 18A). The 10-40-day plot of slide occurrence shows particularly dispersed regions of higher relative frequency; increased relative frequency occurs during most conditions except where previous rainfall is more than 4 inches or antecedent rainfall is less than 4 inches (fig. 18A). Conversely, the relative frequency of rainfall conditions is concentrated near the origin and along the $\mathrm{x}$-axis in all three considered thresholds (figs. $16 B, 17 B$, and $18 B$ ). The relative frequency of rainfall conditions above the indicated thresholds in figures $16 B, 17 B$, and $18 B$ is always below 0.02 ; this low frequency increases the probability of sliding when those conditions do occur (figs. $16 C, 17 C$, and $18 C$ ). It is notable that the probability of sliding during the conditions when slides most frequently occur is virtually zero - the rainfall conditions occur too frequently without landslides to use them for landslide prediction.

The best-performing thresholds in this report do not match those identified by Chleborad and others $(2006,2008)$. This is likely explained by our smaller monitoring station network and larger study area. The thresholds of Chleborad and others $(2006,2008)$ relied on data collected from the city of Seattle rain-gage network, National Weather Service gages, and SchoolNet Automated Weather System gages that were concentrated along bluffs in central Seattle. The rain gages were generally located within 1.5 miles of the slides that were studied. Our analysis relies on KSEA to characterize all of the Seattle area slides, which are 3.5-20 miles away. KSEA is also roughly 3.5 miles inland so it receives less precipitation than the bluff-adjacent gages. The additional distance from the coast helps explain the lowered y-intercept and slope of the modified 3-15-day threshold.

The 10-40-day threshold reliably identifies the largest number of true events at each location, but is an inadequate discriminator between true and nonevents. Nearly all MI precipitation sums exceed the threshold, lowering the probability that any one of them is true. The high true positive rates indicate that a sizeable proportion of true positive conditions exceed the threshold, but the low precisions indicate that a much larger proportion of false positives also pass the threshold. The ratio of false positives to true positives is so high that the threshold loses its predictive power. Consequently, the 10-40-day threshold is not considered further.

Figure 15 (following page). Mukilteo daily precipitation totals at a specified monitoring station minus the daily precipitation totals at Everett Paine Field from October 1, 2015, to April 30, 2016. Daily differences are typically less than 0.5 inches. Breaks in the plot occur when data are missing at either Everett Paine Field or the Mukilteo station. Grey vertical lines indicate the dates of known slides. 
Mukilteo Daily Precipitation Compared to Everett Paine Field Daily Precipitation October 1, 2015-April 30, 2016
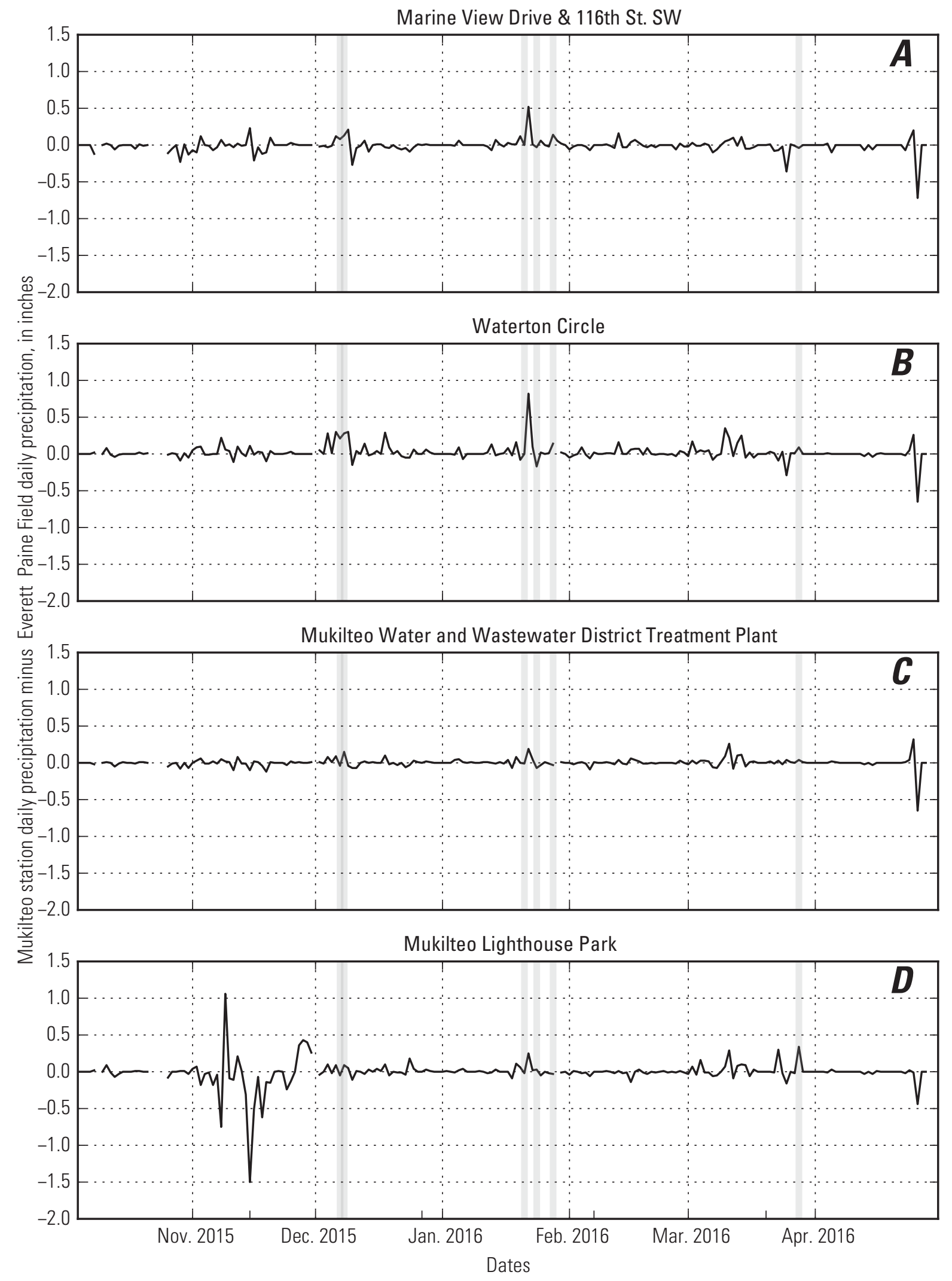

Landslide date 
Cumulative Precipitation 18 Days Prior to Landsliding Seattle Tacoma International Airport, Washington

1978-2003
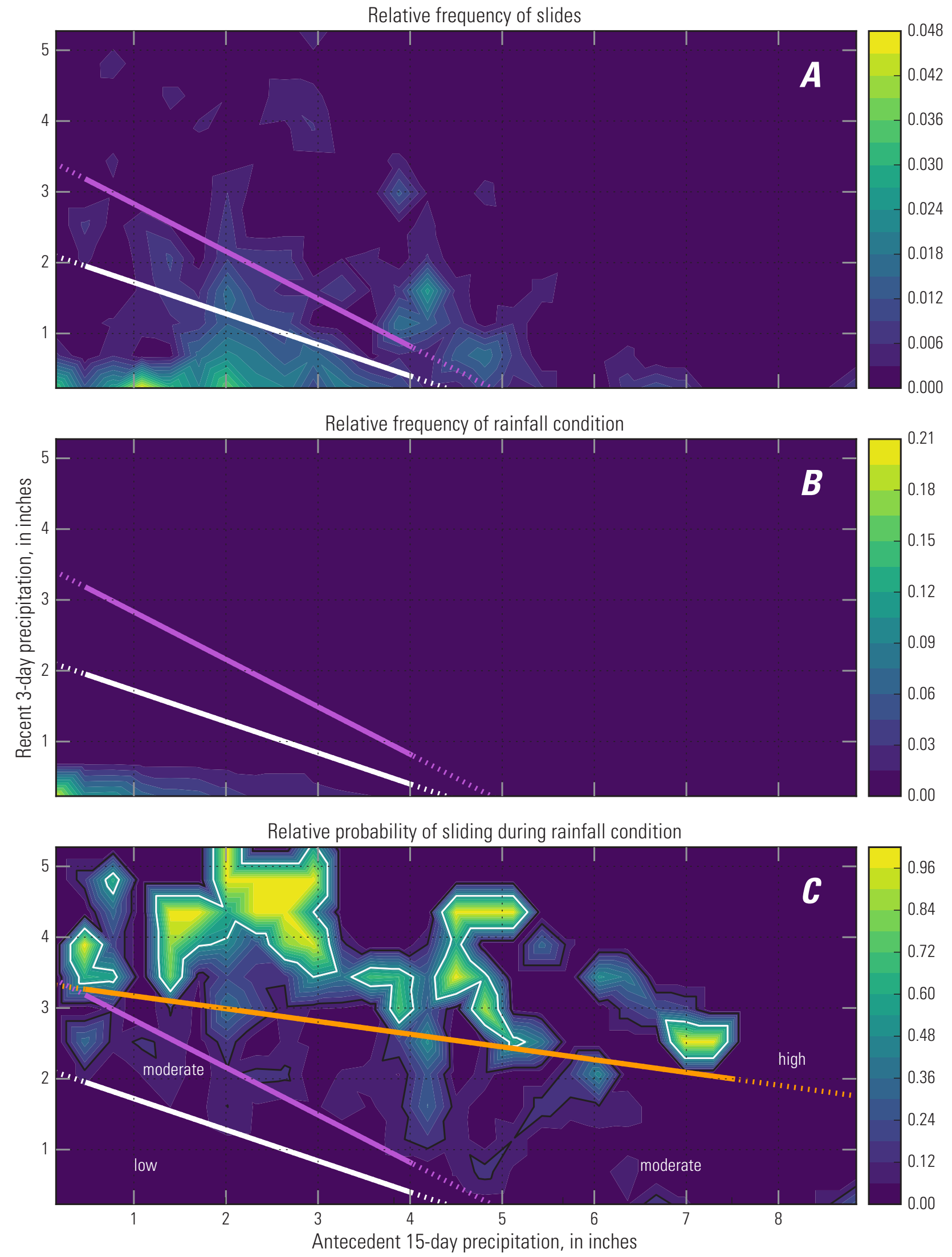
Figure 16 (previous page). Relative slide frequency, relative rainfall condition frequency, and sliding probability defined by the precipitation in the previous 3 days against the antecedent 15-day precipitation (18 days total) at Seattle Tacoma International Airport during 1978-2003. Note that the color bars in each plot do not represent the same values. The threshold of Chleborad and others (2008) is shown in purple. The modified 3-15-day threshold is displayed in white. $A$, Relative frequency of slides, given by the number of slides at any given condition divided by the total number of known slides. $B$, Relative frequency of rainfall conditions, given by the count of rainfall condition occurrence during 1978-2003 divided by the number of recorded hours in the dataset. $C$, Relative probability of sliding during any given rainfall condition, determined by dividing the number of landslides at a given condition by the count of condition occurrence. High probability regions ( 0.50 or more) are contoured in white and moderate probability regions $(0.12$ or more) are contoured in black. The regions are generalized into zones of low, moderate, and high probability using the modified 3-15-day threshold (white) and the orange line. The orange line follows the appearance locations of high probability regions and is defined as $P_{3}=3.35-0.18 P_{15^{\prime}}$, where $P_{3}$ is the precipitation accumulation (inches) over the 3 days prior to the considered date and $P_{15}$ is the precipitation accumulation (inches) during the 15 days preceding $P_{3}$.

Decision makers must strike a balance between false alarms and failed alarms. False alarms occur more frequently with thresholds that give higher true positive rates and lowered precision, as with the 10-40-day threshold. Failed alarms occur more frequently with thresholds that are more reliable during exceedance conditions (higher precision) but do not identify slides that occur below the stricter threshold (lower true positive rate), exemplified here by the threshold of Chleborad and others $(2006,2008)$.

Statistics from both KSEA and KPAE indicate that the 3-32-day threshold best balances these concerns. The 3-32-day threshold gives the highest true positive rate (excluding the 10-40-day threshold) and the second highest precision (tables 5 and 8). The FI statistics, calculated only at KSEA, show the same relative performance.

The Mukilteo datasets indicate that the 3-32-day threshold gives the highest precision, but the modified 3-15-day threshold often gives the highest true positive rates. Because the difference in true positive rates is quite small — ranging from 0.005 to 0.088 - the 3-32-day threshold still deserves consideration at Mukilteo. Additionally, similar precipitation conditions at Mukilteo and Everett indicate that the 3-32-day threshold may be the most appropriate threshold This consistency across all three datasets indicates that decision makers may want to consider examining the 3-32-day threshold at all points along the Everett-Seattle railway corridor.

\section{Intensity-Duration Thresholds}

The ID thresholds rarely identify hours of slide dates that the cumulative thresholds miss. The ID thresholds identified between 0 and 141 KSEA landslide date hours not found by RA thresholds; conversely, each RA threshold found more than 1,000 KSEA landslide date hours that did not exceed the ID thresholds (table 11). True hours that exceeded both types of thresholds were more likely to fall on dates with two or more known landslides (Ratio C, table 12). Combining both tools may be helpful in identifying dates with multiple landslides, which are more likely to impact Sound Transit's commuter rail system.

The AWI was not incorporated into this analysis because of its atypical ROC curve shape and its area under the curve of less than 0.5. However, all slides near KSEA had an AWI more than 1.18 inches. The AWI may be useful to decision makers for identifying when the landslide season begins and ends. Conditions with an AWI less than 1.18 inches and in exceedance of a given threshold may be less worrisome than those same threshold conditions with an AWI of more than 1.18 inches.

\section{Threshold Precision}

The probability plots in figures $16 C, 17 C$, and $18 C$ help explain the differences in precision between different RA cumulative thresholds. The 3-15- and 3-32-day thresholds closely follow the regions of increasing probability (more than 0.06 ) and approach regions of moderate probability ( 0.12 or more). The 10-40-day threshold is not located close to the zones of increased probability and instead divides a region of near-zero probability (fig. 18C). The 10-40-day threshold does not adequately discriminate between conditions with moderate probability of sliding and conditions with almost no probability of sliding, causing it to predict landslides on dates with very low chances of slope failure. The 10-40-day threshold precision is low, varying between 0.015 and 0.072 .

Generally, the model precision is higher for the ID thresholds than the RA cumulative thresholds (table 16). This can be partially understood by comparing figures $11,16 C, 17 C$, and $18 C$. The zones of high probability ( 0.50 or more) in figure 11 lie near the threshold of Godt and others (2006) and are approximately evenly distributed across the considered range. Figures $16 C$, $17 C$, and $18 C$ indicate that there are probability hot spots above the RA thresholds. These hot spots are concentrated at discrete recent rainfall ranges and are also located far above the identified thresholds (3-day recent precipitation of more than 3.5 inches; 
Cumulative Precipitation 35 Days Prior to Landsliding

Seattle Tacoma International Airport, Washington

1978-2003

Relative frequency of slides

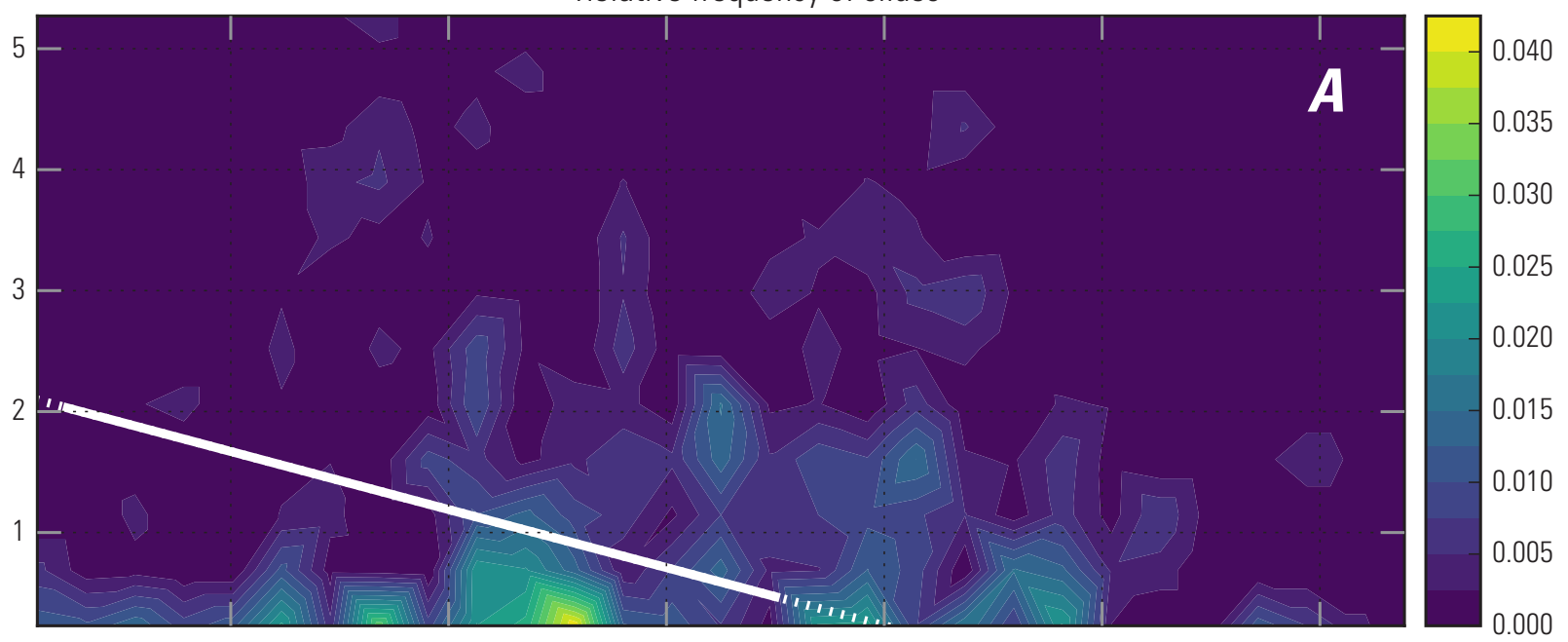

Relative frequency of rainfall condition

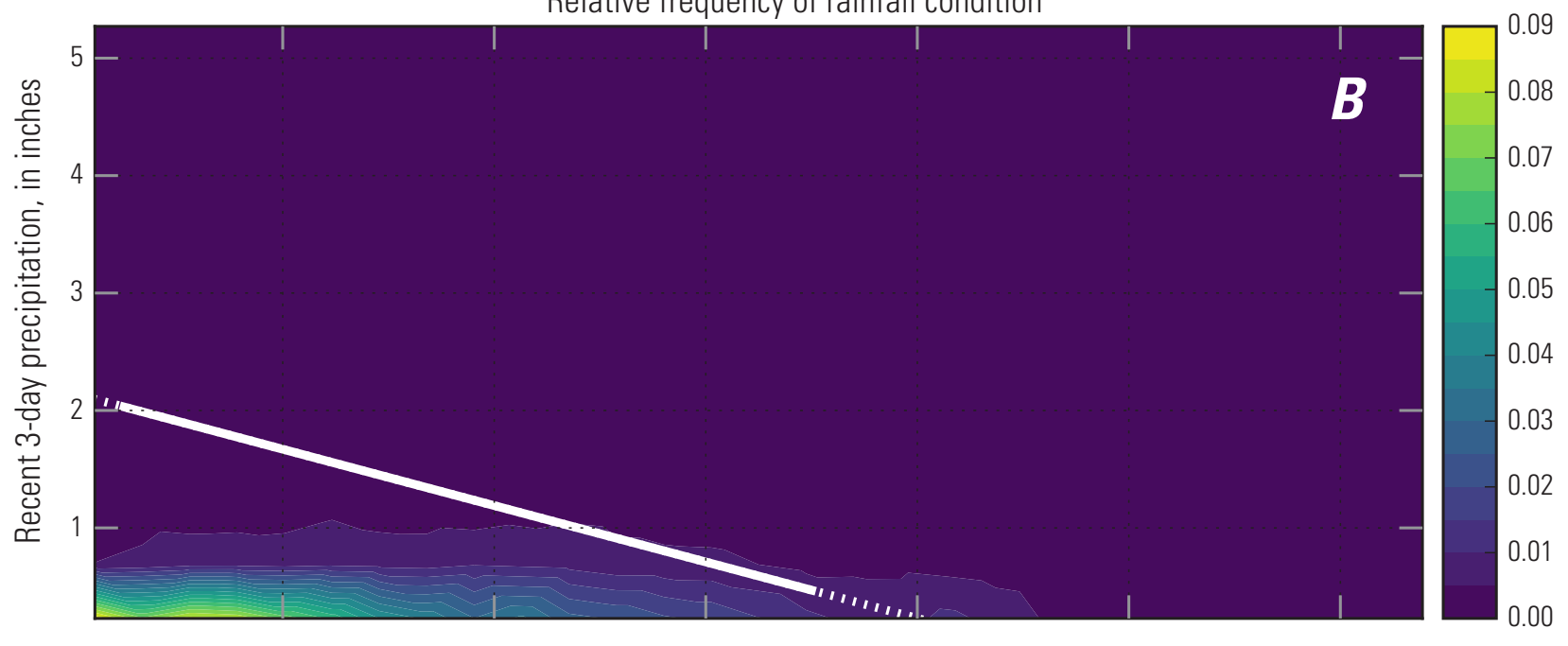

Relative probability of sliding during rainfall condition

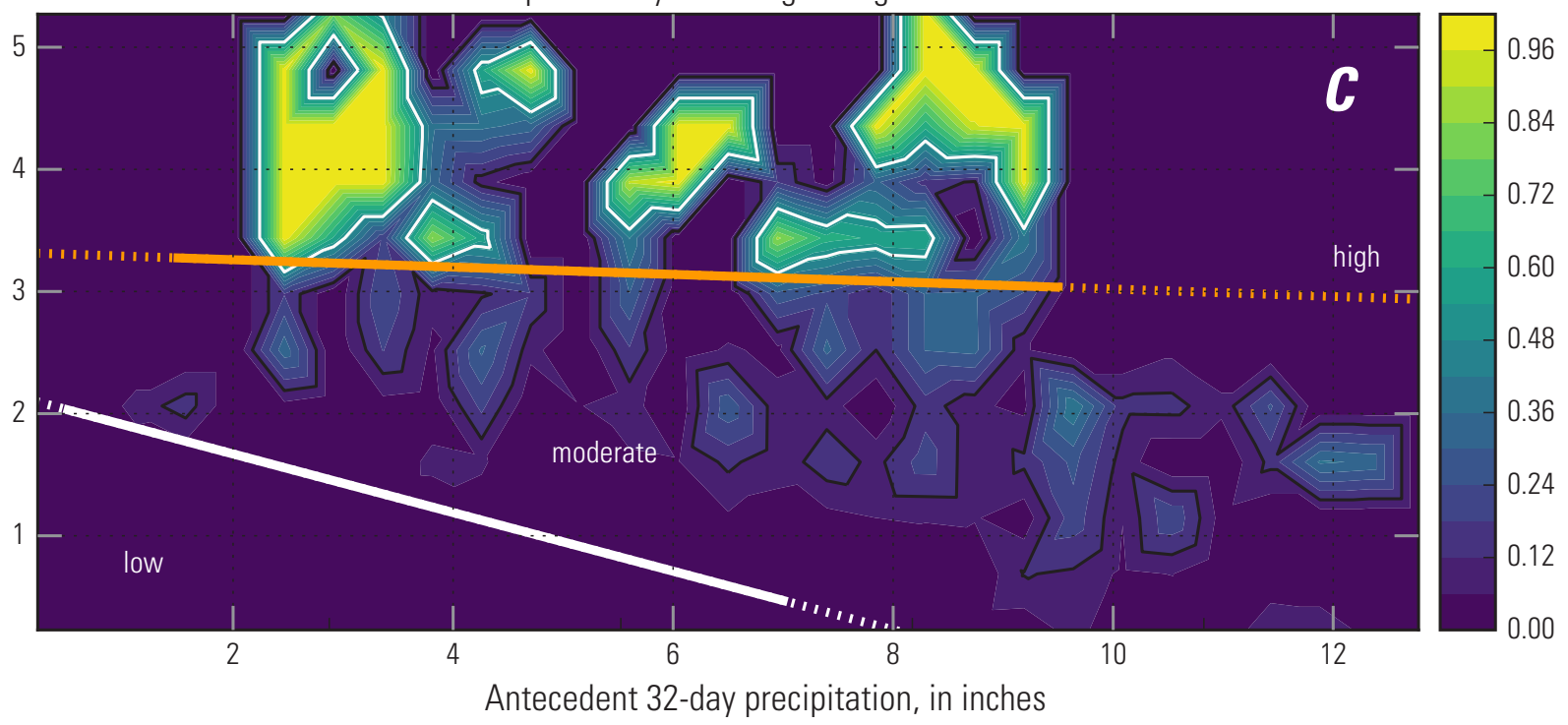


Figure 17 (previous page). Relative slide frequency, relative rainfall condition frequency, and sliding probability defined by the precipitation in the previous 3 days against the antecedent 32-day precipitation (35 days total) at Seattle Tacoma International Airport during 1978-2003. A, Relative frequency of slides, given by the number of slides at any given condition divided by the total number of known slides. $B$, Relative frequency of rainfall conditions, given by the count of rainfall condition occurrence during 1978-2003 divided by the number of recorded hours in the dataset. $C$, Relative probability of sliding during any given rainfall condition, determined by dividing the number of landslides at a given condition by the count of condition occurrence. High probability regions (0.50 or more) are contoured in white and moderate probability regions ( 0.12 or more) are contoured in black. The regions are generalized into zones of low, moderate, and high probability using the modified 3-32-day threshold (white) and the orange line. The orange line follows the appearance locations of high probability regions and is defined as $P_{3}=3.32-0.03 P_{32}$, where $P_{3}$ is the precipitation accumulation (inches) over the 3 days prior to the considered date and $P_{32}$ is the precipitation accumulation (inches) during the 32 days preceding $P_{3}$.

Table 16. Model precision across all considered thresholds and locations, applied to moving interval precipitation sums.

\begin{tabular}{|c|c|c|c|c|c|c|c|}
\hline Location & $\begin{array}{c}\text { Chleborad } \\
\text { and others } \\
\text { (2008) }\end{array}$ & $\begin{array}{l}\text { Modified } \\
\text { 3-15 } \\
\text { Threshold }\end{array}$ & $\begin{array}{c}\text { 3-32 } \\
\text { Threshold }\end{array}$ & $\begin{array}{l}10-40 \\
\text { Threshold }\end{array}$ & $\begin{array}{c}\text { Godt and } \\
\text { others } \\
(2006)\end{array}$ & $\begin{array}{c}\text { One- } \\
\text { landslide } \\
\text { minimum }\end{array}$ & $\begin{array}{c}\text { Two- } \\
\text { landslide } \\
\text { minimum }\end{array}$ \\
\hline \multicolumn{8}{|c|}{ Seattle Tacoma International Airport, 164 dates } \\
\hline Seattle Tacoma International Airport (KSEA) & 0.080 & 0.059 & 0.067 & 0.041 & 0.374 & 0.165 & 0.265 \\
\hline \multicolumn{8}{|c|}{ Everett Paine Field, Washington, 36 dates } \\
\hline Marine View Drive \& 116th St. SW (VH) & 0.070 & 0.102 & 0.128 & 0.066 & 0.111 & 0.345 & 0.597 \\
\hline Waterton Circle (LS) & 0.083 & 0.081 & 0.084 & 0.054 & 0.175 & 0.251 & 0.425 \\
\hline $\begin{array}{l}\text { Mukilteo Water and Wastewater } \\
\text { District Treatment Plant (M2) }\end{array}$ & 0.067 & 0.089 & 0.108 & 0.072 & 0.0 & 0.260 & 0.347 \\
\hline
\end{tabular}

10-day recent precipitation of more than 5 inches). The hot spots define combinations of recent and antecedent precipitation that rarely occurred but usually led to landslide activity when they did occur. Thus, an event that passes the threshold may only plot in an area of moderate probability (between 0.12 and 0.49$)$, rather than high probability ( 0.50 or more).

The probability maps were used to generalize zones of low, moderate, and high landslide probability. The hot spot effect noted in figures $16 C, 17 \mathrm{C}$, and $18 \mathrm{C}$ can give a misleading impression of probability when areas of high probability are close to areas of near-zero probability, as near $(5,4.5)$ in figure $17 C$. The KSEA dataset contains 15 hours that experienced 4.5 inches of recent precipitation and 5 inches of antecedent precipitation; similar conditions of 4.5 inches of recent precipitation and 5.5 inches of antecedent precipitation were never recorded. The lack of recorded instances at that specific rainfall condition results in zero probability at $(5.5,4.5)$ (fig. 17C). However, we expect that landsliding would occur if the area experienced 4.5 inches of recent precipitation and 5.5 inches of antecedent precipitation, despite the zero probability indicated on the plot. We thus delineated general zones of low, moderate, and high probability in order to mitigate the hotspot effect. The high probability boundaries follow the lower edges of the high probability contours. The probability zone maps (figs. 11, 16C, $17 C$, and 18C) may prove to be more valuable tools for landslide-risk decision makers than the yes-no thresholds.

\section{Application Limitations}

Precipitation amounts on a significant number of landslide dates do not exceed any of the precipitation thresholds we have proposed and most likely would not exceed any useful precipitation threshold that could be devised. Of the landslide dates, 21 percent in Everett and 37 percent in Seattle occurred entirely during conditions classified as "dry," that is, less than 1 inch of 3-day recent rainfall and less than 4 inches of antecedent 15-day rainfall (figs. 8 and 3-1). The dates not identified by the RA thresholds tend to have experienced isolated, single landslides. Of the KSEA slide hours not identified by the 3-32-day thresholds, 86 percent belonged to dates with only one known landslide.

The occurrence of landslides on dates of low rainfall in the Seattle, Mukilteo, and Everett areas has several probable causes. Previous studies have shown that some recorded landslides are directly related to various human causes including construction 
Cumulative Precipitation 50 Days Prior to Landsliding

Seattle Tacoma International Airport, Washington

1978-2003
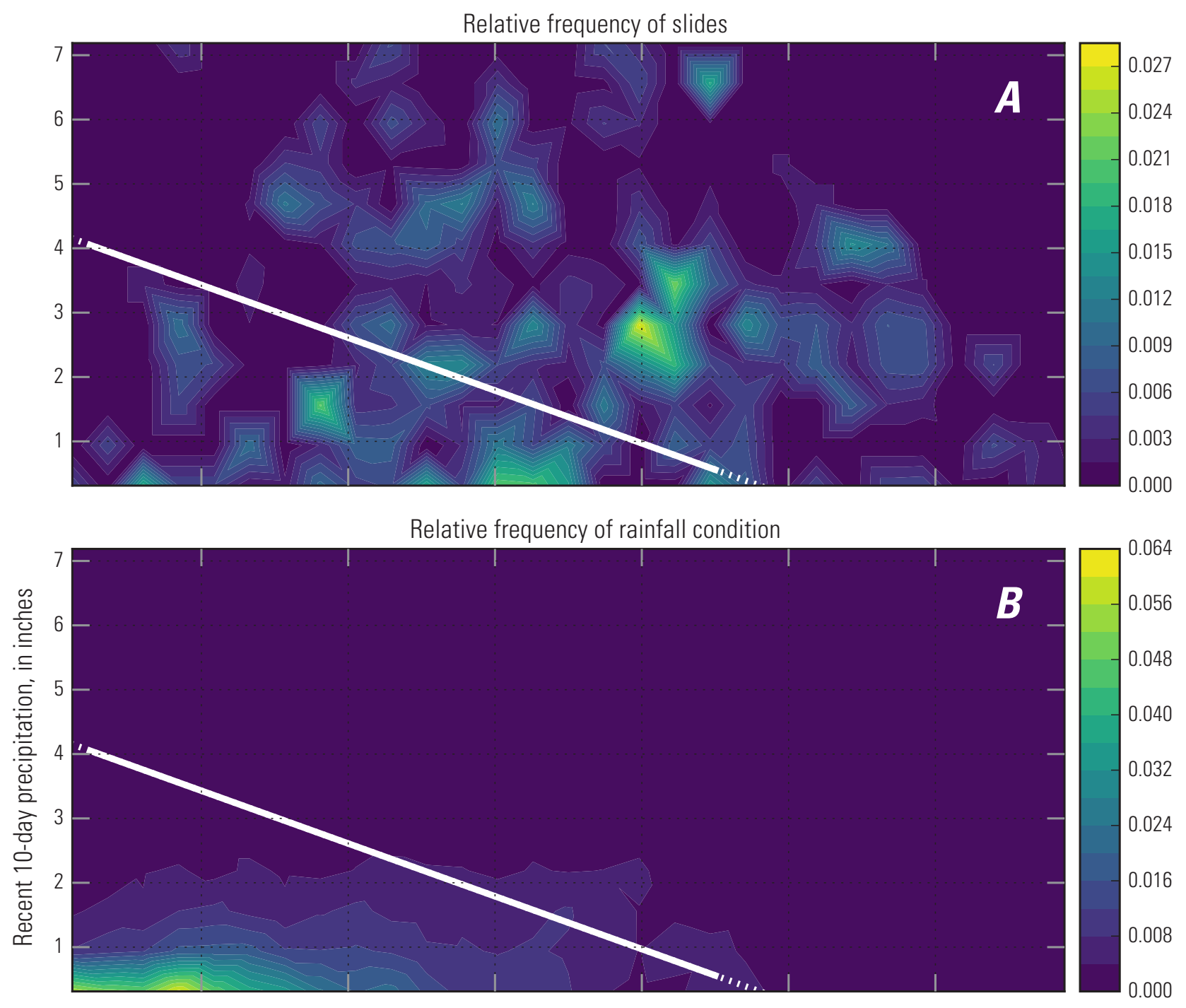

Relative probability of sliding during rainfall condition

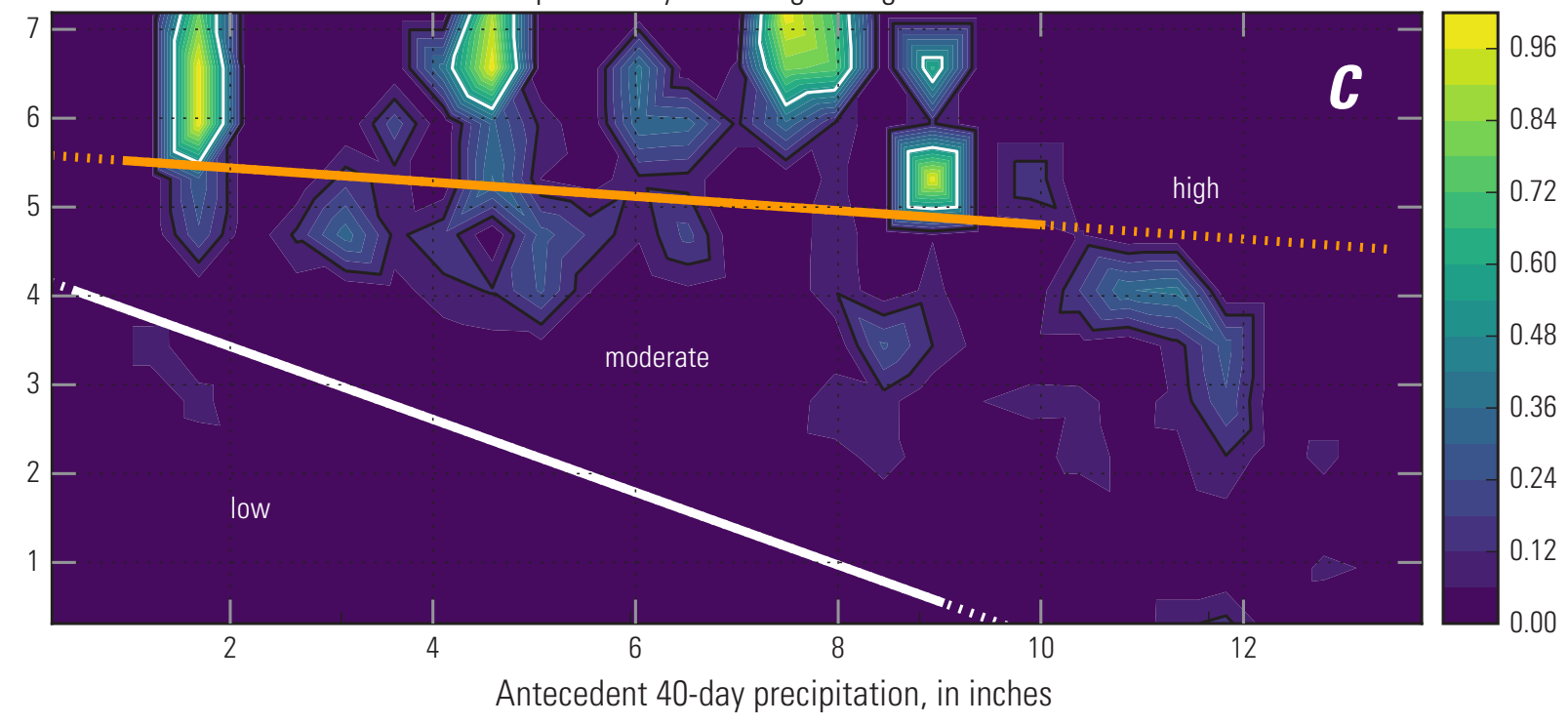


Figure 18 (previous page). Relative slide frequency, relative rainfall condition frequency, and sliding probability defined by the precipitation in the previous 10 days against the antecedent 40-day precipitation (50 days total) at Seattle Tacoma International Airport during 1978-2003. A, Relative frequency of slides, given by the number of slides at any given condition divided by the total number of known slides. $B$, Relative frequency of rainfall conditions, given by the count of rainfall condition occurrence during 1978-2003 divided by number of recorded hours in dataset. $C$, Relative probability of sliding during any given rainfall condition, determined by dividing the number of landslides at a given condition by the count of condition occurrence. High probability regions ( 0.50 or more) are contoured in white and moderate probability regions ( 0.12 or more) are contoured in black. The regions are generalized into zones of low, moderate, and high probability using the modified 3-15-day threshold (white) and the orange line. The orange line follows the appearance locations of high probability regions and is defined as $P_{10}=5.60-0.08 P_{40}$ where $P_{10}$ is the precipitation accumulation (inches) over the 10 days prior to the considered date and $P_{40}$ is the precipitation accumulation (inches) during the 40 days preceding $P_{3}$.

excavation, fill failures, overwatering, water- or sewer-main breaks, and deranged or improper surface drainage (Laprade and others, 2000). Indeed, human activities contributed to, but were not always the direct cause of, about 80 percent of landslides in Seattle (Laprade and others, 2000; Laprade and Tubbs, 2008). Delayed response of soil moisture and pore pressure to rainfall was identified as a cause of the landslide that destroyed a USGS monitoring station in January 2006 (Godt and others, 2009, 2012). Deep, slow-moving landslides commonly occur gradually in response to precipitation, with prolonged acceleration preceding any rapid movement (Iverson, 2000). Most recorded landslide dates (87 percent) listed in tables 1-1, 1-2, and 1-3 in appendix 1 have occurred during the five rainy-season months (November 1-March 31), and limiting use of the thresholds to that period of time (or perhaps mid-October through mid-April) would improve our computed threshold performance by eliminating the 8-12 percent of dates that fall outside the time when precipitation is likely to be a direct cause of landslides. Combining the tracking of precipitation relative to the thresholds with subsurface monitoring should further improve performance, but not totally eliminate false negatives (failed alarms) and false positives (false alarms).

\section{Conclusions}

This analysis pursued multiple methods for identifying precipitation thresholds that indicate increased probability of landsliding, including simple cumulative thresholds, compound cumulative thresholds, and intensity-duration (ID) thresholds . Simple cumulative thresholds with durations of 15-60 days give areas under the receiver operating characteristics curve of $0.79-0.815$, designating them as acceptable classifiers. The probability of landslides during exceedance of simple cumulative thresholds is often low, usually hovering below 0.1 when the considered duration is more than 15 days. Simple durations with precision more than 0.1 return true positive rates between 0.142 and 0.229 . Thresholds identified for 12-60 hours give an area under the curve of less than 0.75 . The associated receiver operating characteristics curves show steep rising limbs before shallowing, indicating that some portion of landslides are well correlated with recent (less than 72 hours) precipitation accumulation. This result is consistent with previous observations that many dates on which one or two landslides occurred are poorly correlated with recent precipitation, whereas dates on which many landslides occurred are well correlated with recent precipitation.

Compound cumulative thresholds, which combine recent and antecedent precipitation, are also acceptable, but imperfect, classifiers. As with the simple cumulative thresholds, the 3-32- and modified 3-15-day thresholds have low model precision, hovering between 0.06 and 0.13 . The 10-40-day threshold is an unacceptable classifier because of its dismal precision, which ranges from 0.02 to 0.07 . The threshold that maximized the true positive rate at Seattle Tacoma International Airport and Everett Paine Field, Washington, was defined as:

$$
P_{3}=2.16-0.22 P_{32}
$$

where $\quad P_{3} \quad$ is the cumulative precipitation in the recent 3 days, and

$P_{32}$ is the cumulative precipitation over the 32 days antecedent to the recent 3 days.

The threshold that maximized the true positive rate at the Mukilteo, Wash., stations was defined as:

$$
P_{3}=2.16-0.44 P_{15}
$$

where $P_{15} \quad$ is the cumulative precipitation over the 15 days antecedent to the recent 3 days.

This conclusion is based on 1 season of data at Mukilteo, in contrast to the 8 seasons of data at Everett Paine Field and the 25 seasons of data at Seattle Tacoma International Airport. The 3-32-day threshold consistently gave the highest precision at Mukilteo and gave true positive rates within 0.088 of the 3-15-day threshold at three of the four Mukilteo stations. 
Probability and frequency of landslides indicate that compound threshold space can be divided into areas of low (less than $0.12)$, moderate ( 0.12 to 0.49$)$ and high $(0.50$ or more) probability and low and moderate relative frequency. The moderate probability boundary, 0.12 , is low, but was selected because of the broad gradients observed and because a higher boundary makes the model less conservative. The high probability boundary, 0.5 , identified precipitation conditions where one in two occurrences corresponded to a landslide date. Areas of high and moderate landslide probability coincide with areas of low precipitation frequency and low to moderate landslide frequency. Areas of high relative landslide frequency typically have low landslide probability because the rainfall conditions commonly occur.

Many dates when landslides occurred occupy areas on the recent-antecedent (RA) threshold plots that indicate no, or very low, 3-day rainfall and low, or no, 32-day (or 15-day) antecedent rainfall. This poor correlation between recent precipitation and certain historical landslides indicates that a significant number of future landslides are likely to be missed by precipitation thresholds even if one is willing and able to accept a large number of false positives. Our data and previous studies indicate that it is not reasonable to assume that rainfall is directly and causally involved in all landslides occurring in the corridor. For example, previous studies found human activity contributed to roughly 80 percent of the landslides in Seattle. Further adjustment of the precipitation thresholds proposed in this report for any particular purpose, such as deciding when to cancel rail service, would require analysis of the costs as a function of the probabilities.

The rainfall ID threshold, although applicable to only a subset of conditions that induce landslides, appears to be a useful classifier under limited conditions. Rainfall conditions that exceed both an RA threshold and an ID threshold are more likely to fall on dates with multiple landslides than conditions that exceed only the RA threshold. Therefore, rainfall conditions that exceed both thresholds may lead to a higher alert level than simple RA exceedance. The ID space can also be subdivided into low, moderate, and high probability contours; these bands help clarify the effectiveness of each proposed ID threshold. An ID threshold developed previously appeared to be inappropriate near Everett and Mukilteo, Wash., based on limited data. However, the onelandslide and two-landslide ID thresholds derived from precipitation thresholds at hourly durations performed much better.

The relative probability of landsliding is unevenly distributed across different precipitation conditions. Decision makers may find the report's probability maps to be equally as useful as the quantitative precipitation thresholds because they can consider quantitative probability of landslide occurrence against current or forecasted precipitation accumulation. The generalized zones of low, moderate, and high probability demarcated in the probability maps provide a simplified way for assessing the likelihood of landslides given various precipitation conditions. Revised thresholds presented in this report can potentially improve the accuracy of landslide forecasts for the rail corridor in Mukilteo and Everett. Thresholds or probability plots based on precipitation alone may not provide adequate criteria for forecasting slide activity and could be supplemented by subsurface monitoring.

\section{Acknowledgments}

This work was funded jointly by a U.S. Geological Survey Technical Assistance Agreement with Sound Transit and the U.S. Geological Survey Landslide Hazard Program. Jeff Chou of Sound Transit provided coordination and support in securing access to sites for monitoring, interfaced with operations staff, and reviewed the content of this report to assure that the information meets the needs of Sound Transit. Dennis Staley of the U.S. Geological Survey and Francesco Fusco (U.S. Geological Survey visiting researcher, University of Naples, Federico II) provided technical reviews of this report.

\section{References Cited}

Associated Press, 2011, No passenger service through Mukilteo for 48 hours: [Everett, Washington] Daily Herald [HeraldNet. com], January 29, 2011, accessed July 22, 2016, at http://archive.heraldnet.com/article/20110129/NEWS03/701299861.

Associated Press, 2012a, Everett-Seattle trains postponed indefinitely: [Everett, Washington] Daily Herald [HeraldNet.com], December 22, 2012, accessed July 22, 2016, at http://archive.heraldnet.com/article/20121222/NEWS03/712229895.

Associated Press, 2012b, More Sounder, Amtrak runs canceled: [Everett, Washington] Daily Herald [HeraldNet.com], December 28, 2012, accessed July 22, 2016, at http://archive.heraldnet.com/article/20121228/NEWS03/712289798.

Associated Press, 2012c, Mudslides in Washington hit railroad tracks between Mukilteo, Everett: Oregon Live, December 20, 2012, accessed July 22, 2016, at http://www.oregonlive.com/pacific-northwest-news/index.ssf/2012/12/mudslides_in washington_hit_ra.html. 
Associated Press, 2012d, Second mudslide hits BNSF tracks in W. Washington: The Seattle Times, December 17, 2012, accessed July 22, 2016, at http://blogs.seattletimes.com/today/2012/12/second-mudslide-hits-bnsf-tracks-in-w-washington/.

Associated Press, 2013a, Mudslides prevent passenger rail north of Seattle: [Everett] Daily Herald [HeraldNet.com], January 10, 2013, accessed July 22, 2016, at http://archive.heraldnet.com/article/20130110/NEWS03/701109902.

Associated Press, 2013b, Mudslide suspends Wash. Amtrak service: KOIN 6, April 8, 2013, accessed July 22, 2016, at http:// koin.com/2013/04/08/mudslide-suspends-wash-amtrak-service/.

Associated Press, 2016, Landslide closes train tracks north of Seattle: The Washington Times, March 28, 2016, accessed September 29, 2016, at http://www.washingtontimes.com/news/2016/mar/28/landslide-closes-train-tracks-north-of-seattle/.

Baum, R.L., and Godt, J.W., 2010, Early warning of rainfall-induced shallow landslides and debris flows in the USA: Landslides, v. 7, no. 3, p. 259-272, accessed June 21, 2016, at https://doi.org/10.1007/s10346-009-0177-0.

Begueria, S., 2006, Validation and evaluation of predictive models in hazard assessment and risk management: Natural Hazards, v. 37, p. 315-329, accessed June 21, 2016, at https://doi.org/10.1007/s11069-005-5182-6.

Broom, Jack, and Lee, Jessica, 2015, Massive flooding threatens communities as rain, snowmelt continue: The Seattle Times, December 8, 2015, accessed September 29, 2016, at http://www.seattletimes.com/seattle-news/weather/heavy-rain-plus-melting-snow-saturates-washington/.

Campbell, R.H., Soil slips, debris flows, and rainstorms in the Santa Monica Mountains and vicinity, southern California: U.S. Geological Survey Professional Paper 851, 51 p., accessed March 17, 2017, at https://pubs.er.usgs.gov/publication/pp851.

Chuck Cady \& Associates, 2011, Mudslides cancel Northline Sounder service through Tuesday: Tri Star Team RE/MAX NW, March 15, 2011, accessed July 22, 2016, at http://www.tristarteamre.com/Blog/Mudslides-Cancel-Northline-Sounder-ServiceThrough-Tuesday.

Chleborad, A.F., 2000, Preliminary method for anticipating the occurrence of precipitation-induced landslides in Seattle, Washington: U.S. Geological Survey Open-File Report 00-469, 29 p., accessed June 21, 2016, at http://pubs.usgs.gov/of/2000/ ofr-00-0469/.

Chleborad, A.F., 2003, Preliminary evaluation of a precipitation threshold for anticipating the occurrence of landslides in the Seattle, Washington, area: U.S. Geological Survey Open-File Report 03-463, accessed June 21, 2016, at http://pubs.usgs.gov/ of/2003/ofr-03-463/.

Chleborad, A.F., Baum, R.L., and Godt, J.W., 2006, Rainfall thresholds for forecasting landslides in the Seattle, Washington, area-Exceedance and probability: U.S. Geological Survey Open-File Report 2006-1064, 31 p., accessed June 21, 2016, at http://pubs.usgs.gov/of/2006/1064/.

Chleborad, A.F., Baum, R.L., Godt, J.W., and Powers, P.S., 2008, A prototype system for forecasting landslides in the Seattle, Washington, area, in Baum, R.L., Godt, J.W., and Highland, L.M., eds., Landslides and engineering geology of the Seattle, Washington, area: Geological Society of America Reviews in Engineering Geology, v. 20, p. 103-120, accessed June 21, 2016, at https://doi.org/10.1130/2008.4020(06).

CNN Wire Staff, 2010, Flooding hits western Washington, mudslides halt Amtrak service: CNN, December 12, 2010, accessed July 22, 2016, at http://www.cnn.com/2010/US/12/12/washington.mudslide/.

Cornwall, Paige, and Associated Press, 2014, Mudslide - Sounder Northline suspended until at least Monday: The Seattle Times, December 10, 2014, accessed July 22, 2016, at http://www.seattletimes.com/news/mudslide-sounder-northlinesuspended-until-at-least-monday/.

Daily Herald, 2010a, Mudslide cancels Sounder service from Seattle to Everett: [Everett] Daily Herald [HeraldNet.com], March 12, 2010, accessed July 22, 2016, at http://archive.heraldnet.com/article/20100312/NEWS01/100319939.

Daily Herald, 2010b, Mudslide stops Sounder service between Mukilteo and Everett: [Everett] Daily Herald [HeraldNet.com], March 25, 2010, accessed July 22, 2016, at http://archive.heraldnet.com/article/20100325/NEWS01/100329896.

Daily Herald, 2014, Mudslide halts Everett-Seattle passenger train service: [Everett] Daily Herald [HeraldNet.com], December 24, 2014, accessed July 22, 2016, at http://archive.heraldnet.com/article/20141224/NEWS01/141229461. 
de Leon, John, 2013, Mudslide cancels Sounder service between Seattle and Everett: The Seattle Times, March 21, 2013, accessed July 22, 2016, at http://www.seattletimes.com/seattle-news/mudslide-cancels-sounder-service-between-seattle-andeverett/.

Ellison, Jake, 2006, Relentless rains bring mudslide misery to city: Seattle Post-Intelligencer [SeattlePI.com], January 30, 2006, accessed July 22, 2016, at http://www.seattlepi.com/local/article/Relentless-rains-bring-mudslide-misery-to-city-1194374.php.

Fawcett, T., 2006, An introduction to ROC analysis: Pattern Recognition Letters, v. 27, p. 861-874, accessed June 21, 2016, at https://doi.org/10.1016/j.patrec.2005.10.010.

Gilmore, Susan, and Kimball, Jill, 2011, Soggy weather, flood of mudslides: The Seattle Times, March 14, 2011, accessed July 22, 2016, at http://www.seattletimes.com/seattle-news/soggy-weather-flood-of-mudslides/.

Godt, J.W., Baum, R.L, and Chleborad, A.F., 2006, Rainfall characteristics for shallow landsliding in Seattle, Washington, USA: Earth Surface Processes and Landforms, v. 31, p. 97-110, accessed June 21, 2016, at https://doi.org/10.1002/esp.1237.

Godt, J.W., Baum, R.L., and Lu, Ning, 2009, Landsliding in partially saturated materials: Geophysical Research Letters, v. 36, no. 2, 5 p. [Also available at https://doi.org/10.1029/2008GL035996.]

Godt, J.W., Sener-Kaya, B., Lu, N., and Baum, R.L., 2012, Stability of infinite slopes under transient partially saturated seepage conditions: Water Resources Research, v. 48, no. 5, 14 p.

Gutierrez, Scott, 2011, Mudslides halt Amtrak service between Seattle and Vancouver, B.C.: Seattle Post-Intelligencer [SeattlePI.com], November 23, 2011, accessed July 11, 2016, at http://www.seattlepi.com/local/transportation/article/Mudslides-halt-Amtrak-service-between-Seattle-and-2284572.php.

Guzzetti, F., Peruccacci, S., Rossi, M., and Stark, C.P., 2008, The rainfall intensity-duration control of shallow landslides and debris flows - an update: Landslides, v. 5, no. 1, p. 3-17. [Also available at https://doi.org/10.1007/s10346-007-0112-1.]

Iverson, R.M., 2000, Landslide triggering by rain infiltration: Water Resources Research, v. 36, no.7, p. 1897-1910. [Also available at https://doi.org/10.1029/2000WR900090.]

Korell, Kevin, 2012, Cascades-Another mudslide service disruption: On Track On Line Forums, December 22, 2012, accessed February 23, 2017 at http://www.on-track-on-line.com/forums/index.php?showtopic=43178\&p=88942. [Originally published as an Amtrak service announcement.]

Laprade, W.T., Kirkland, T.E., Nashem, W.D., and Robertson, C.A., 2000, Seattle landslide study: Shannon and Wilson, Inc., Internal Report W-7992-07, 164 p., accessed October 7, 2016, at http:/www.seattle.gov/dpd/cs/groups/pan/@pan/documents/ web_informational/p2156831.pdf.

Laprade, W.T., and Tubbs, D.W., 2008, Landslide mapping in Seattle, Washington, in Baum, R.L., Godt, J.W., and Highland, L.M., eds., Landslides and engineering geology of the Seattle, Washington, area: Geological Society of America Reviews in Engineering Geology, v. 20, p. 37-54. [Also available at https://doi.org/10.1130/2008.4020(02).]

Markovich, Matt, 2015, Mudslide shuts down passenger train service between Seattle and Everett: KOMONews.com, December 8, 2015, accessed September 29, 2016, at http://komonews.com/news/local/mudslide-shuts-down-passenger-trainservice-between-seattle-and-everett.

McLain, Cathy, 2013, Mudslide cancels Northline Sounder service tonight and tomorrow: The Seattle Times, January 3, 2013 , accessed July 22, 2016, at http://blogs.seattletimes.com/today/2013/01/mudslide-cancels-northline-sounder-service-tonightand-tomorrow $/$.

Mirus, B.B., Smith, J.B., Stark, Benjamin, Lewis, York, Michel, Abigail, and Baum, R.L., 2016, Assessing landslide potential on coastal bluffs near Mukilteo, Washington-Geologic site characterization for hydrologic monitoring: U.S. Geological Survey Open-File Report 2016-1082, 28 p. [Also available at https://doi.org/10.3133/ofr20161082.]

My Edmonds News, 2010, Mudslide may affect Seattle-Everett Sounder train service Monday: My Edmonds News, January 16, 2010, accessed July 22, 2016, at http://myedmondsnews.com/2010/01/mudslide-may-affect-seattle-everett-sounder-trainservice-monday. 
My Edmonds News, 2011, Sounder service to Edmonds suspended Friday due to mudslides: My Edmonds News, January 13, 2011, accessed July 22, 2016, at http://myedmondsnews.com/2011/01/sounder-service-to-edmonds-suspended-friday-due-tomudslides/.

My Edmonds News, 2012a, Edmonds-Seattle Sounder commuter train service canceled Monday due to mudslides: My Edmonds News, December 2, 2012, accessed July 22, 2016, at http://myedmondsnews.com/2012/12/edmonds-seattle-soundercommuter-train-service-canceled-monday-due-to-mudslides/.

My Edmonds News, 2012b, Mudslide cancels Thursday morning Sounder commuter train service: My Edmonds News, March 1, 2012, accessed July 22, 2016, at http://myedmondsnews.com/2012/03/mudslide-cancels-thursday-morningsounder-commuter-train-service/.

My Edmonds News, 2012c, Mudslides cancel Sounder Monday evening commuter train service: My Edmonds News, November 19, 2012, accessed July 22, 2016, at http://myedmondsnews.com/2012/11/mudslides-cancel-sounder-mondayevening-commuter-train-service/.

My Edmonds News, 2012d, Thanks to another mudslide, Sound Transit cancels commuter train service for Friday: My Edmonds News, November 21, 2012, accessed July 22, 2016, at http://myedmondsnews.com/2012/11/thanks-to-another-mudslidesound-transit-cancels-commuter-train-service-for-friday/.

My Edmonds News, 2013a, Mudslide Monday night cancels Tuesday, Wednesday Sounder train service: My Edmonds News, January 7, 2013, accessed July 22, 2016, at http://myedmondsnews.com/2013/01/mudslide-monday-night-cancels-tuesdaywednesday-sounder-train-service/.

My Edmonds News, 2013b, Sounder commuter service for Monday-Tuesday canceled due to mudslide that derailed Amtrak train: My Edmonds News, April 7, 2013, accessed July 22, 2016, at http://myedmondsnews.com/2013/04/sounder-commuterservice-for-monday-tuesday-canceled-due-to-mudslide-that-derailed-amtrak-train/.

My Edmonds News, 2014, No Sounder commuter train service Monday due to mudslide: My Edmonds News, December 28, 2014, accessed July 22, 2016, at http://myedmondsnews.com/2014/12/no-sounder-commuter-train-service-monday-due-mudslide/.

My Edmonds News, 2016, Downed power lines, trees in Edmonds after windstorm sweeps through Sunday: My Edmonds News, March 13, 2016, accessed September 29, 2016, at http://myedmondsnews.com/2016/03/downed-power-lines-trees-inedmonds-after-windstorm-sweeps-area-sunday/.

National Climatic Data Center, 2016, Global Historical Climatology Network database [Mean annual precipitation for Everett and Seattle during 1978-2003]: National Climatic Data Center database, accessed June 4, 2016, at https://www.ncdc.noaa. gov/data-access/land-based-station-data/land-based-datasets/global-historical-climatology-network-ghen.

Seattle Post-Intelligencer, 2006a, Mud stops Amtrak and Sounder trains: Seattle Post-Intelligencer [SeattlePI.com], January 6, 2006, accessed July 11, 2016, at http://www.seattlepi.com/local/transportation/article/Mud-stops-Amtrak-andSounder-trains-1192036.php.

Seattle Post-Intelligencer, 2006b, Mudslide stops Seattle-B.C. Amtrak route: Seattle Post-Intelligencer [SeattlePI.com], April 17, 2006, accessed July 11, 2016, at http://www.seattlepi.com/local/transportation/article/Mudslide-stops-Seattle-B-C-Amtrakroute-1201430.php.

Seattle Post-Intelligencer, 2007, Roads, public transit—Closures, cancellations: Seattle Post-Intelligencer [SeattlePI.com], December 3, 2007, accessed July 11, 2016, at http://www.seattlepi.com/local/article/Roads-public-transit-Closurescancellations-1257619.php.

Seattle Times, 2010a, Mudslide briefly blocks RR tracks near Edmonds: The Seattle Times, December 9, 2010, accessed July 22, 2016, at http:/www.seattletimes.com/seattle-news/mudslide-briefly-blocks-rr-tracks-near-edmonds/.

Seattle Times, 2010b, Mudslide on tracks halts Sounder, Amtrak service between Seattle, Everett: The Seattle Times, January 19, 2010, accessed July 22, 2016, at http://www.seattletimes.com/seattle-news/transportation/mudslide-on-tracks-halts-sounderamtrak-service-between-seattle-everett/.

Seattle Times, 2011, Another mudslide hits railroad track near Mukilteo: The Seattle Times, March 18, 2011, accessed July 22, 2016, at http://www.seattletimes.com/seattle-news/another-mudslide-hits-railroad-track-near-mukilteo/. 
Seattle Times, 2013, Train service north of Seattle hit by mudslide: The Seattle Times, February 18, 2013, accessed July 22, 2016, at http://www.seattletimes.com/seattle-news/train-service-north-of-seattle-hit-by-mudslide/.

Seattle Times, 2014, North Sounder rail service to resume Monday night after slide: The Seattle Times, November 30, 2014, accessed July 22, 2016, at http://www.seattletimes.com/seattle-news/north-sounder-rail-service-to-resume-monday-nightafter-slide- $1 /$.

Sheets, Bill, 2011, Another mudslide stalls commuter rail: [Everett] Daily Herald [HeraldNet.com], March 10, 2011, accessed July 22, 2016, at http://archive.heraldnet.com/article/20110310/BLOG17/110319977.

Sound Transit, 2016, Sound Transit alert—Sounder Everett-Seattle—Canceled—Due to mudslide, January 21, 2016, accessed September 29, 2016, at http://www.soundtransit.org/node/12666.

Staley, D.M., Kean, J.W., Cannon, S.H., Schmidt, K.M., and Laber, J.L., 2013, Objective definition of rainfall intensity-duration thresholds for the initiation of post-fire debris flows in southern California: Landslides, v. 10, p. 547-562.

Stevick, Eric, 2011, Mudslides halt passenger train service: [Everett] Daily Herald [HeraldNet.com], January 19, 2011, accessed July 22, 2011, at http://archive.heraldnet.com/article/20110119/NEWS01/701199808.

Times Snohomish County Bureau, 2006, Mudslides halt Sounder service today, Thursday: The Seattle Times, December 27, 2006, accessed February 22, 2017, at http:/www.seattletimes.com/seattle-news/mudslides-halt-sounder-service-today-thursday/.

Tv, Komo, and Associated Press, 2012, Seattle mudslide cancels north Sounder: Seattle Post-Intelligencer [SeattlePI.com], May 4, 2012, accessed July 11, 2016, at http:/www.seattlepi.com/local/komo/article/Seattle-mudslide-cancels-northSounder-3534415.php.

Vaughn, Alexa, and Spencer, Aaron, 2012a, Another mudslide on BNSF tracks-Passenger service canceled between Seattle and Everett: The Seattle Times, December 19, 2012, accessed July 22, 2016, at http://www.seattletimes.com/news/anothermudslide-on-bnsf-tracks-passenger-service-canceled-between-seattle-and-everett/.

Vaughn, Alexa, and Spencer, Aaron, 2012b, Mudslide cancels Sounder service to Everett and Mukilteo-Again: The Seattle Times, December 4, 2012, accessed July 22, 2016, at http://www.seattletimes.com/seattle-news/mudslide-cancels-sounderservice-to-everett-and-mukilteo-again/.

Wong, B., 2006a, Mudslide stops rail traffic again: Seattle Post-Intelligencer [SeattlePI.com], December 28, 2006, accessed July 11, 2016, at http://www.seattlepi.com/local/article/Mudslide-stops-rail-traffic-again-1223737.php.

Wong, B., 2006b, Mudslides shut down some train service: Seattle Post-Intelligencer [SeattlePI.com], December 26, 2006, accessed July 11, 2016, at http://www.seattlepi.com/local/article/Mudslides-shut-down-some-train-service-1223512.php.

Washington State Department of Transportation, 2015, WSDOT landslide mitigation work resumes along northern rail lines near Everett and Mukilteo: Washington State Department of Transportation, August 17, 2015, accessed June 28, 2016, at http:// www.wsdot.wa.gov/News/2015/08/17_raillandslideprojects.htm. 


\section{Appendix 1. Landslide Date Inventories}

Each database of landslide dates is provided in appendix 1. Landslide Database 1 (table 1-1), with its 25-year period of record, was used to calibrate all of the thresholds proposed in this report. Landslide Databases 2 (table 1-2) and 3 (table 1-3) are used to validate the thresholds and to evaluate their effectiveness along the Seattle-Everett-Mukilteo railway corridor. Referenced news stories all note dates of landsliding that affected Sound Transit or Amtrak service near Seattle. 
Table 1-1. Landslide Database 1—Landslides that occurred during 1978-2003 near Seattle Tacoma International Airport (From Chleborad and others, 2006)

\begin{tabular}{|c|c|c|c|c|c|}
\hline Date & Landslide count & Date & Landslide count & Date & Landslide count \\
\hline March 20, 1978 & 1 & April 10, 1984 & 1 & September 29, 1994 & 1 \\
\hline December 5, 1978 & 1 & May 15,1984 & 1 & February 19, 1995 & 1 \\
\hline December 15, 1979 & $2+$ & August 2, 1984 & 1 & August 25, 1995 & 1 \\
\hline December 17, 1979 & $2+$ & December 8, 1984 & 1 & November 11, 1995 & 1 \\
\hline December 18, 1979 & $2+$ & December 28, 1984 & 1 & December 15, 1995 & 1 \\
\hline January 12,1980 & 1 & January 17, 1986 & $2+$ & February 9, 1996 & $2+$ \\
\hline February 8, 1980 & 1 & January 18, 1986 & $2+$ & February 10, 1996 & 1 \\
\hline February 28, 1980 & 1 & January 19, 1986 & $2+$ & February 12, 1996 & 1 \\
\hline April 4, 1980 & 1 & January 23, 1986 & 1 & February 16, 1996 & 1 \\
\hline April 28, 1980 & 1 & January 24, 1986 & $2+$ & February 26, 1996 & 1 \\
\hline January 18, 1982 & 1 & February 20, 1986 & 1 & January 1, 1997 & $2+$ \\
\hline February 10, 1982 & 1 & February 24, 1986 & $2+$ & January 2, 1997 & $2+$ \\
\hline February 19, 1982 & 1 & February 27, 1986 & $2+$ & January 3, 1997 & $2+$ \\
\hline February 20, 1982 & 1 & March 11, 1986 & 1 & January 4, 1997 & 1 \\
\hline March 12, 1982 & 1 & March 17, 1986 & 1 & January 19, 1997 & 1 \\
\hline December 3, 1982 & $2+$ & March 19, 1986 & 1 & February 13, 1997 & 1 \\
\hline December 15,1982 & 1 & March 21, 1986 & $2+$ & March 18, 1997 & $2+$ \\
\hline December 18,1982 & 1 & November 23, 1986 & $2+$ & March 19, 1997 & $2+$ \\
\hline December 21, 1982 & $2+$ & February 2, 1987 & $2+$ & March 20, 1997 & $2+$ \\
\hline January 4, 1983 & $2+$ & February 11, 1987 & 1 & March 23, 1997 & 1 \\
\hline January 5, 1983 & 1 & March 3, 1987 & 1 & April 2, 1997 & 1 \\
\hline December 10, 1983 & 1 & March 5, 1990 & 1 & January 28, 1999 & 1 \\
\hline December 11, 1983 & $2+$ & December 31, 1990 & $2+$ & January 30, 1999 & 1 \\
\hline December 12,1983 & 1 & February 6, 1991 & 1 & February 20, 1999 & 1 \\
\hline December 13, 1983 & 1 & April 5, 1991 & $2+$ & February 24, 1999 & $2+$ \\
\hline December 30, 1983 & 1 & April 12, 1991 & 1 & February 25, 1999 & $2+$ \\
\hline January 17, 1984 & 1 & July 22, 1991 & 1 & February 26, 1999 & $2+$ \\
\hline February 24, 1984 & 1 & January 30, 1992 & 1 & April 12, 1999 & $2+$ \\
\hline March 7, 1984 & 1 & September 24, 1992 & 1 & October 27, 1999 & 1 \\
\hline November 10, 1999 & 1 & November 21, 2001 & $2+$ & January 15, 2002 & 1 \\
\hline December 2, 1999 & 1 & November 23, 2001 & 1 & January 19, 2002 & 1 \\
\hline December 16, 1999 & 1 & November 25, 2001 & 1 & January 25,2002 & $2+$ \\
\hline January 12, 2000 & 1 & November 26, 2001 & 1 & January 31, 2002 & 1 \\
\hline February 15,2000 & 1 & December 3, 2001 & 1 & May 9, 2002 & 1 \\
\hline March 16, 2000 & 1 & December 5, 2001 & 1 & May 20, 2002 & 1 \\
\hline March 28, 2000 & 1 & December 13, 2001 & $2+$ & November 23, 2002 & 1 \\
\hline August 21, 2000 & 1 & December 16, 2001 & $2+$ & March 22, 2003 & 1 \\
\hline February 28, 2001 & 1 & December 18, 2001 & $2+$ & October 20, 2003 & $2+$ \\
\hline November 2, 2001 & 1 & December 19, 2001 & $2+$ & October 21,2003 & 1 \\
\hline November 14, 2001 & $2+$ & December 20, 2001 & $2+$ & November 19, 2003 & 1 \\
\hline November 15, 2001 & $2+$ & January 8, 2002 & $2+$ & & \\
\hline November 19, 2001 & 1 & January 10, 2002 & 1 & & \\
\hline
\end{tabular}


Table 1-2. Landslide Database 2—Landslides that occurred during 2006-2014 near Everett, Washington.

[Landslide counts of "1" indicate that only one landslide is verifiable from the news report. Some of these dates may have experienced multiple slides which were not deemed newsworthy.]

\begin{tabular}{|c|c|c|}
\hline Date & Slide count & Citation \\
\hline January 6, 2006 & $2+$ & Seattle Post-Intelligencer (2006a) \\
\hline January 29, 2006 & 4 & Ellison (2006) \\
\hline April 17, 2006 & 1 & Seattle Post-Intelligencer (2006b) \\
\hline December 26, 2006 & $2+$ & Wong (2006b) \\
\hline December 27, 2006 & 1 & Times Snohomish County Bureau (2006) \\
\hline December 28, 2006 & 1 & Wong (2006a) \\
\hline December 3, 2007 & 1 & Seattle Post-Intelligencer (2007) \\
\hline January 16, 2010 & 1 & My Edmonds News (2010) \\
\hline January 19, 2010 & 2 & Seattle Times (2010b) \\
\hline March 12, 2010 & 1 & Daily Herald (2010a) \\
\hline March 25, 2010 & 1 & Daily Herald (2010b) \\
\hline December 9, 2010 & 1 & Seattle Times (2010a) \\
\hline December 12, 2010 & $2+$ & CNN Wire Staff (2010) \\
\hline January 13, 2011 & 1 & My Edmonds News (2011) \\
\hline January 19, 2011 & 2 & Stevick (2011) \\
\hline January 29, 2011 & 1 & Associated Press (2011) \\
\hline March 10, 2011 & $2+$ & Sheets (2011) \\
\hline March 13, 2011 & $2+$ & Gilmore and Kimball (2011) \\
\hline March 14, 2011 & $2+$ & Gilmore and Kimball (2011) \\
\hline March 15, 2011 & 1 & Chuck Cady \& Associates (2011) \\
\hline March 18, 2011 & 1 & Seattle Times (2011) \\
\hline November 23, 2011 & 1 & Gutierrez (2011) \\
\hline March 1, 2012 & 1 & My Edmonds News (2012b) \\
\hline May 3, 2012 & 1 & Tv and Associated Press (2012) \\
\hline November 19, 2012 & 1 & My Edmonds News (2012c) \\
\hline November 21, 2012 & 1 & My Edmonds News (2012d) \\
\hline December 1, 2012 & $2+$ & My Edmonds News (2012a) \\
\hline December 4, 2012 & 1 & Vaughn and Spencer (2012a) \\
\hline December 17, 2012 & 2 & Associated Press (2012d) \\
\hline December 19, 2012 & 1 & Vaughn and Spencer (2012a) \\
\hline December 20, 2012 & $2+$ & Associated Press (2012c) \\
\hline December 21, 2012 & 1 & Associated Press (2012a) \\
\hline December 22, 2012 & $2+$ & Associated Press (2012a), Korell (2012) \\
\hline December 26, 2012 & 1 & Associated Press (2012b) \\
\hline January 3, 2013 & 1 & McLain (2013) \\
\hline January 7, 2013 & 1 & My Edmonds News (2013a) \\
\hline January 9, 2013 & 2 & Associated Press (2013a) \\
\hline January 10, 2013 & 1 & Associated Press (2013a) \\
\hline February 17, 2013 & 1 & Seattle Times (2013) \\
\hline March 21, 2013 & 1 & de Leon (2013) \\
\hline April 7, 2013 & 1 & My Edmonds News (2013b) \\
\hline April 8, 2013 & 1 & Associated Press (2013b) \\
\hline November 24, 2014 & 1 & Seattle Times (2014) \\
\hline November 29, 2014 & 1 & Seattle Times (2014) \\
\hline December 10, 2014 & 1 & Cornwall and Associated Press (2014) \\
\hline December 24, 2014 & 1 & Daily Herald (2014) \\
\hline December 28, 2014 & 1 & My Edmonds News (2014) \\
\hline
\end{tabular}


Table 1-3. Landslide Database 3-Landslides that occurred during 20152016 along the railway corridor between Seattle and Everett, Washington.

[Only one landslide per date was identified in news reports or with the USGS time lapse camera, but this does not preclude the occurrence of other slides. USGS, U.S. Geological Survey]

\begin{tabular}{lcl}
\hline \multicolumn{1}{c}{ Date } & $\begin{array}{c}\text { Landslide } \\
\text { count }\end{array}$ & \multicolumn{1}{c}{ Source } \\
\hline December 7, 2015 & 1 & Markovich (2015) \\
December 8, 2015 & 1 & Broom and Lee (2015) \\
January 21, 2016 & 1 & Sound Transit (2016) \\
January 24, 2016 & 1 & USGS time lapse camera \\
January 28, 2016 & 1 & USGS time lapse camera \\
March 13, 2016 & 1 & My Edmond News (2016) \\
March 28, 2016 & 1 & Associated Press (2016) \\
\hline
\end{tabular}




\section{Appendix 2. Intensity-Duration Threshold Conditions}

The intensity duration thresholds are defined by a curve fitted to the values provided in tables $2-1$ and $2-2$. Each intensity is found by dividing the optimum cumulative threshold (table 3 ) by its corresponding accumulation duration.

Table 2-1. One-landslide minimum intensity-duration curve, where $I=0.134 D^{-0.35}$ and $R^{2}=0.842$.

[D, duration in hours; I, rainfall intensity in inches/hour; $\mathrm{R}^{2}$, coefficient of determination]

\begin{tabular}{ccc}
\hline $\begin{array}{c}\text { Domain: } \\
\text { duration (hours) }\end{array}$ & $\begin{array}{c}\text { Intensity } \\
\text { (inches/hour) }\end{array}$ & $\begin{array}{c}\text { Power-law fitted intensity } \\
\text { (inches/hour) }\end{array}$ \\
\hline 12 & 0.058 & 0.056 \\
18 & 0.049 & 0.049 \\
24 & 0.042 & 0.044 \\
36 & 0.039 & 0.038 \\
48 & 0.029 & 0.035 \\
60 & 0.036 & 0.032 \\
\hline
\end{tabular}

Table 2-2. Two-landslide minimum intensity-duration curve, where $I=0.193 D^{-0.34}$ and $\mathrm{R}^{2}=0.855$.

[D, duration in hours; I, rainfall intensity in inches/hour; $\mathrm{R}^{2}$, coefficient of determination]

\begin{tabular}{ccc}
\hline $\begin{array}{c}\text { Domain: } \\
\text { duration (hours) }\end{array}$ & $\begin{array}{c}\text { Intensity } \\
\text { (inches/hour) }\end{array}$ & $\begin{array}{c}\text { Power-law fitted intensity } \\
\text { (inches/hour) }\end{array}$ \\
\hline 12 & 0.082 & 0.083 \\
18 & 0.070 & 0.072 \\
24 & 0.071 & 0.066 \\
36 & 0.059 & 0.057 \\
48 & 0.059 & 0.052 \\
60 & 0.043 & 0.048 \\
\hline
\end{tabular}




\section{Appendix 3. Support Figures for Everett and Mukilteo Datasets}

Recent-antecedent thresholds examined in the report are plotted with data from Everett Paine Field (fig. 3-1) and Mukilteo weather stations (figs. 3-2, 3-3, and 3-4). The three considered intensity-duration thresholds are plotted with storm intensity data collected at Everett Paine Field (fig. 3-5).

Figure 3-1 (following page). Precipitation accumulation calculated using moving intervals on dates of known landsliding near Everett Paine Field, Washington, during 2006-2014. A date's hour with the highest previous 3-day precipitation is represented with an opaque circle. Note that the circles, although not taken from a consistent hour on each date, approximate a plot of fixed interval precipitation sums because only a single sum is represented per date. $A$, The modified 3-15-day threshold, defined as $P_{3}=2.16-0.44 P_{15}$ where $P_{3}$ is the precipitation accumulation (inches) over 3 days and $P_{15}$ is the precipitation accumulation (inches) during the 15 days preceding $P_{3}$. $B$, The 3-32-day threshold, defined as $P_{3}=2.16-0.22 P_{32}$ where $P_{3}$ is the precipitation accumulation (inches) over 3 days and $P_{32}$ is the precipitation accumulation (inches) during the 32 days preceding $P_{3^{*}}$ C . The 10-40-day threshold, defined as $P_{10}=4.25-0.41 P_{40}$ where $P_{10}$ is the precipitation accumulation (inches) over 10 days and $P_{40}$ is the precipitation accumulation (inches) during the 40 days preceding $P_{10}$. 
Recent - Antecedent Thresholds

Everett Paine Field, Washington

2006-2014

3-15 Threshold
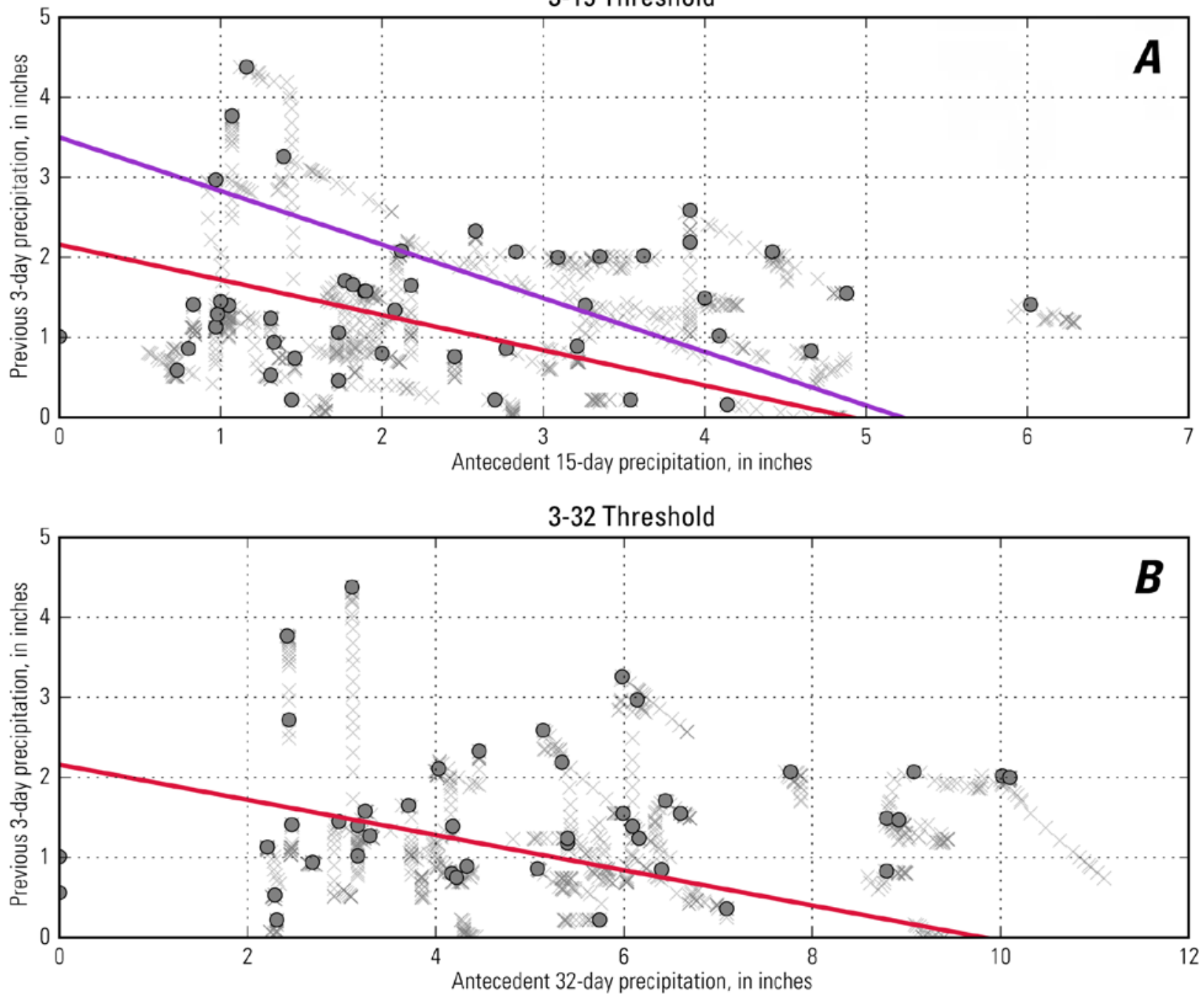

10-40 Threshold

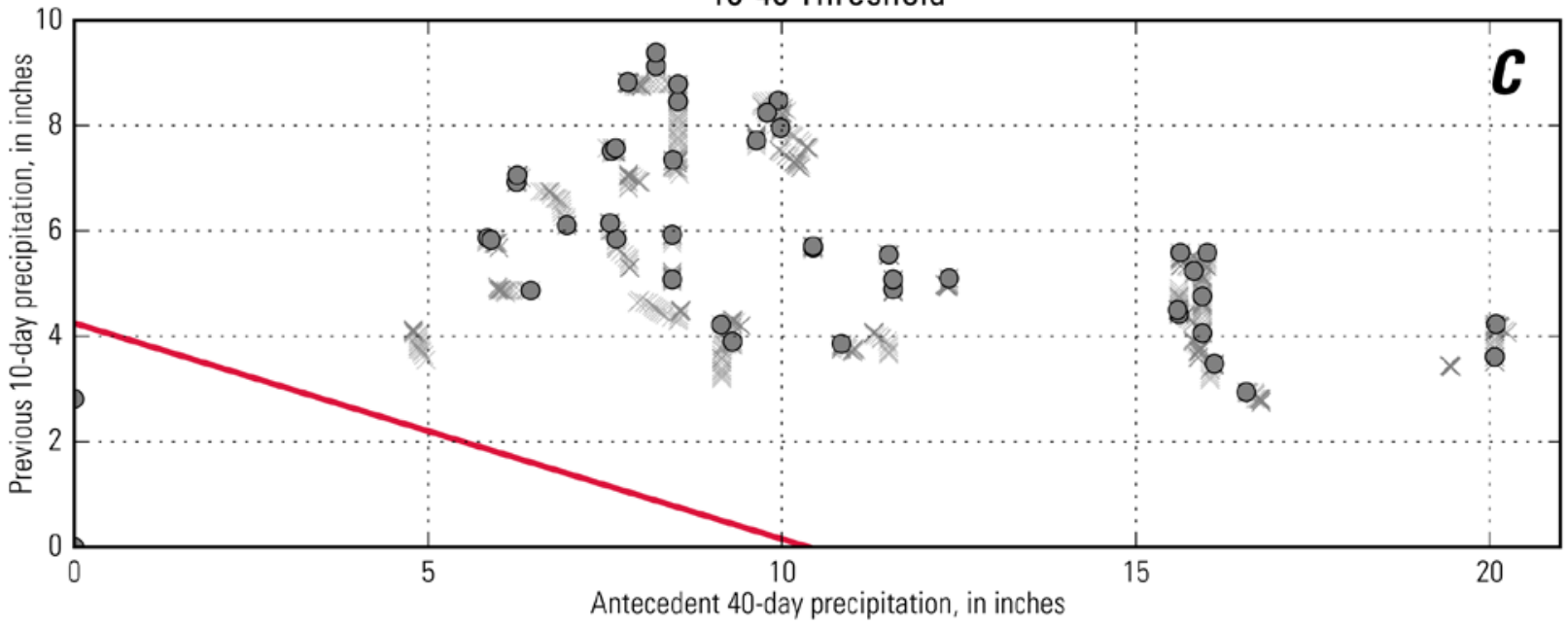

$\times \quad$ Moving interval sums from slide dates
Highest moving interval sum of slide date
Analyzed threshold, this report
Chleborad and others (2008) $P_{3}=3.50-0.67 P_{15}$ 


\section{Cumulative Precipitation 18 Days Prior to Landsliding Mukilteo, Washington 2015-2016}
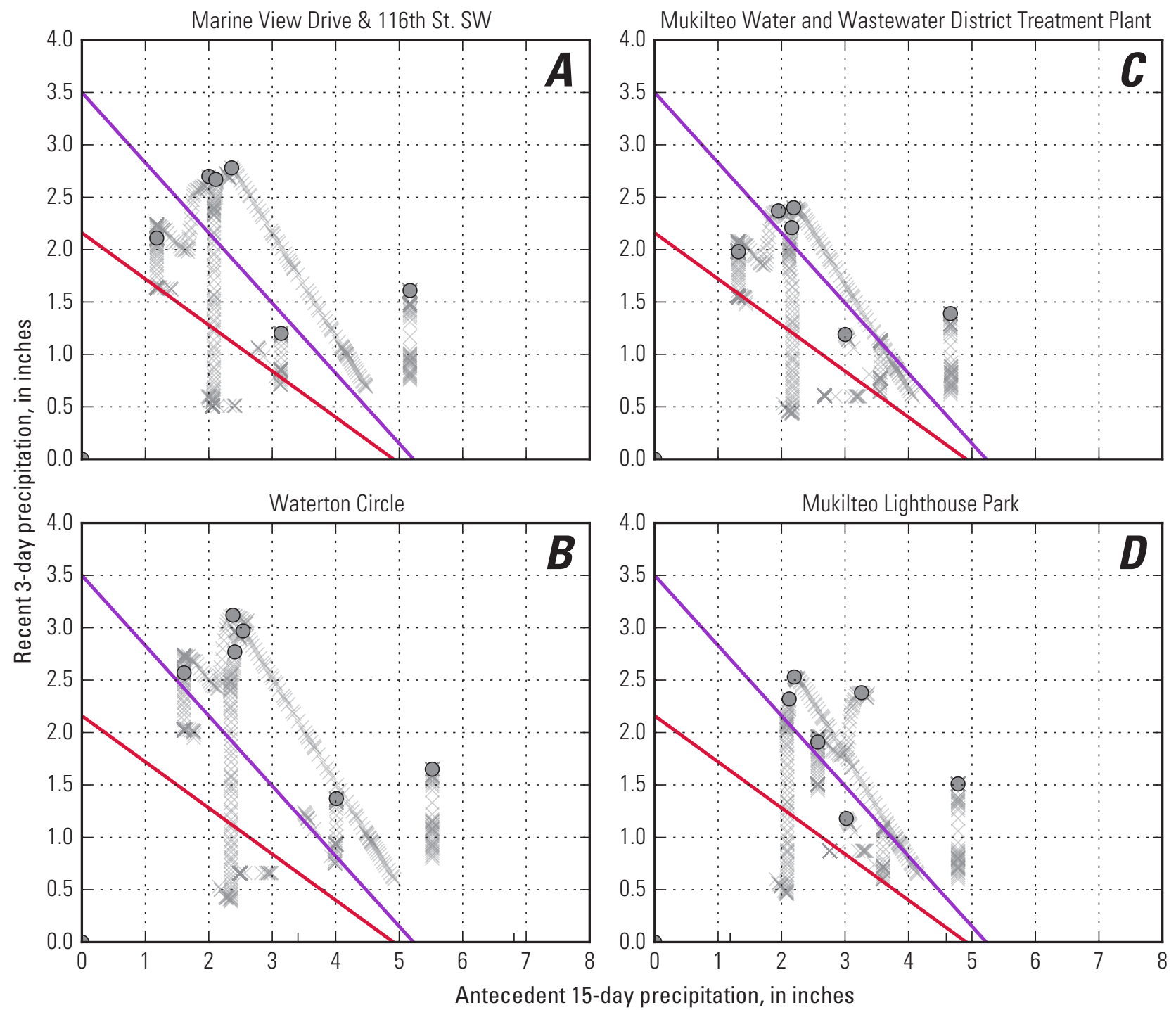

Antecedent 15-day precipitation, in inches

\begin{tabular}{|c|c|c|c|c|c|}
\hline$x$ & $\begin{array}{l}\text { Moving interval sums } \\
\text { from slide dates }\end{array}$ & 0 & $\begin{array}{l}\text { Highest moving interval } \\
\text { sum of slide date }\end{array}$ & $\begin{array}{l}\text { Modified 3-15 threhold } \\
P_{3}=2.16-0.44 P_{15}\end{array}$ & $\begin{array}{l}\text { Chleborad and others (2008) } \\
P_{3}=3.5-0.67 P_{15}\end{array}$ \\
\hline
\end{tabular}

Figure 3-2. Recent-antecedent precipitation accumulation (3-15 days) calculated using moving intervals on dates of known landsliding near Mukilteo, Washington, during 2015-2016. Note that the " $x$ " markers denote measurements taken every 15 minutes. A date's 15 minutes with the highest previous 3-day precipitation is represented with an opaque circle. Note that the circles, although not taken from a consistent hour on each date, approximate a plot of fixed interval precipitation sums because only a single sum is represented per date. The modified 3-15-day threshold, $P_{3}=2.16-0.44 P_{15}$ is compared to the threshold of Chleborad and others (2008). A, Marine View Drive \& 116th St. SW (VH). $B$, Waterton Circle (LS). C, Mukilteo Water and Wastewater District Treatment Plant (M2). $D$, Mukilteo Lighthouse Park (M1). $\left(P_{3^{\prime}}\right.$ precipitation accumulation (inches) over the 3 days prior to the considered date; $P_{15^{\prime}}$ precipitation accumulation (inches) during the 15 days preceding $P_{3}$ ) 


\section{Cumulative Precipitation 35 Days Prior to Landsliding Mukilteo, Washington 2015-2016}

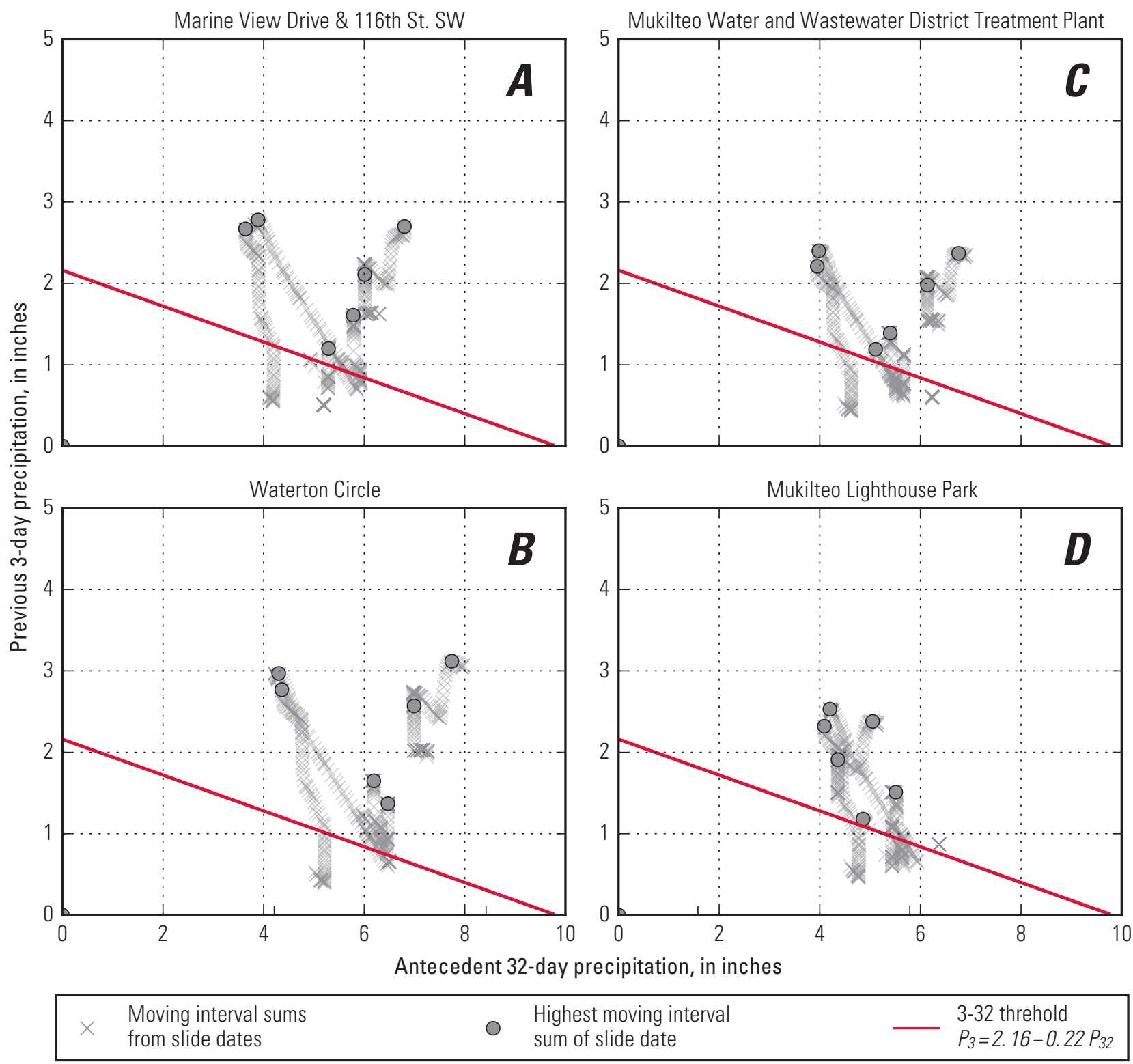

Figure 3-3. Recent-antecedent precipitation accumulation (3-32 days) calculated using moving intervals on dates of known landsliding near Mukilteo, Washington. Note that the " $x$ " markers denote measurements taken every 15 minutes. A date's 15 minutes with the highest previous 3-day precipitation is represented with an opaque circle. Note that the circles, although not taken from a consistent hour on each date, approximate a plot of fixed interval precipitation sums because only a single sum is represented per date. The data are plotted against the 3-32-day threshold, $P_{3}=2.16-0.22 P_{32}$ $A$, Marine View Drive \& 116th St. SW (VH). B, Waterton Circle (LS). C, Mukilteo Water and Wastewater District Treatment Plant (M2). $D$, Mukilteo Lighthouse Park (M1). $\left(P_{3^{\prime}}\right.$ precipitation accumulation (inches) over 3 days; $P_{32^{\prime}}$ precipitation accumulation (inches) during the 32 days preceding $P_{3}$ ) 


\section{Cumulative Precipitation 50 Days Prior to Landsliding Mukilteo, Washington 2015-2016}

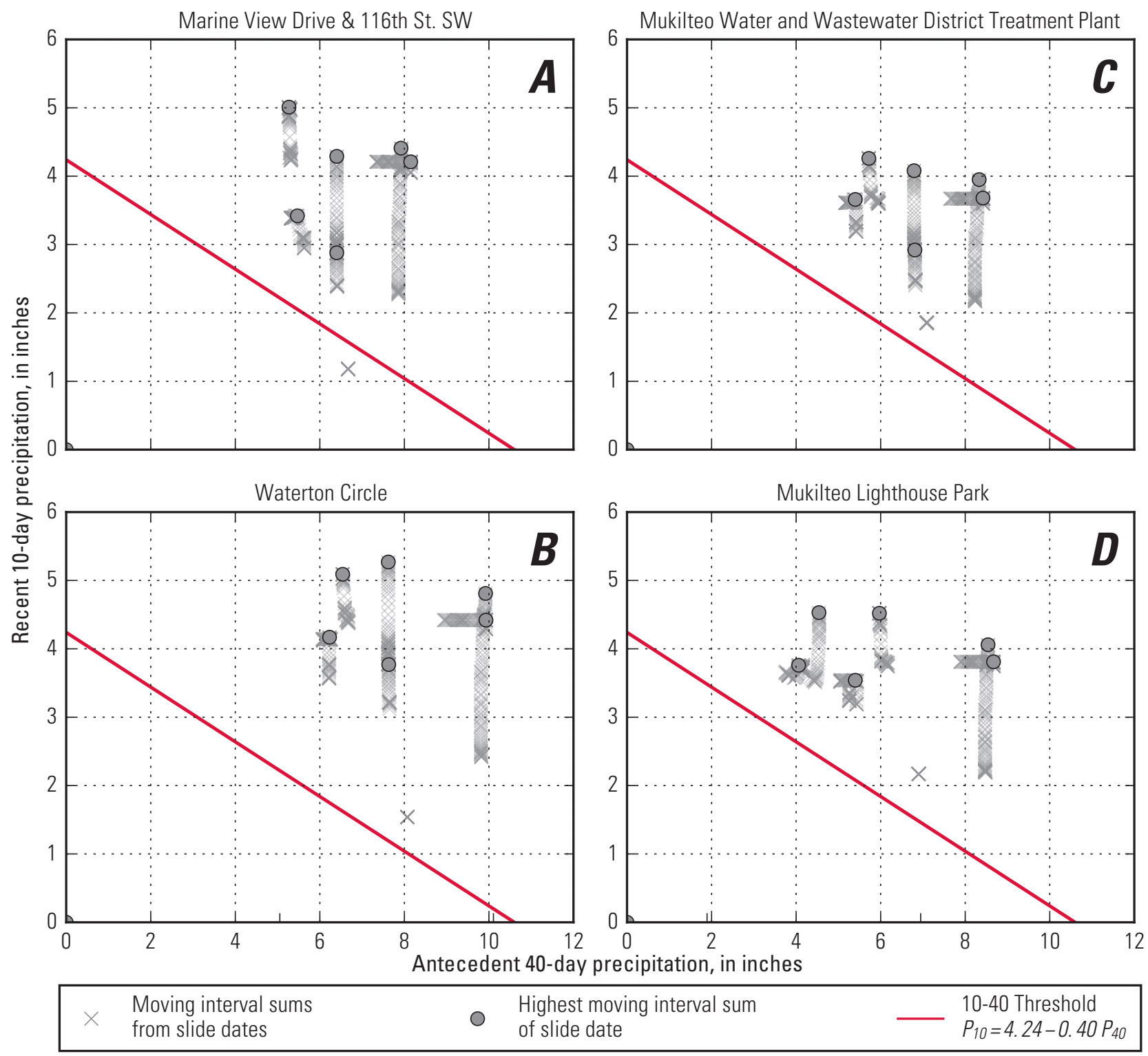

Figure 3-4. Recent-antecedent precipitation accumulation (10-40 days) calculated using moving intervals on dates of known landsliding near Mukilteo, Washington. Note that the " $x$ " markers denote measurements taken every 15 minutes. A date's 15 minutes with highest previous 3-day precipitation is represented with an opaque circle. Note that the circles, although not taken from a consistent hour on each date, approximate a plot of fixed interval precipitation sums because only a single sum is represented per date. The data are plotted against the 10-40-day threshold, $P_{10}=4.25-0.41 P_{40}$. $A$, Marine View Drive \& 116th St. SW (VH). B, Waterton Circle (LS). C, Mukilteo Water and Wastewater District Treatment Plant (M2). D, Mukilteo Lighthouse Park (M1). $P_{10^{\prime}}$ precipitation accumulation (inches) over 10 days; $P_{40^{\prime}}$ precipitation accumulation (inches) during the 42 days preceding $P_{10}$ ) 
Storm Event Intensity on Slide Dates

Everett, Washington, 2006-2014

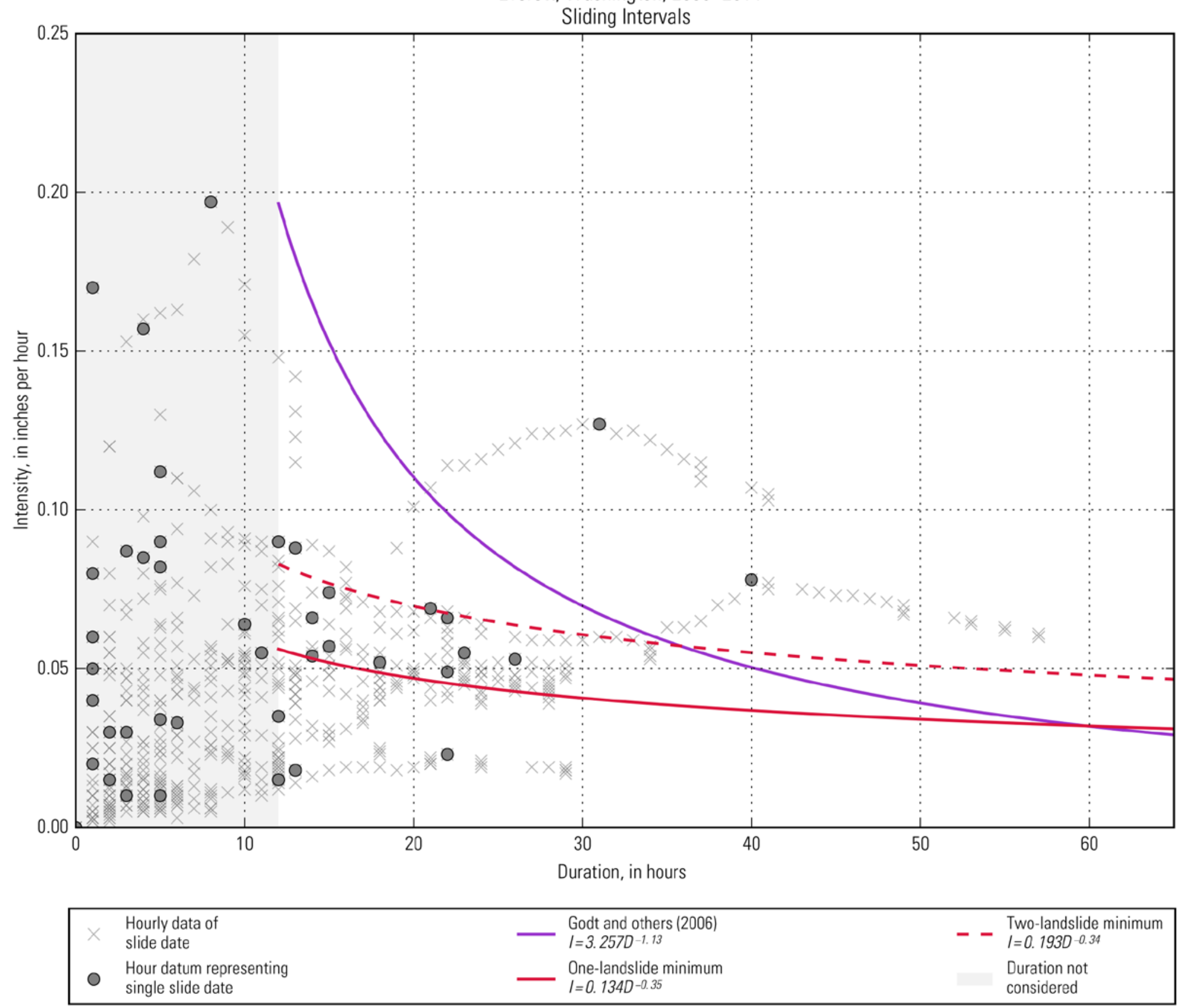

Figure 3-5. Landslides near Everett Paine Field, Washington, plotted by rainfall intensity and storm duration. The grey region represents the 12 hours not considered by this report's intensityduration thresholds. A date's hour of highest storm intensity is marked with a grey circle. (D, duration in hours; I, rainfall intensity in inches per hour) 


\section{$\frac{\mathbb{2}}{\mathrm{C}}$}

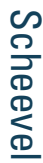

言

产

ISSN 2331-1258 (online) 